\title{
NUMERICAL ANALYSIS OF EFFECTS OF LEADING-EDGE PROTUBERANCES ON AIRCRAFT WING PERFORMANCE
}

\author{
A Thesis by \\ Anil Kumar Malipeddi \\ Bachelors of Technology, Jawaharlal Nehru Technological University, 2007
}

Submitted to the Department of Aerospace Engineering and the faculty of Graduate School of

Wichita State University

in partial fulfillment of

the requirements for the degree of

Master of Science

July 2011 
(C) Copyright 2011 by Anil Kumar Malipeddi

All Rights Reserved 


\section{NUMERICAL ANALYSIS OF EFFECTS OF LEADING-EDGE PROTUBERANCES ON AIRCRAFT WING PERFORMANCE}

The following faculty members have examined the final copy of this thesis for form and content, and recommend that it can be accepted in partial fulfillment of the requirements for the degree of Master of Science with a major in Aerospace Engineering.

Klaus A. Hoffmann, Committee Chair

Krishna Krishnan, Committee Member

Roy Myose, Committee Member 


\section{DEDICATION}

To my parents 
All that we are is the result of what we have thought.

The mind is everything. What we think we become.

If I have the belief that I can do it, I shall surely acquire the capacity to do it even if I may not have it at the beginning. 


\section{ACKNOWLEDGEMENTS}

I express my sincere gratitude to my academic and thesis advisor, Dr. Klaus A Hoffmann, for his scholarly and patient guidance. He has been a great support to my student life at Wichita State University. I extend my thankfulness to Dr. Krishna Krishnan and Dr. Roy Myose, for serving as committee members of my thesis and for the helpful suggestions on this project. I would like to thank my friends and every individual who made this thesis possible.

Last but not least, I am very thankful to my parents for their unconditional love and support, and I am grateful to have them, especially my dad, who boosts my courage levels and inspires me with his work. 


\begin{abstract}
This thesis investigates the effects of biologically inspired leading-edge protuberances on aircraft wings. The study of humpback whales and their flipper performance was the impetus to modifying the leading edge of an aircraft wing in order to gain an aerodynamic advantage during flight. This study examines the effect of leading-edge modification on wing performance at a low Reynolds number (Re), since low Reynolds number flows have unique features, and the knowledge about this flight regime is extremely important for small aircraft, called unmanned aerial vehicles (UAVs), flying at low speeds.

Simulations were executed on wings with leading-edge sinusoidal protuberances, in order to compare the lift and drag characteristics with that of a wing with a smooth leading edge. All wings had the same cross section of National Advisory Committee for Aeronautics (NACA) 2412 and a simulated Reynolds number of $5.7 * 10^{5}$. Results from numerical simulations revealed that a decrease in lift and an increase in drag was observed at low angles of attack (AoA) in all cases of the modified wings. At higher angles $\left(\alpha \geq 16^{\circ}\right)$, the lift of the modified wings was up to $48 \%$ greater than the baseline wing, with $44 \%$ less drag or no drag penalty. The amplitude of protuberances significantly affects wing performance. Although the maximum lift generated by modified wings was lower than baseline, protuberances along the leading edge of the wing proved to have a profound advantage in obtaining higher lift at high angles of attack.
\end{abstract}




\section{TABLE OF CONTENTS}

Chapter

Page

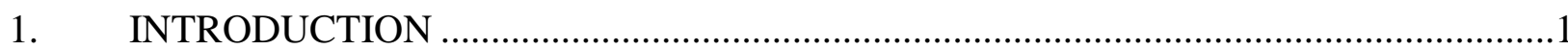

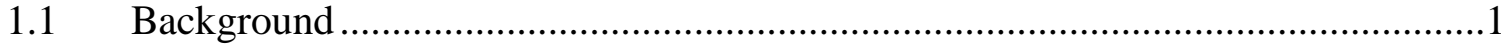

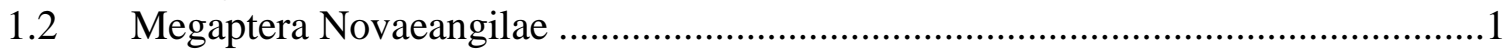

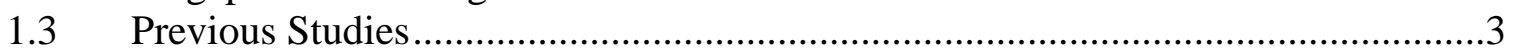

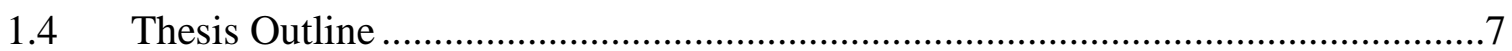

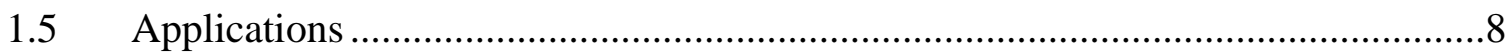

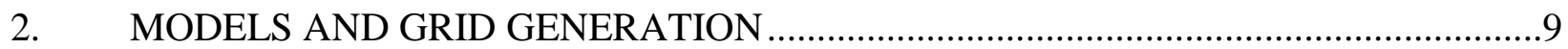

2.1 Baseline Model ...................................................................................

2.2 Models with Leading-Edge Protuberances ...............................................12

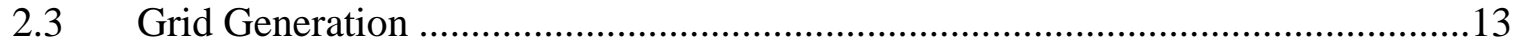

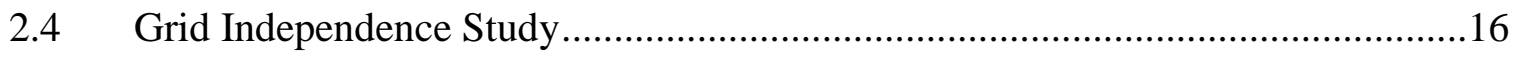

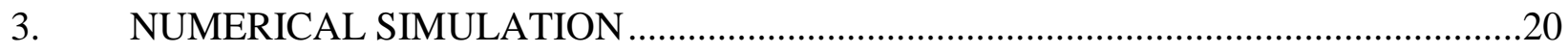

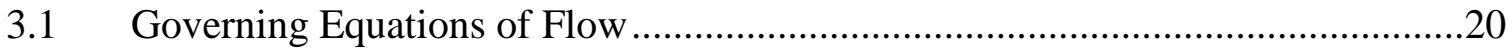

3.2 Turbulence Model ....................................................................................21

3.2.1 DES with Spallart-Allmaras Model ..................................................21

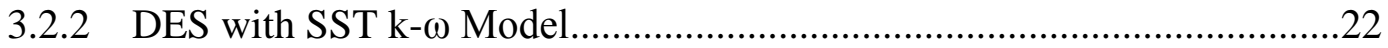

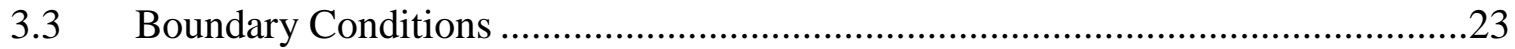

3.4 Numerical Procedure and Simulation Setup ..................................................24

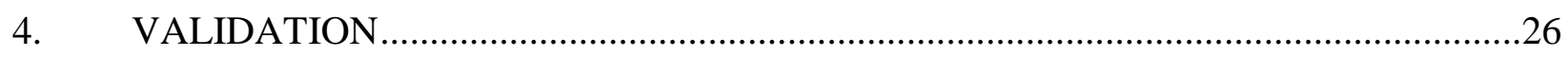

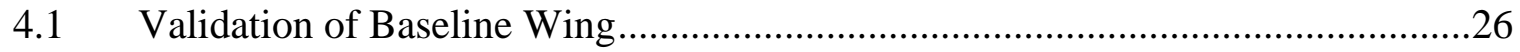

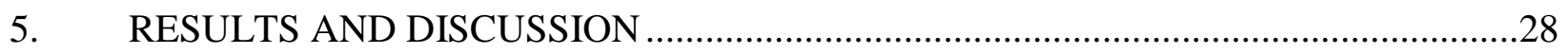

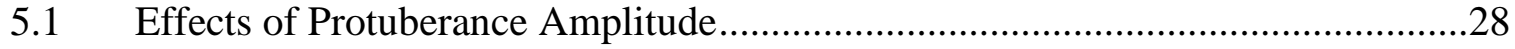

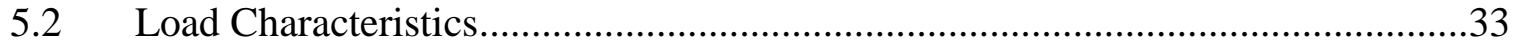

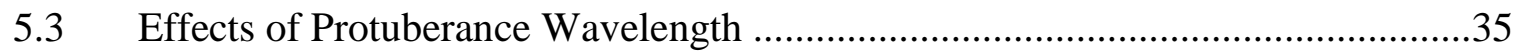

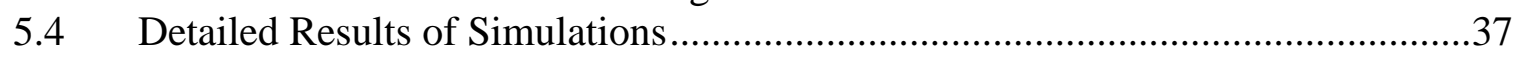

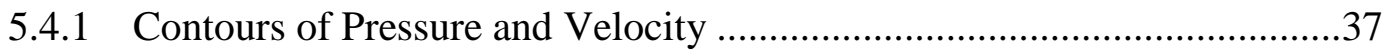

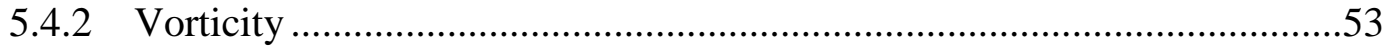

5.4.3 Pressure Contours on Surface of Wings .............................................59

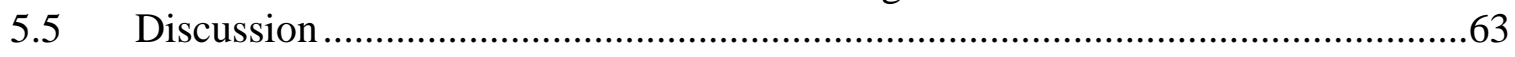

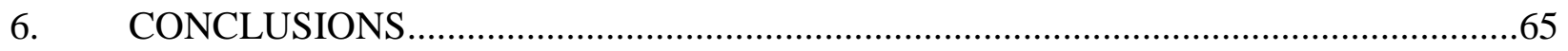

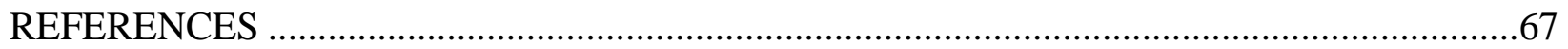




\section{LIST OF TABLES}

Table

Page

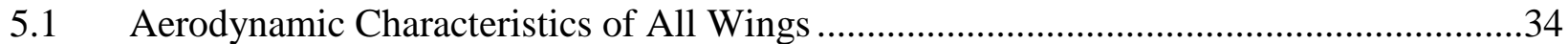




\section{LIST OF FIGURES}

Figure $\quad$ Page

1.1 Humpback whale (Megaptera novaeangilae) ..........................................................2

1.2 Flipper of humpback whale showing leading-edge tubercles.......................................2

1.3 Scalloped (left) and smooth (right) flipper models tested in wind tunnel .......................4

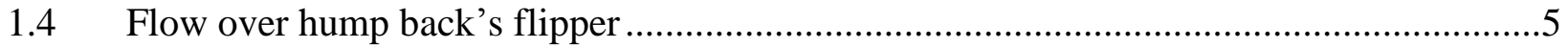

1.5 Flipper and computational domain used in simulations ........................................6

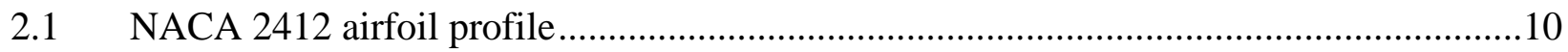

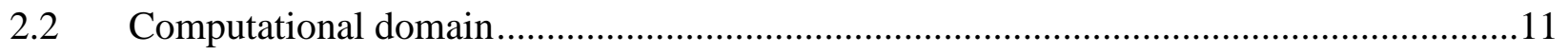

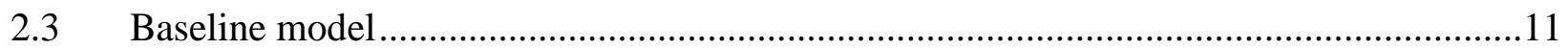

2.4 Modified wings with leading-edge protuberances ...................................................13

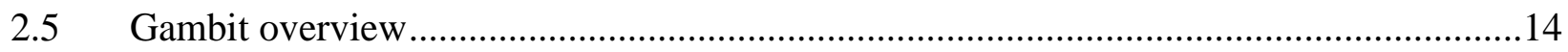

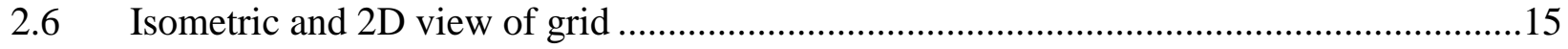

2.7 Zoom-in view of grid over wing cross section ...................................................16

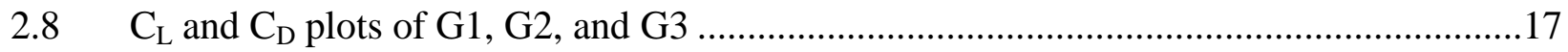

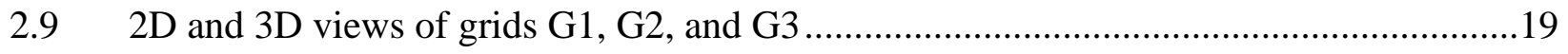

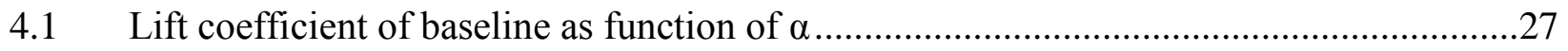

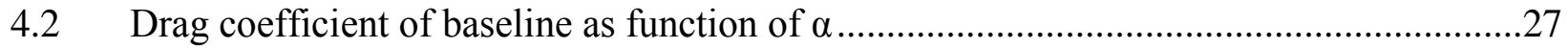

5.1 (a) Lift and (b) Drag coefficients of wings with $0.25 \mathrm{c}$ wavelength as function of $\alpha$........30

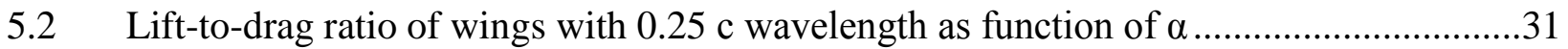

5.3 (a) Lift and (b) Drag coefficients of wings with $0.5 \mathrm{c}$ wavelength as function of $\alpha$..........32

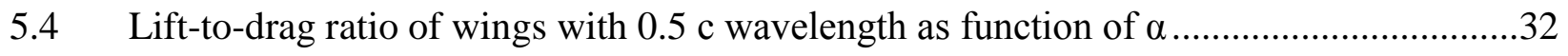

5.5 (a) Lift and (b) Drag coefficients of 4B wing normalized by baseline values..................34 


\section{LIST OF FIGURES (continued)}

Figure

Page

5.6 (a) Lift and (b) Drag coefficients of wings with $0.025 \mathrm{c}$ amplitude as function of $\alpha$........36

5.7 (a) Lift and (b) Drag coefficients of wings with $0.05 \mathrm{c}$ amplitude as function of $\alpha$..........37

5.8 Pressure contours of baseline at $\mathrm{z}=$ (a) $0.025 \mathrm{~m}$, (b) $0.05 \mathrm{~m}$, and (c) $0.075 \mathrm{~m} \ldots \ldots \ldots \ldots \ldots . . . . .39$

5.9 Velocity contours of baseline at $\mathrm{z}=$ (a) $0.025 \mathrm{~m}$, (b) $0.05 \mathrm{~m}$, and (c) $0.075 \mathrm{~m} \ldots \ldots \ldots \ldots \ldots . . .41$

5.10 Pressure contours of $4 \mathrm{~A}$ wing at $\mathrm{z}=$ (a) $0.025 \mathrm{~m}$, (b) $0.05 \mathrm{~m}$, and (c) $0.075 \mathrm{~m} \ldots \ldots \ldots \ldots . . . .42$

5.11 Velocity contours of $4 \mathrm{~A}$ wing at $\mathrm{z}=$ (a) $0.025 \mathrm{~m}$, (b) $0.05 \mathrm{~m}$, and (c) $0.075 \mathrm{~m} \ldots \ldots \ldots \ldots . . . .44$

5.12 Pressure contours of $2 \mathrm{~A}$ wing at $\mathrm{z}=$ (a) $0.025 \mathrm{~m}$, (b) $0.05 \mathrm{~m}$, and (c) $0.075 \mathrm{~m} \ldots \ldots \ldots \ldots . . . .45$

5.13 Velocity contours of $2 \mathrm{~A}$ wing at $\mathrm{z}=$ (a) $0.025 \mathrm{~m}$, (b) $0.05 \mathrm{~m}$, and (c) $0.075 \mathrm{~m} \ldots \ldots \ldots \ldots . . . .47$

5.14 Pressure contours of 4B wing at $\mathrm{z}=$ (a) $0.025 \mathrm{~m}$, (b) $0.05 \mathrm{~m}$, and (c) $0.075 \mathrm{~m} \ldots \ldots \ldots \ldots \ldots . . . .48$

5.15 Velocity contours of $4 \mathrm{~B}$ wing at $\mathrm{z}=$ (a) $0.025 \mathrm{~m}$, (b) $0.05 \mathrm{~m}$, and (c) $0.075 \mathrm{~m} \ldots \ldots \ldots \ldots . . .50$

5.16 Pressure contours of $2 \mathrm{~B}$ wing at $\mathrm{z}=$ (a) $0.025 \mathrm{~m}$, (b) $0.05 \mathrm{~m}$, and (c) $0.075 \mathrm{~m} \ldots \ldots \ldots \ldots \ldots . . . . .51$

5.17 Velocity contours of $2 \mathrm{~B}$ wing at $\mathrm{z}=$ (a) $0.025 \mathrm{~m}$, (b) $0.05 \mathrm{~m}$, and (c) $0.075 \mathrm{~m} \ldots \ldots \ldots \ldots . .53$

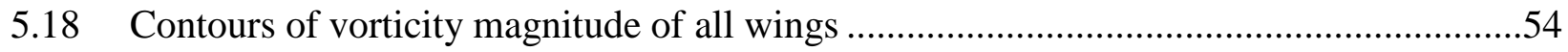

5.19 Instantaneous vorticity magnitude iso-surface on all wings ......................................56

5.20 Vorticity magnitude slices in chord-wise direction at $\mathrm{x}=0.05 \mathrm{~m}$ and $0.126 \mathrm{~m} \ldots \ldots \ldots \ldots . .57$

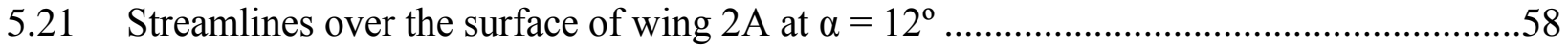

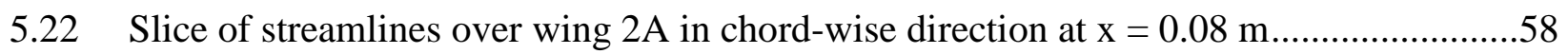

5.23 Pressure contours on the surface of various wings ...................................................60

5.24 Instantaneous pressure iso-surface of baseline colored by pressure .............................61

5.25 Instantaneous pressure iso-surface of 4A wing colored by pressure .............................61

5.26 Instantaneous pressure iso-surface of $2 \mathrm{~A}$ wing colored by pressure ............................62 


\section{LIST OF FIGURES (continued)}

Figure $\quad$ Page

5.27 Instantaneous pressure iso-surface of 4B wing colored by pressure ............................62

5.28 Instantaneous pressure iso-surface of $2 \mathrm{~B}$ wing colored by pressure ...........................63 


\section{LIST OF ACRONYMS/NOMENCLATURE}

2A Wing with leading edge protuberance of wavelength $=0.25 \mathrm{c}$ and amplitude $=$ $0.025 \mathrm{c}$

2B Wing with leading edge protuberance of wavelength $=0.25 \mathrm{c}$ and amplitude $=$ $0.05 \mathrm{c}$

2D Two-dimensional

3D Three-dimensional

4A Wing with leading edge protuberance of wavelength $=0.5 \mathrm{c}$ and amplitude $=$ $0.025 \mathrm{c}$

4B Wing with leading edge protuberance of wavelength $=0.5 \mathrm{c}$ and amplitude $=0.05 \mathrm{c}$

AoA Angle(s) of Attack

c Chord

$\mathrm{C}_{\mathrm{D}} \quad$ Coefficient of Drag

$\mathrm{C}_{\mathrm{L}} \quad$ Coefficient of Lift

$\mathrm{C}_{\mathrm{Lmax}} \quad$ Maximum Coefficient of Lift

D Drag

DES Direct Eddy Simulation

L Lift

L/D Lift to Drag Ratio

LES Large Eddy Simulation

Ma Mach number

NACA National Advisory Committee for Aeronautics

NASA National Aeronautics and Space Administration

P Pressure 


\section{LIST OF ACRONYMS/NOMENCLATURE (continued)}

$\begin{array}{ll}\text { RANS } & \text { Reynolds Average Navier-Stokes Equation } \\ \text { Re } & \text { Reynolds Number } \\ \text { S } & \text { Span } \\ \text { S-A } & \text { Spallart-Allmaras Turbulence Model } \\ \text { SIMPLE } & \text { Semi-Implicit Method for Pressure-Linked Equations } \\ \text { U } & \text { Free-Stream Velocity } \\ \text { V } & \text { Velocity } \\ \alpha & \text { Angle of Attack } \\ \rho & \text { Density }\end{array}$




\section{CHAPTER 1}

\section{INTRODUCTION}

\subsection{Background}

The inception of modifying the leading edge of control surfaces such as wings and hydrofoils emerged from the work of a marine biologist, whose interest was to explore the morphology of humpback whales. To transform a creative idea of applying biomechanics in engineering problems, the work performed by researchers (such as Fish and Battle [1] and Summers and Wynne [2]) is commendable. They presumed that the agility and maneuverability of a whale is due to the design of its flipper, which improves the fluid dynamic characteristics. The design of a humpback whale's flipper and its advantages and applications are further discussed in this chapter.

\section{$1.2 \quad$ Megaptera novaeangilae}

The scientific name of the humpback whale, shown in Figure 1.1, is Megaptera novaeangilae, which means "giant wings of New England." This whale has the longest flippers of any cetacean, even larger than those of the blue whale, the largest animal on the planet [1]. Adults range in length from 12 to 16 meters and can weigh 36,000 kilograms. Humpback whales have a distinct body shape, with long flippers that have non-smooth, bumpy leading edges called tubercles. The placement of leading-edge tubercles represents the uniqueness of humpback whales' flippers, and these tubercles function as enhanced lift devices to control flow over the flipper and maintain lift at a high angle of attack (AoA) [3]. Humpback whales are extremely maneuverable and have unique feeding behavior. They catch prey by creating a bubble net and swimming through it. The size of the bubble net depends on the type of prey pursued by the whale, but it may vary from 5 to 150 feet wide. 


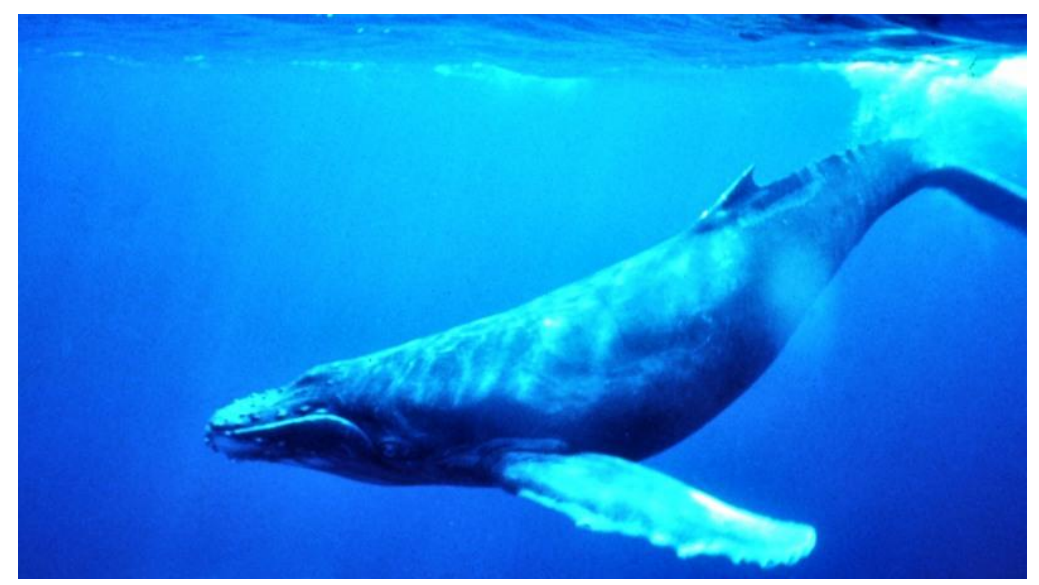

Figure 1.1 Humpback whale (Megaptera novaeangilae) [3]

Flippers are the main asset to the extreme maneuverability of humpback whales. These whales have such astonishing agility that they have caught the attention of marine researchers, who presumed that some principles learned from it could be applied to designing submersibles and unmanned aerial vehicles (UAVs). The two flippers on a whale have a high aspect ratio (s/c $\approx 6$ ) and look like wings: each is about 9 to 12 feet long and situated substantially forward of the whale's center of mass, placed well to exert turning forces. Each flipper has large bumps, called tubercles, on the rounded leading edge, giving the flipper a serrated appearance. The tubercles on the flipper vary in amplitude and wavelength, with an amplitude range of $2.5 \%$ to $12 \%$ of the chord length and wavelength varying from $10 \%$ to $50 \%$ of the chord.

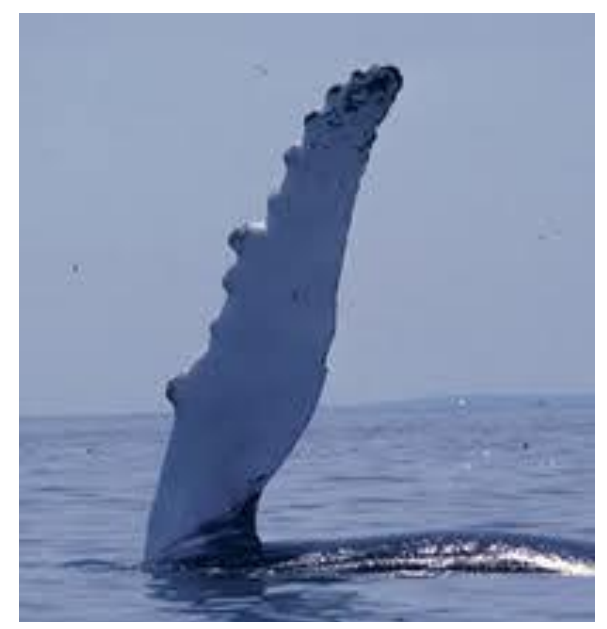

Figure 1.2 Flipper of humpback whale showing leading-edge tubercles 


\subsection{Previous Studies}

It was hypothesized by Watts and Fish [4] that the protuberances along the leading edge of a humpback whale flipper act as passive flow control. A passive-flow control mechanism can be attained by non-moving parts on an object and help create beneficial characteristics by the flow field. However, having no moving parts in the flow field can lead to an increase in drag. Flow control can also be achieved by an active mechanism. An active system has non-stationary parts, which can be activated and mechanically controlled at required times. Therefore, flow control can be achieved when needed, which undoubtedly eliminates the increase in drag in the case of a passive mechanism. However, active systems are associated with added complexities.

Frank E. Fish, a biochemist at West Chester University of Pennsylvania, worked with three engineers-David S. Miklosovic and Mark M. Murray, both from the U.S. Naval Academy in Annapolis, Maryland, and Laurens E. Howle of Duke University in Durham, North Carolina-to test his hypothesis that tubercles help the flipper hydrodynamically [5]. They constructed two scaled flipper models tapered from root to tip - one with a sinusoidal leadingedge profile approximating the pattern found on the specimen flipper, and the other with a smooth leading edge but with the same area and cross section as depicted in Figure 1.3. Both models were based on a symmetrical NACA 0020 wing profile and tested in a low-speed closedcircuit wind tunnel at the United States Naval Academy. Experiments were conducted at a Reynolds number $(\mathrm{Re})$ of $5.05 * 10^{5}-5.2 * 10^{5}$, and by performing tests on the effect of $\operatorname{Re}$, it was shown that the lift coefficient was relatively insensitive to the Re at moderate incidence angles. Fish and his colleagues found that the tubercles enable the flipper to continue generating lift at attack angles $40 \%$ steeper than are possible with a smooth wing. But where drag is concerned, at a low AoA, the scalloped flipper introduced more drag than that of a smooth 
flipper, and at a high AoA, drag was lower. A $6 \%$ increase in the maximum lift coefficient was observed on the scalloped model over the smooth model, which indicates that the flipper with the scalloped leading edge delayed stall by providing higher lift at a high AoA with lower drag.

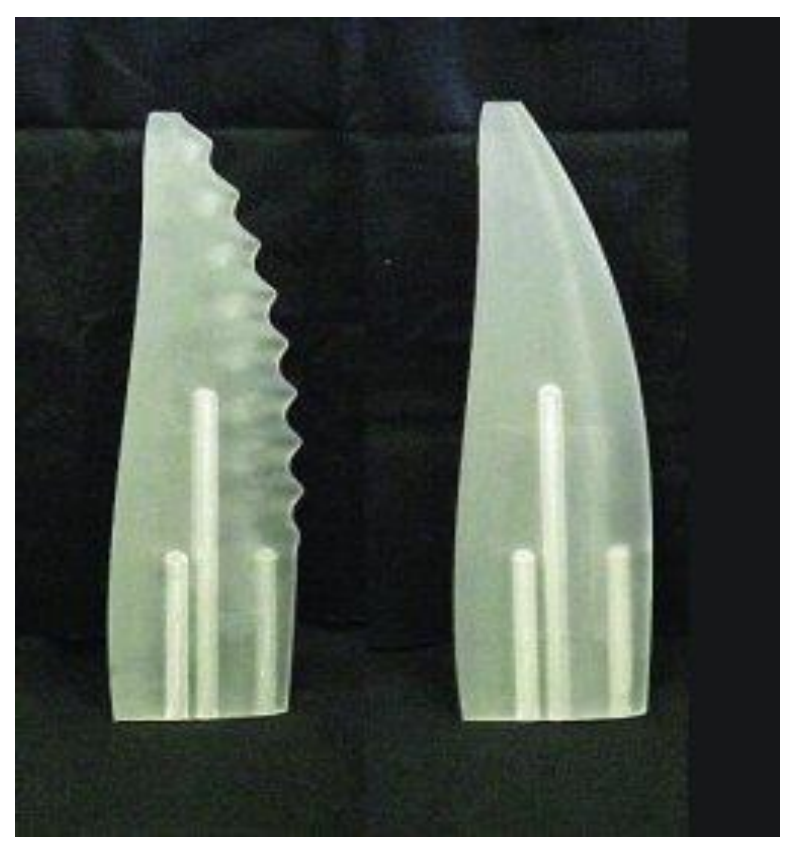

Figure 1.3 Scalloped (left) and smooth (right) flipper models tested in wind tunnel by Miklosovic et al. [5]

Hamid Johari, from Worchester Polytechnic Institute, Massachusetts, with his research assistants, D. Custodio and A. Levshin [6], measured the lift, drag, and pitching moments of airfoils with leading-edge sinusoidal protuberances and compared them with those of a baseline NACA 634-021 airfoil in a water tunnel. Six airfoils with sinusoidal leading edges were tested at three different velocities, and the data reported was only at Re of $1.83 * 10^{5}$ with a free-stream velocity of $1.83 \mathrm{~m} / \mathrm{s}$. They found the lift reduction and drag increase for modified airfoils at angles of attack less than the baseline stall angle. Post the stalling angle, the lift of the airfoil with leading-edge sinusoidal protuberances was up to $50 \%$ greater than the baseline foil with little or no drag increase. It was also found that the amplitude of protuberances had a distinct effect on the performance of the airfoils, whereas the wavelength had little effect. They also 
performed a tuft and dye flow visualization and found that visualizations of modified airfoils showed attached flow on the peaks and separated flow in the valleys of the protuberances at angles beyond the stall angle of the baseline foil.

An examination of influence of passive, leading-edge tubercles on a low-aspect ratio wing using numerical methods was performed by Watts and Fish [4]. In this study, at 10 degree angle of attack $\left(\alpha=10^{\circ}\right)$, a $4.8 \%$ increase in lift, a 10.9\% reduction in induced drag, and a $17.6 \%$ increase in lift-to-drag ratio were observed on wings with tubercles over a baseline. Stein and Murray [7] analyzed a two-dimensional airfoil with a protuberance amplitude and wavelength equal to the average value for humpback's flipper and found that this results in a loss of lift and an increase in drag for AoA from 8 to 12 degrees. No data was reported above 12 degrees of AoA. This contradiction is probably due to the effect of protuberances along the leading edge on the spanwise flow on wings, since all earlier works tested finite wings. Miklosovic et al. investigated the effects of leading-edge protuberances on sweptback flipper models and reported enhanced aerodynamic performance with increasing sweep angle [8].

As shown in Figure 1.4, the humpback's flipper with tubercles is advantageous over a flipper with a smooth leading edge because the flow over it is organized due to troughs formed by the tubercles/protuberances, whereas flow over a smooth flipper is disorganized into eddies at steeper angle of attacks [3].
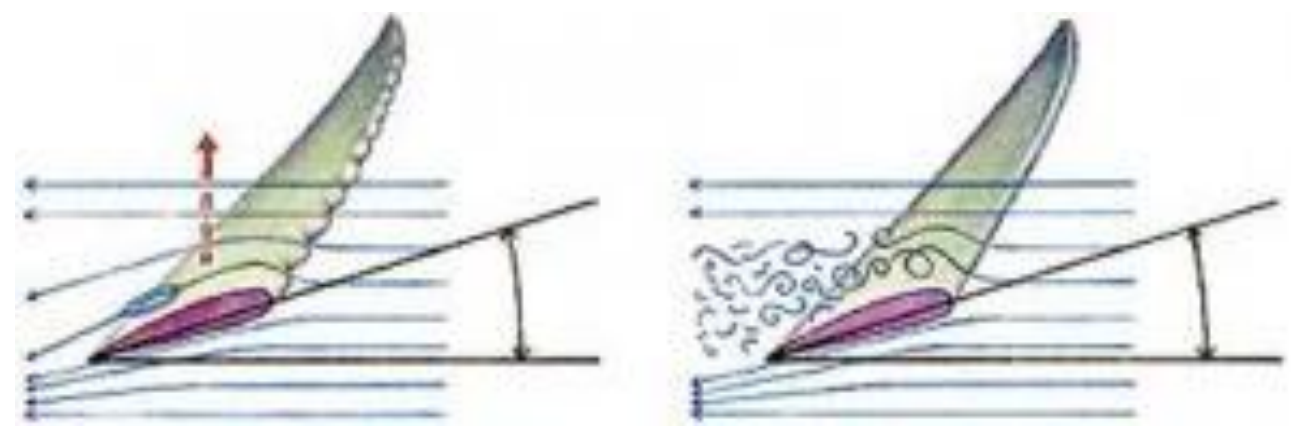

Figure 1.4 Flow over humpback's flipper 
A recent numerical study on the humpback whale flipper was conducted by Pedro and Kobayashi [9] at a low Reynolds number $\left(<5 * 10^{\wedge} 5\right)$. The flipper and computational domain used in their simulations are shown in Figure 1.5. Flippers with scalloped leading edges and smooth leading edges were simulated numerically. The numerical simulations were concentrated in an angle-of-attack range of 12 to 18 degrees, considering that this is the AoA range where most noticeable differences would occur. Their study found an increase in the aerodynamic performance of the scalloped flipper. They concluded that the DES turbulence model was successful in determining the flipper aerodynamics at a low Reynolds number and that the higher aerodynamic performance of the scalloped flipper is due to the presence of streamwise vortices originated by the tubercles.

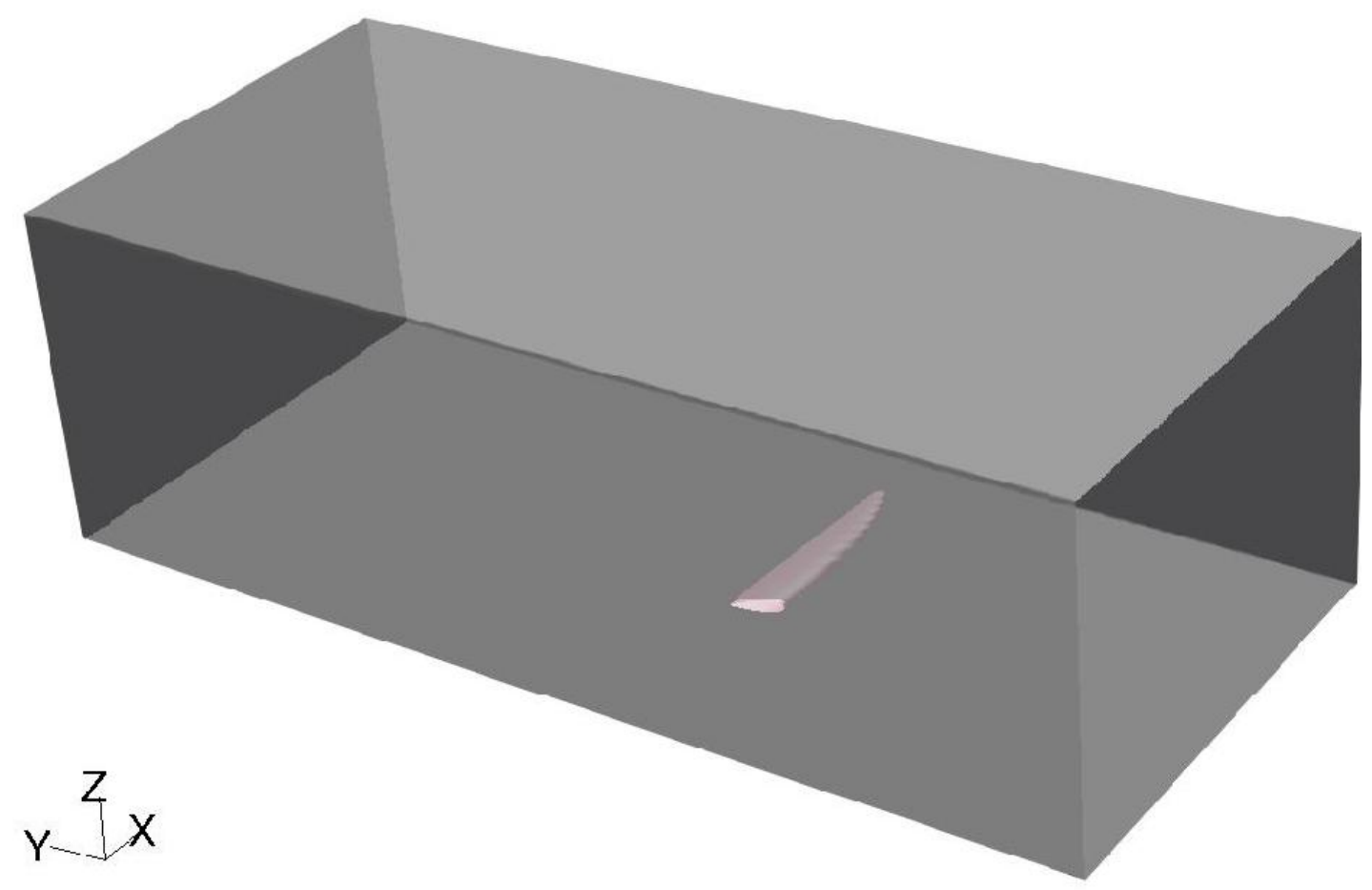

Figure 1.5 Flipper and computational domain used in simulations by Pedro and Kobayashi 2008 


\section{$1.4 \quad$ Thesis Outline}

This thesis focuses on the application of protuberances on wings. It begins with a brief review of the effect of protuberances on finite wings and two-dimensional foils, conducted by researchers and marine biologists, as discussed in Chapter 1. Most previous efforts have been experimental and have dealt with finite wings similar to the cross section of humpback whale flipper. Since the interest in small aerial vehicles (which operate at low velocity) has increased in the past few years, there is a need to know how the protuberances affect the conventional control surfaces of wings, which can be helpful in determining the efficiency of the modified leading edge. Four cases of wings were considered in this study in order to identify the effect of protuberances by comparing them to wing with a smooth leading edge (baseline wing) at low Reynolds numbers. The three-dimensional effects of the wing tip were excluded, and protuberances were varied uniformly in wavelength and amplitude along the leading edge of a wing. Two different wavelengths and amplitudes were chosen based on the range of those found on a humpback whale's flipper. Chapter 2 discusses the model and gird generation, and Chapter 3 presents the numerical procedure for the simulations. The results of baseline from numerical simulations are validated in Chapter 4. Chapter 5 contains the results, comparing the wing characteristics with and without leading-edge protuberances, and is followed by conclusions in Chapter 6 . This is the first numerical study to report the effect of protuberances on wings with a NACA 2412 cross section. The main objectives of this study are as follows:

1. To investigate the effect of protuberances along the leading edge of wings on lift and drag characteristics over a wide range of angles of attack.

2. To compare the performance of wings with and without protuberances at low Re. 


\subsection{Applications}

In the past few decades, the design of small unmanned aerial vehicles has been increasing. These vehicles can perform diverse missions such as surveillance, reconnaissance, and detection of biological, chemical, or nuclear materials. To carry out such missions, UAVs or underwater vehicles require a long flight duration at low altitudes and low speeds, high maneuverability, light weight size, and all-weather capabilities. The velocity at which they operate (self-governed or remotely controlled) results in a low Reynolds number flight regime at which the aerodynamic performance of wings can deteriorate as the Re decreases. This demands further study in low Re flows to improvise the aerodynamic performance of wings [10].

Typically in most engineering applications, the control surfaces are lifting surfaces with an airfoil profile capable of imparting a fluid momentum change to create force on its surface and with leading edges that are straight, because of historical reasons related to manufacturing methods. Small modifications near the leading edge can significantly alter, delay, or reduce separation effects. The idea of modifying a leading edge in a wavy profile was motivated from a biological species, the humpback whale. The bio-inspired products and applications of this strategy, as mentioned in Ask Nature [3], involve the industrial sectors of energy, manufacturing, and aeronautics relative to such ideas as more efficient wind turbines, hydroelectric turbines, ceiling fans, airplane wings, under water vehicles. It is possible that leading-edge protuberances

could be utilized as advantageous mechanism on wings to increase performance at high angles of attack as well as increasing the range of operation. Propulsion systems with propellers could benefit from this mechanism as well. 


\section{CHAPTER 2}

\section{MODELS AND GRID GENERATION}

\subsection{Baseline Model}

NACA four-digit series foils are the simplest asymmetric airfoils, and the shape of their profiles is determined by three parameters: the maximum camber (first digit, $\mathrm{m}$ ), the position of the maximum camber (second digit, $\mathrm{p}$ ), and the maximum thickness ( $\mathrm{t}$ ) in percent (last two digits). Therefore, NACA 2412 airfoil has a camber of $2 \%$ located $40 \%$ back from the leading edge $(0.4 \mathrm{c})$, with a maximum thickness of $12 \%$. Using the values of $\mathrm{m}, \mathrm{p}$, and $\mathrm{t}$, the coordinates were calculated to generate the airfoil shape. These formulas are given by equations (2.1) to (2.4).

$$
y_{c}= \begin{cases}\frac{m}{p^{2}} 2 p x-x^{2} & \text { from } \mathrm{x}=0 \text { to } \mathrm{x}=\mathrm{p} \\ \frac{m}{\left(1-p^{2}\right)}\left[1-2 p+2 p x-x^{2}\right] & \text { from } \mathrm{x}=\mathrm{p} \text { to } \mathrm{x}=\mathrm{c}\end{cases}
$$

After computing the mean camber line from the above equations, the thickness distribution above (+) and below (-) the mean line was calculated using

$$
\pm y_{t}=\frac{t}{0.2} 0.2969 \sqrt{x}-0.126 x-0.3516 x^{2}+0.2843 x^{3}-0.1015 x^{4}
$$

where $\mathrm{x}$ is the position along the chord, and $\mathrm{y}_{\mathrm{t}}$ is the corresponding thickness distribution.

The coordinates for the wing upper and lower surfaces were determined by using equations (2.3 and (2.4).

$$
\begin{aligned}
& x_{u}=x-y_{t} \sin \theta \\
& y_{u}=y_{c}+y_{t} \cos \theta \\
& x_{l}=x+y_{t} \sin \theta \\
& y_{l}=y_{c}-y_{t} \cos \theta
\end{aligned}
$$


where $\theta=\arctan \left(\frac{d y_{c}}{d x}\right)$

Thus, the airfoil geometry was defined by a set of coordinate points derived from the above equations. The more points defined, the greater the increase in the accuracy of model; hence, the geometry considered here was defined by 132 points for upper and lower surfaces to obtain a smooth profile. Figure 2.1 shows the basic airfoil profile of NACA 2412.

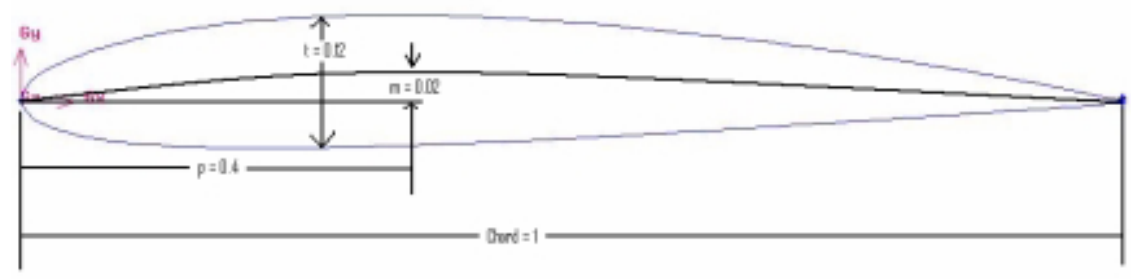

Figure 2.1 NACA 2412 airfoil profile [11]

The C-type mesh boundary was defined over the airfoil, followed by the spanwise sweeping it, in order to generate the desired geometry and the domain. Figure 2.2 and Figure 2.3 show the computational domain and baseline model, respectively, used for the simulations. The inflow boundary is located $7 \mathrm{c}$ upstream from the leading edge of the wing. The upper and lower boundaries of the domain are located at a distance of $10 \mathrm{c}$ from the chord, and the outflow boundary is located $16 \mathrm{c}$ away from the trailing edge of the wing, in order to reduce the disturbances reflected from the outflow boundary. The chord (c) of the wing is $0.1 \mathrm{~m}$ long. The size of the computational domain is $23 \mathrm{c} \times 20 \mathrm{c} x 1 \mathrm{c}$ (length $\mathrm{x}$ height $\mathrm{x}$ depth). 


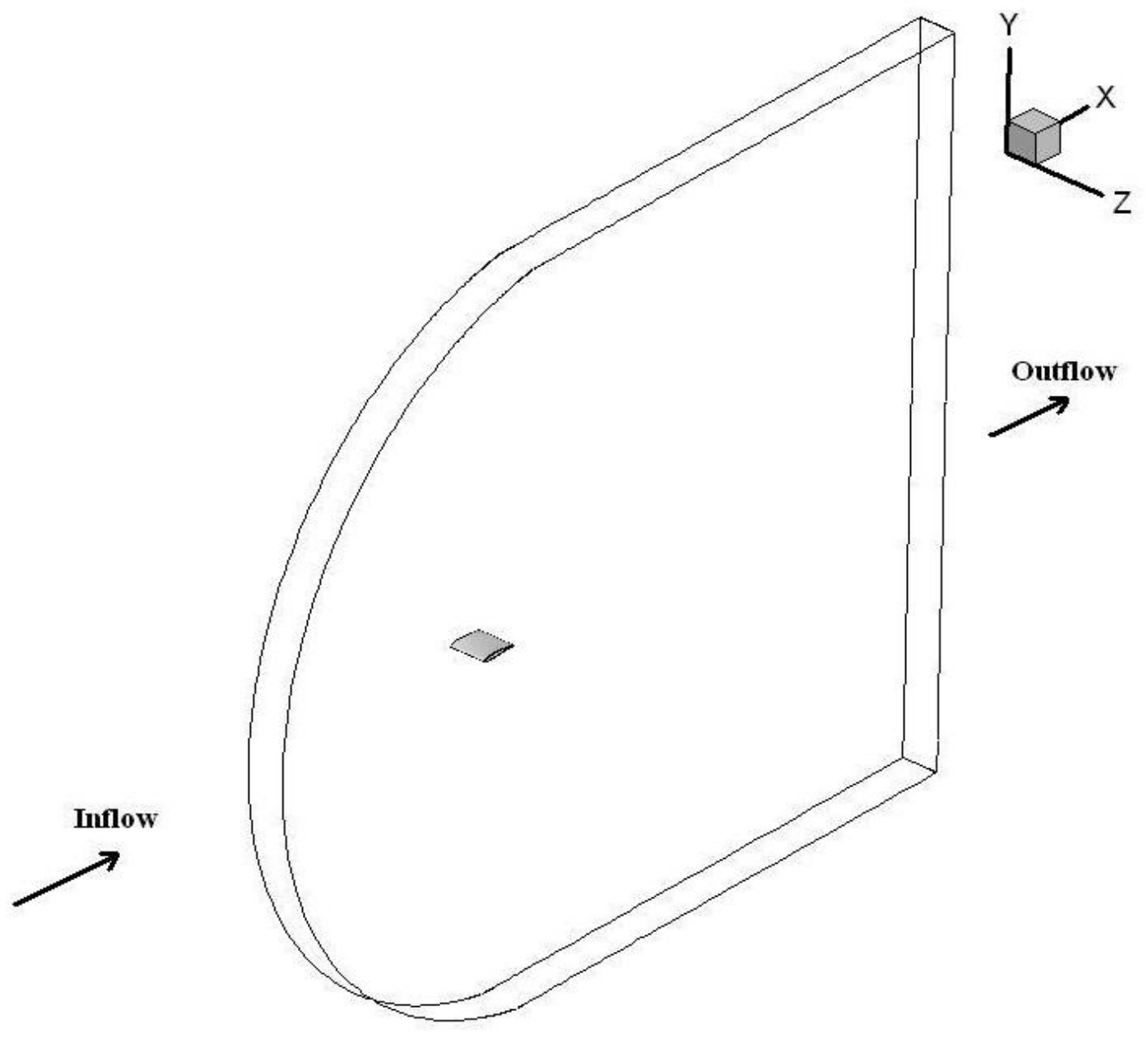

Figure 2.2 Computational domain

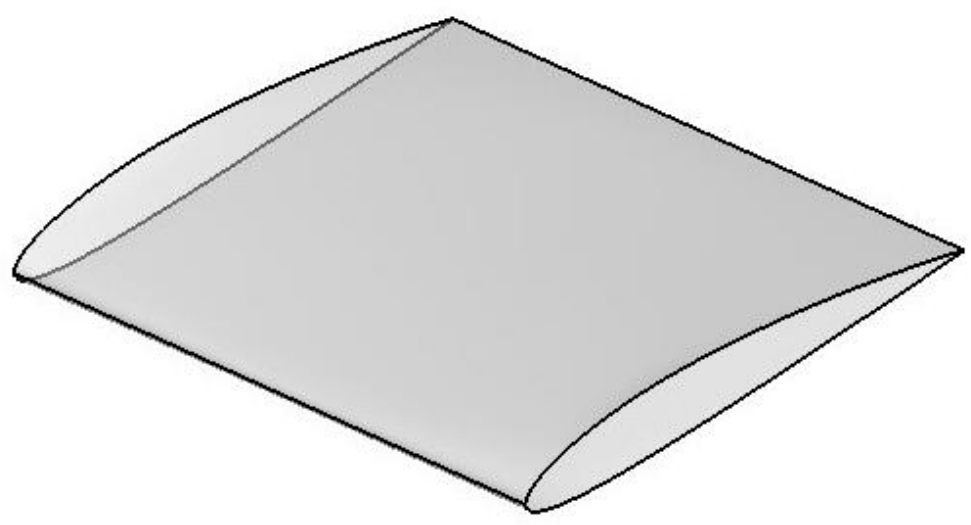

Figure 2.3 Baseline model (wing with smooth leading edge) 


\subsection{Models with Leading-Edge Protuberances}

The size of the computational domain for all models with leading-edge protuberances was the same as the baseline model. Figure 2.4 shows the four wing models considered in the current research, each having a chord length of $\mathrm{c}=0.1 \mathrm{~m}$ and span of $\mathrm{s}=0.1 \mathrm{~m}$. Thus, all models have the same platform area. These four wings had the sinusoidal wave profile as the leading edge with varying wavelength and amplitude, called protuberances or tubercles in anatomy. Two amplitudes of $0.025 \mathrm{c}$ and $0.05 \mathrm{c}$ and two wavelengths of $0.25 \mathrm{c}$ and $0.5 \mathrm{c}$ were used to define the size of protuberances in the current research. These amplitude and wavelengths were considered within the range of tubercles found on the flippers of the humpback whale. In Figure 2.4, the nomenclature 2 and 4 represent the two wavelengths of $0.25 \mathrm{c}$ and $0.5 \mathrm{c}$, respectively, and A and B represent the two amplitudes of $0.025 \mathrm{c}$ and $0.05 \mathrm{c}$, respectively.

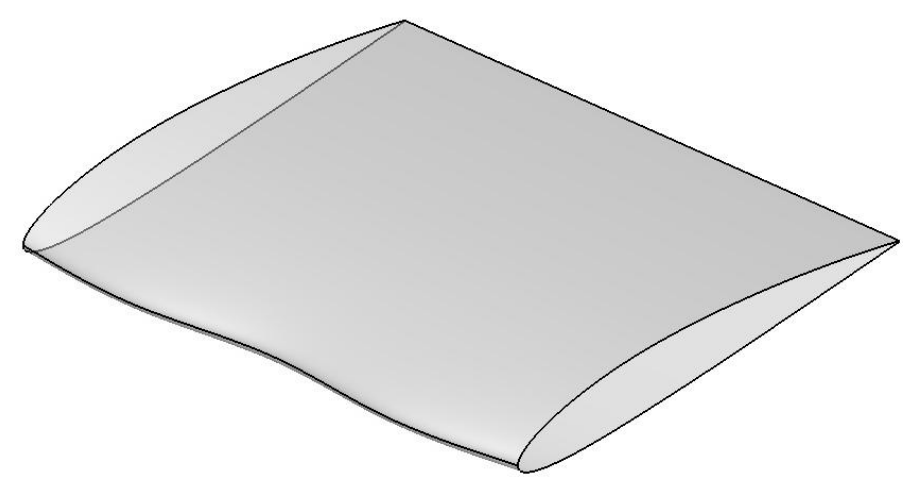

(4A)

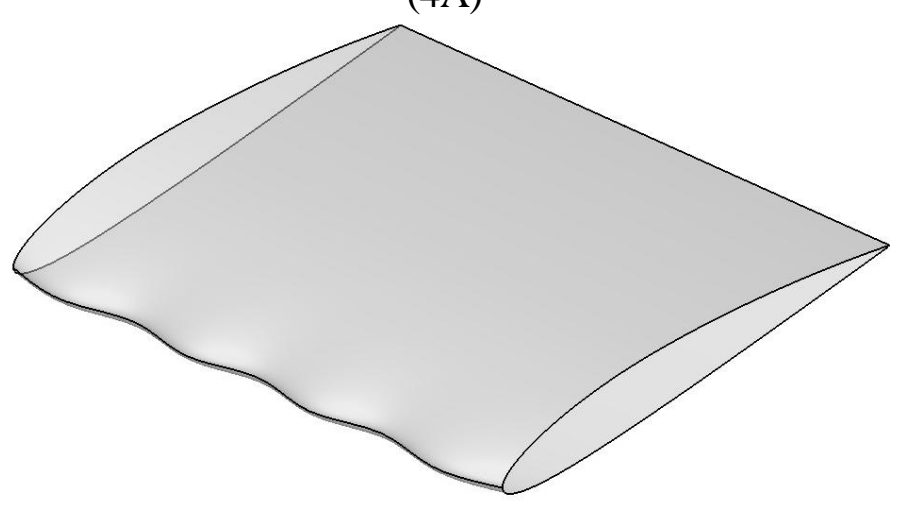

(2A)

Figure 2.4 Modified wings with leading edge protuberances 


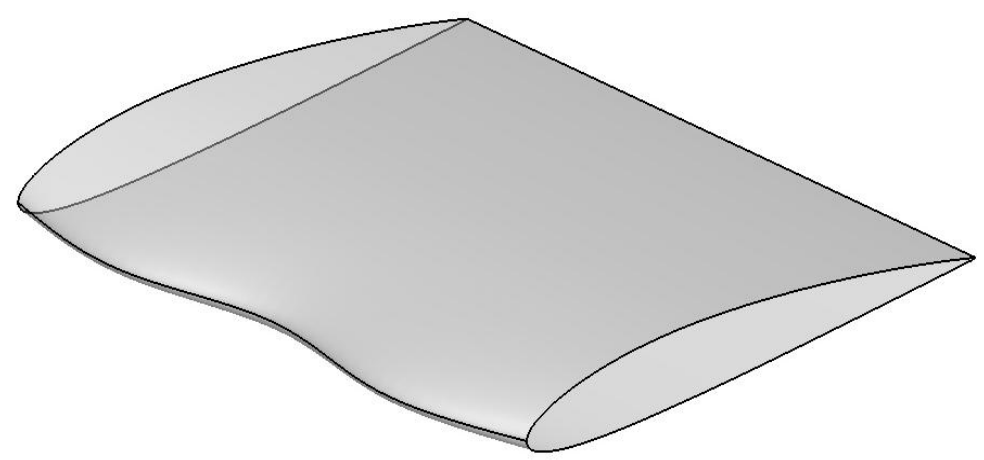

(4B)

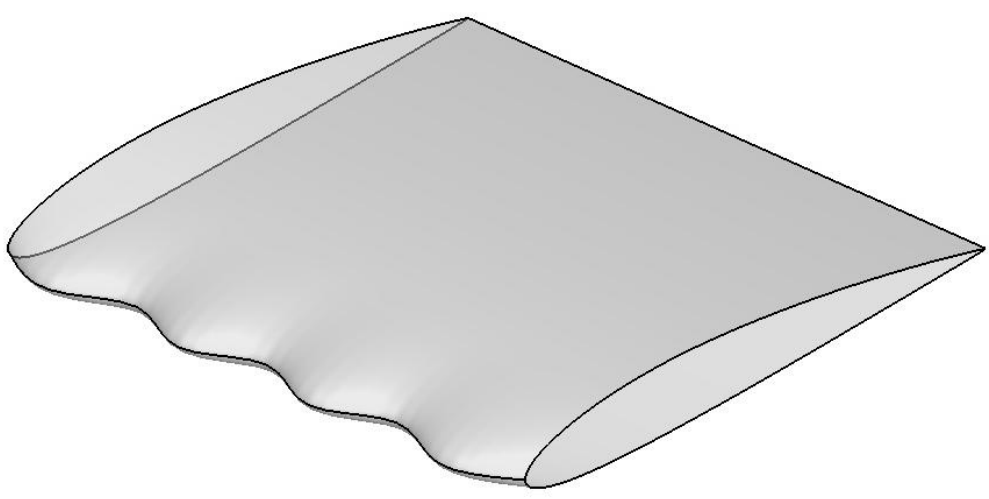

(2B)

Figure 2.4 Modified wings with leading edge protuberances (continued)

\subsection{Grid Generation}

The preprocessor tool of FLUENT, Gambit 2.4.6, was used to create the geometries and to generate the C-type structured mesh. An outline of geometry and grid generation process in Gambit is shown in Figure 2.5.

Generating the mesh for such complex geometries involving curved surfaces, shown in Figures 2.3 and 2.4, was a challenging task, especially for the wings with leading edge protuberances. An unstructured mesh with tetrahedral elements for the geometries proved to be cumbersome. It was laborious and ineffective to control the mesh density around the wing. Therefore, splitting the computational domain into the smaller volumes was feasible enough to 
produce hexahedral elements in mesh, and moreover, it increases the performance of the finite volume numerical method [12]. The computational domain was split into six volumes. The first three volumes were generated around the wing, which are sufficiently clustered to resolve the viscous boundary layer near the wall. The fourth volume was at the upstream, and the remaining two volumes were downstream of the wing. Each volume was meshed individually to have the desired cell density in the region. Although it was a time consuming process to mesh multiple volumes, doing so provided control over the mesh density.

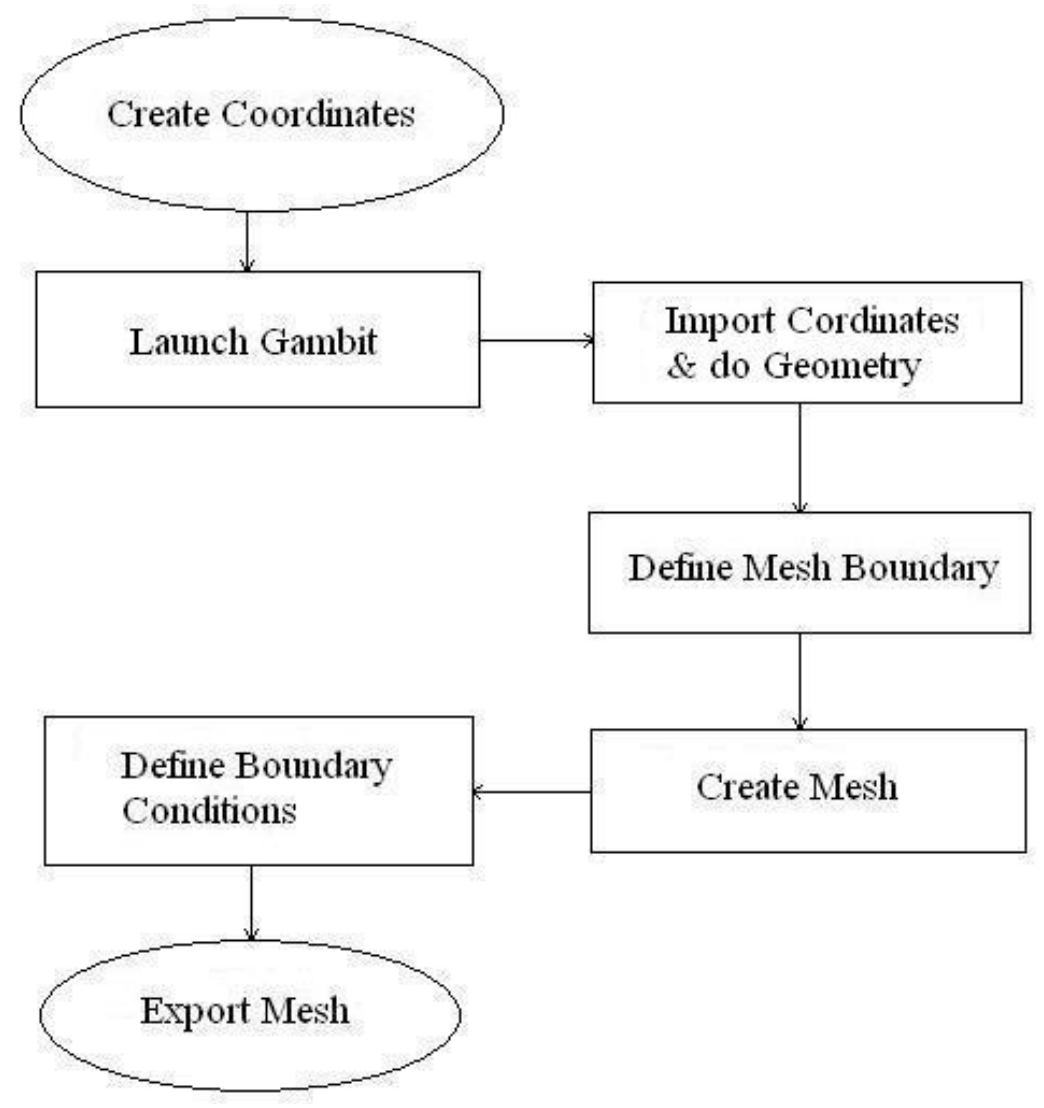

Figure 2.5 Gambit overview

The cell quality is also important to ensure a good mesh, which is measured by the parameters equiskew and aspect ratio. The aspect ratio and equiskew of cells were maintained within the range throughout the domain. The leading edge protuberances induced more complexity to the mesh with hexahedral elements near the surface of wing. To avoid inverted 
cell volumes and high skewness, the least possible cell distance near the wall was used while meshing the inner volume (first) of the domain, and adaption of boundary was used in Fluent where required. The meshes generated for the geometries shown had about 1.43 million cells. Figure 2.6 shows the isometric and two-dimensional (2D) front view of the grid. The zoom-in view of the grid around the wing is shown in Figure 2.7.
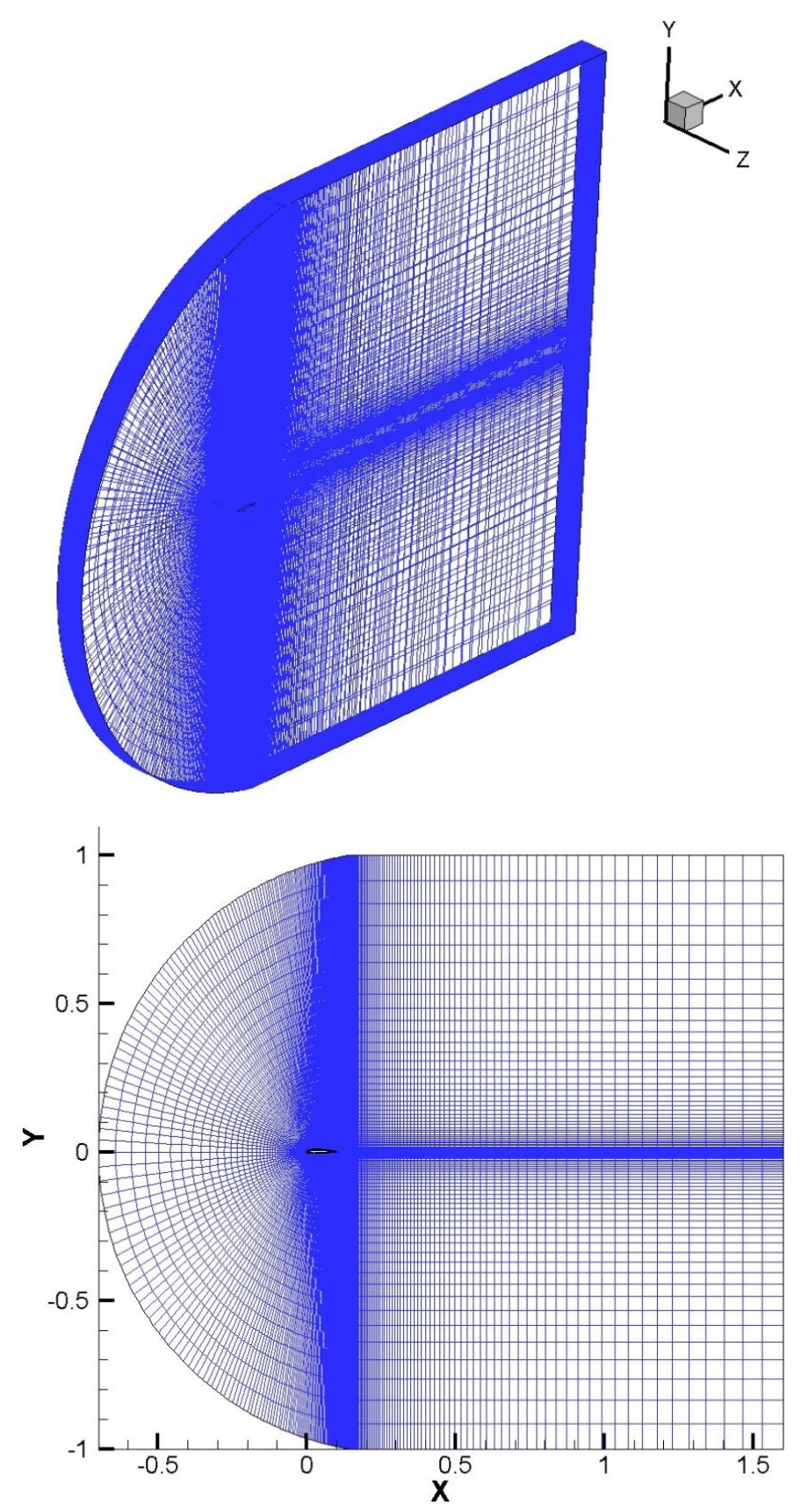

Figure 2.6 Isometric and 2D view of grid 


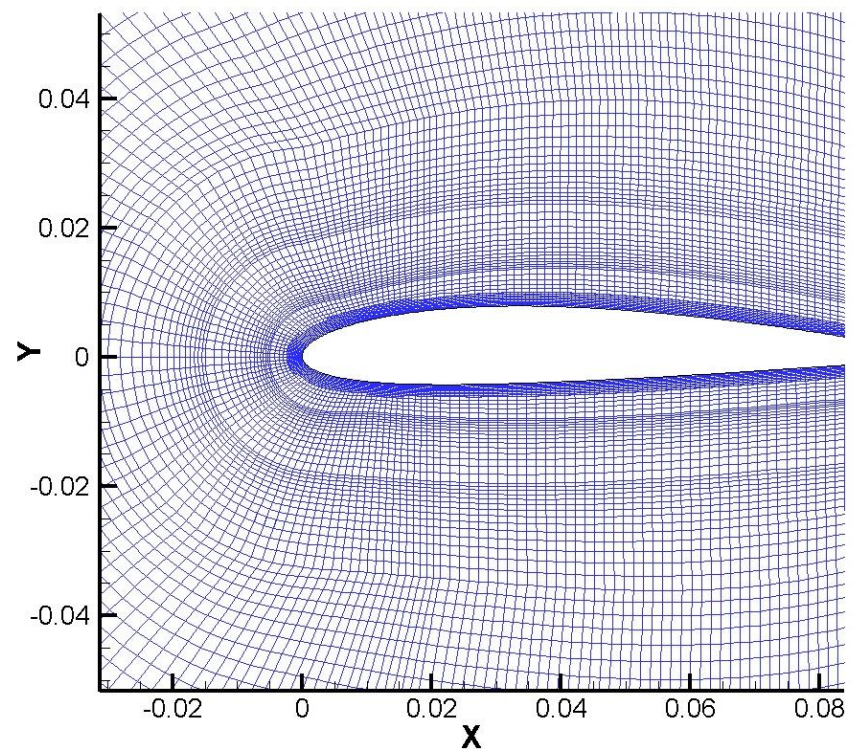

Figure 2.7 Zoom-in view of grid over wing cross section

\subsection{Grid Independence Study}

A grid independence study is significant in numerical analysis because the grid resolution should be sufficiently fine to resolve all important flow parameters such as lift and drag. This study should be able to provide the ideal grid in which a further increase in grid cells does not alter or improve the results. Three cases were considered in this study: first grid (G1) with 217,000 cells, second grid (G2) with 634,000 cells, and third grid (G3) with 1430,000 cells in the domain. The grid boundaries of the domain were placed sufficiently far from the interested nearwall region in order to avoid reflecting flow disturbances. The lift and drag coefficients of baseline at various angles of attack from three grids were compared with that of experimental values available in the work of Abbot and von Doenhoff (Theory of Wing Sections) [13].

The lift coefficient $\left(\mathrm{C}_{\mathrm{L}}\right)$ values from G1, G2, and G3 were in good agreement with the experimental values at all AoA. The G1 grid could not predict the correct drag coefficient $\left(\mathrm{C}_{\mathrm{D}}\right)$ values. The drag coefficient values from G2 grid were a bit close to that of experimental values at lower angles, and at higher angles the difference increased. A further increase in AoA lead to 
the rapid increase in drag coefficients due to massive separation over the upper surface of the wing. The results from grid G3 are in good agreement at all AoA. The $C_{L}$ and $C_{D}$ plots from G1, G2, and G3 compared with that of experimental values are shown in Figure 2.8.

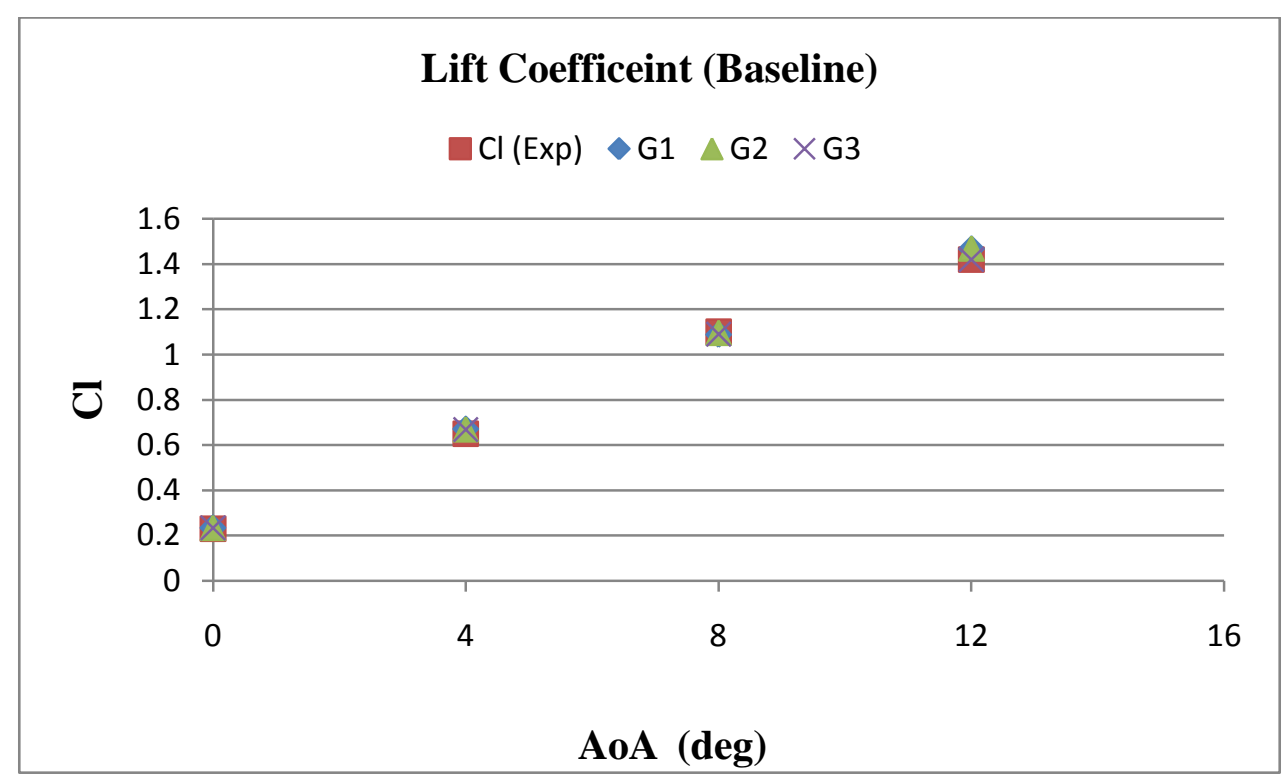

(a)

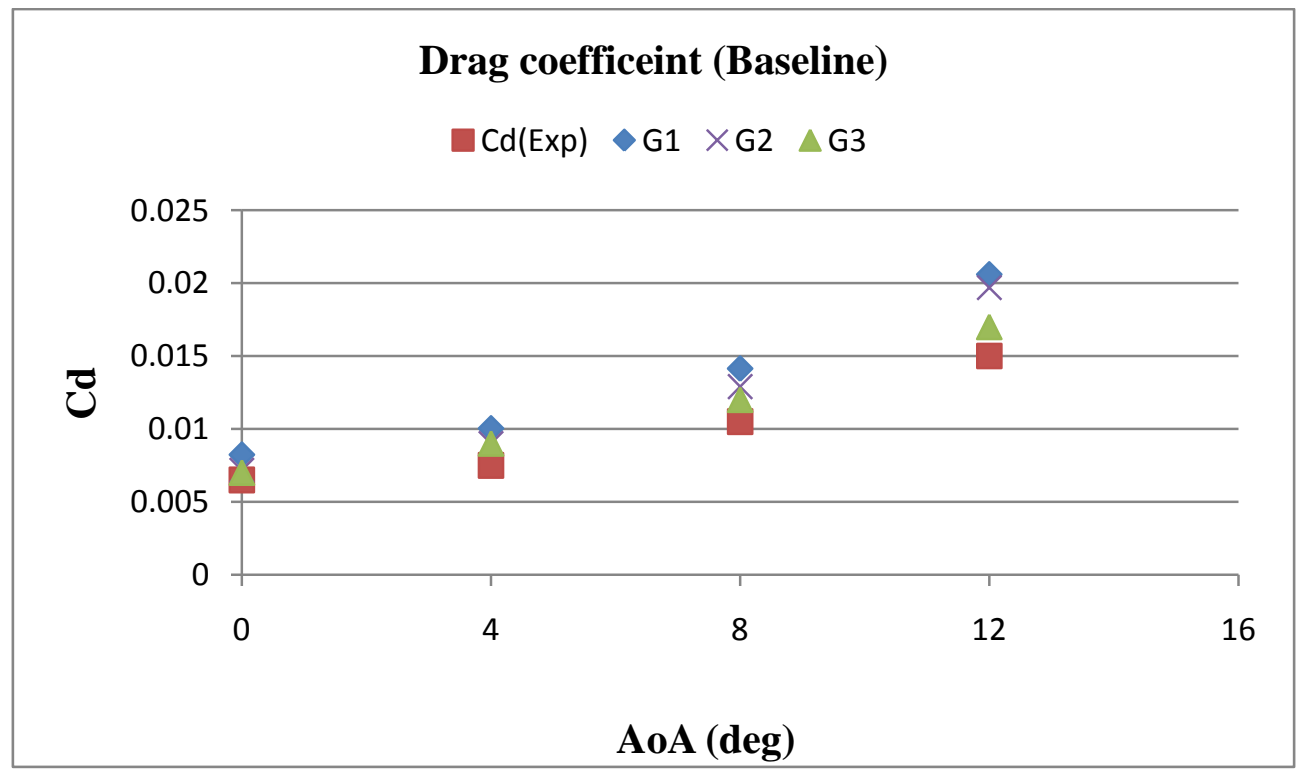

(b)

Figure 2.8 $\mathrm{C}_{\mathrm{L}}$ and $\mathrm{C}_{\mathrm{D}}$ plots from $\mathrm{G} 1, \mathrm{G} 2$, and $\mathrm{G} 3$ 
This grid independence study helped the research to generate the grid G3 with sufficient cells over the upper surface of the wing to resolve the flow at high AoA, which lead to the thought of splitting the domain into multiple volumes and meshing them. The cell distribution over the wing in all grids is shown in Figure 2.9, which shows that grid G3 has evenly distributed grid cells in the domain and more clustering at the leading and trailing edges.
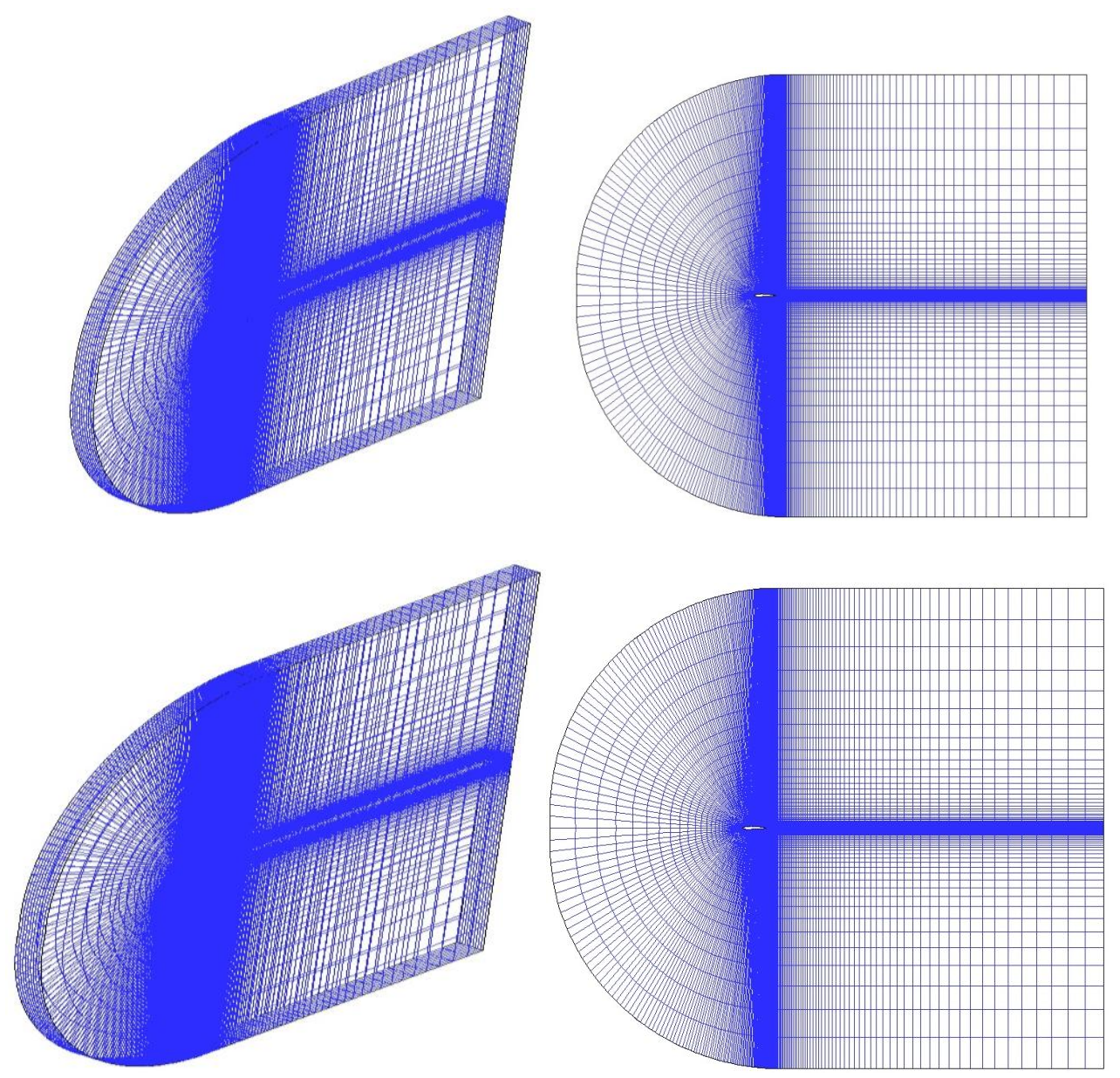

Figure 2.9 3D and 2D views of grids G1, G2, and G3 (respectively from top) 

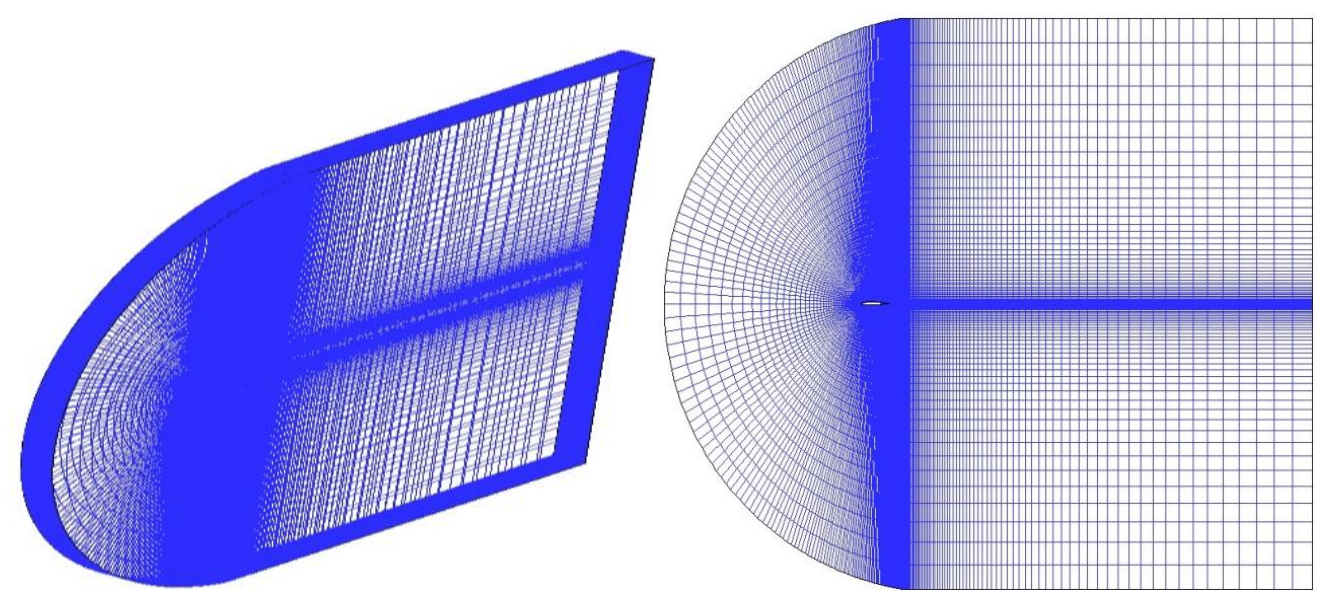

Figure 2.9 3D and 2D views of grids G1, G2, and G3 (respectively from top) (continued) 


\section{CHAPTER 3}

\section{NUMERICAL SIMULATION}

\subsection{Governing Equations of the Flow}

The flow around all the wings was modeled as incompressible at a low Reynolds number with the software package FLUENT. This is a finite volume-based code, where a turbulent flow is solved using the turbulence models provided in the solver. A turbulent flow can be defined as a flow containing self-sustaining fluctuations of flow properties imposed on the main flow. The $\operatorname{Re}$ is the fundamental quantity in describing the transition to turbulent flow, wherein external flows (such as flow over a flat plate), a transition to turbulent flow, can be achieved at Re around $300,000 \sim 500,000$ [14]. Since the simulations carried out in this current research were at $\operatorname{Re} \approx$ 5.7e5, the flow was considered turbulent. A turbulent flow can be predicted by solving conservation equations in differential form referred to as Navier-Stokes equations. The incompressible Navier-Stokes equation of the flow is given by equation (3.1).

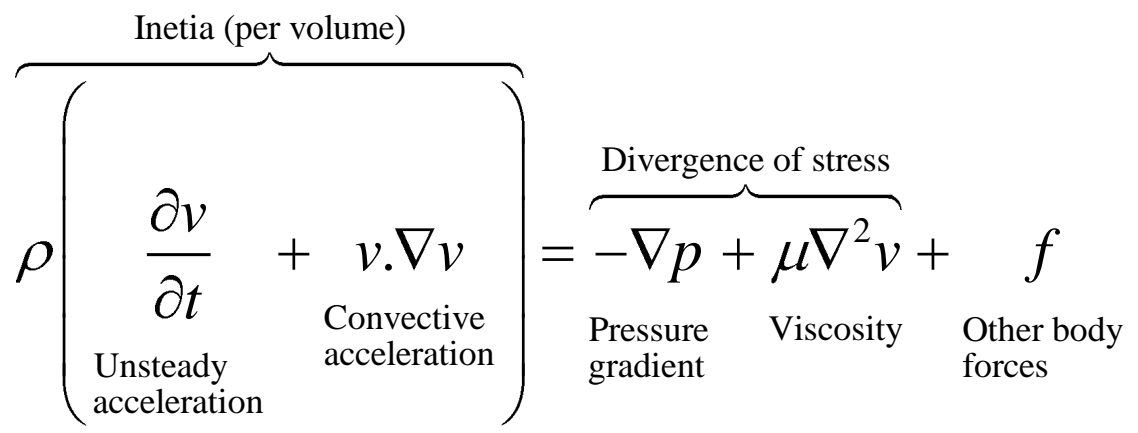

The turbulent flows are characterized by fluctuating velocity fields, which are computationally expensive to simulate directly in practical engineering problems. Therefore, governing equations are time-averaged to obtain a modified set of equations that are less expensive to solve. However, these equations still have unknown variables, and turbulence models are required to determine those variables. 


\subsection{Turbulence Model}

A turbulence model is a semi-empirical equation relating the fluctuating correlation to mean-flow variables with various constants provided from experimental investigations. FLUENT provides various turbulent models, indeed no turbulence model is universally accepted for all types of problems. The DES approach based on the Spallart-Allmaras (SA) model and the SST $\mathrm{k}-\omega$ model was used in the current research to solve the flow characteristics over the wings. The DES models are often referred to as a hybrid of RANS and LES models, where the RANS model is employed in the near-wall region, and the LES model is employed in the core turbulent region. The computational cost for the DES approach is lower than the LES approach and greater than the RANS approach.

\subsubsection{DES with Spallart-Allmaras Model}

The Spallart-Allmaras model is a one-equation model, which solves a transport equation for kinematic turbulent viscosity [15]. This model was designed for aerospace applications involving wall-bounded flows, and it has proven to provide good results. The transported variable in the SA model, $\tilde{v}$, is identical to turbulent kinematic viscosity, and its transport equation is

$$
\frac{\partial}{\partial t}(\rho \tilde{v})+\frac{\partial}{\partial x_{i}}\left(\rho \tilde{v} u_{i}\right)=G_{v}+\frac{1}{\sigma_{\tilde{v}}}\left[\frac{\partial}{\partial x_{j}}\left\{\mu+\rho \tilde{v} \frac{\partial \tilde{v}}{\partial x_{j}}\right\}+C_{b 2} \rho\left(\frac{\partial \tilde{v}}{\partial x_{j}}\right)^{2}\right]-Y_{v}
$$

where $G_{v}=C_{b 1} \rho \tilde{S} \tilde{v}$ is the production term of turbulent viscosity, and $Y_{v}=C_{w 1} \rho f_{w}\left(\frac{\tilde{v}}{d}\right)^{2}$ is the destruction term of turbulent viscosity where

$$
\tilde{S}=S+\frac{\tilde{v}}{k d^{2}} f_{v 2}, \quad f_{v 2}=1-\frac{X}{1+X f_{v 1}}
$$


and

$$
f_{w}=g\left[\frac{1+C_{w 3}^{6}}{g^{6}+C_{w 3}^{6}}\right]^{1 / 6}, \quad g=r+C_{w 2} r^{6}-r, \quad r=\frac{\tilde{v}}{\tilde{S} k^{2} d^{2}}
$$

The turbulent viscosity, $\mu_{t}$, is computed from

$$
\begin{aligned}
& \mu_{t}=\rho \tilde{v} f_{v 1} \\
& f_{v 1}=\frac{X^{3}}{X^{3}+C_{v 1}^{3}} \text { and } X=\frac{\tilde{v}}{v}
\end{aligned}
$$

where $f_{v 1}$ is the viscous damping function.

The model constants are

$$
\begin{aligned}
& C_{b 1}=0.1355, C_{b 2}=0.622, \sigma_{\tilde{v}}=2 / 3, C_{v 1}=7.1 \\
& C_{w 1}=\frac{C_{b 1}}{k^{2}}+\frac{\left(1+C_{b 2}\right)}{\sigma_{\tilde{v}}}, C_{w 2}=0.3, C_{w 3}=2.0, k=0.4187
\end{aligned}
$$

When the SA model is used in the DES approach, as proposed by Shur et al. [16], $\mathrm{d}$ is replaced by $\tilde{d}$ and defined as

$$
\tilde{d}=\min \left(d, C_{d e s} \Delta\right)
$$

where $\Delta$ is local grid spacing and $C_{d e s}=0.65$.

\subsubsection{DES with SST k- $\omega$ Model}

The shear-stress turbulence model was developed by Menter [17] by blending the k- $\omega$ formulation in the near-wall region with the free-stream independence of the k- $\varepsilon$ model in the far field. The following modifications were described by Menter for the DES with SST k- $\omega$ model. The dissipation term of the turbulent kinetic energy is modified to

$$
Y_{k}=\rho \beta^{*} k \omega f_{\beta^{*}}
$$

where 


$$
\begin{gathered}
f_{\beta^{*}}=\max \left(\frac{L_{t}}{C_{d e s} \Delta}, 1\right) \\
C_{d e s}=0.61
\end{gathered}
$$

The turbulent length scale is defined as

$$
L_{t}=\frac{\sqrt{k}}{\beta^{*} \omega}
$$

These features make the SST k- $\omega$ model more accurate and reliable for a wider class of flows, such as the adverse pressure gradient flows, flow over wings, etc.

\subsection{Boundary Conditions}

Boundary conditions specify the flow variables on the boundaries of the computational domain. FLUENT offers various boundary types, from which the required conditions are selected and implemented based on the type of the problem. Velocity inlet, symmetry, wall, and pressure outlet are the boundary types used for the simulations in this study.

The velocity inlet boundary condition is used to define the flow velocity and the relevant scalar properties. Since the flow is incompressible in simulations, this boundary condition is used at inlet and far-field boundaries. Velocity magnitude and direction and the turbulence parameters are the inputs at this boundary.

The symmetry boundary condition is applied when the geometry and the flow field have symmetry. There is zero flux across the symmetry plane. It is used to model zero-shear slip walls in viscous flows, and there are no input parameters for this type.

To bind the fluid and solid regions, the wall-boundary condition is used, and the no-slip boundary condition is enforced at walls by default in viscous flows. This condition is applied at the surfaces of the wing geometry. The shear stress between the fluid and wall is computed based on flow details in the local flow field. 
The pressure outlet boundary is used at the outlet of the domain. The static pressure is specified and is used only if the flow is subsonic. To minimize the convergence difficulties, a set of back flow conditions are also specified in this boundary type.

\subsection{Numerical Procedure and Simulation Setup}

The pressure-based solver was used to execute the simulations in FLUENT, with higher order spatial discretization. The detached-eddy simulation model, based on SA and k- $\omega$ models, was used with implicit second-order unsteady formulation. In the solution method, the semiimplicit method for pressure linked equations (SIMPLE) algorithm was used for pressurevelocity coupling. The momentum equation was solved using a bounded central differencing scheme. As suggested by the solver, second-order upwind scheme was implemented for discretizing the equations and PRESTO was used as the pressure interpolation scheme. Default under-relaxation factors provided in the solver were used, and reference values were specified to monitor lift and drag forces on wing surfaces.

Numerical simulations model the wings in the defined computational domain. The Re for all simulations was $5.7 * 10^{5}$. In order to maintain the Re, the velocity specified at the inflow boundary was $83.24 \mathrm{~m} / \mathrm{s}$, which corresponded to 0.24 Mach number. In each case, the same geometry and mesh was used to resolve the flow at all angles of attack. The inflow direction was changed to correspond to the AoA. The time step was set to $0.0001 \mathrm{sec}$, as mentioned in the work of Spalart [18]. In each unsteady case, 2,500 to 3,000 time-steps were computed. The mean flow residence time in the solution domain was estimated before executing the simulation $(\mathrm{L} / \mathrm{U}=$ 0.0276 , where $\mathrm{L}=2.3 \mathrm{~m}$ is the characteristic length of the domain, and $\mathrm{U}=83.24 \mathrm{~m} / \mathrm{s}$ is a mean flow velocity). The unsteady DES simulation was executed for $0.25 \mathrm{sec}$, which corresponds to 9 mean flow residence times. Generally, the solution requires two mean flow residence times to 
attain statistical steadiness. The initial 1,500 time-steps were not considered while calculating the time-averaged values. Full execution required approximately 5 to 6 days. 


\section{CHAPTER 4}

\section{VALIDATION}

\subsection{Validation of Baseline Wing}

This chapter begins with validation of the baseline model performance. The numerical results of baseline were validated with that of experimental values in the Theory of Wing Sections [13]. The comparison of baseline lift coefficients is shown in Figure 4.1, and the drag coefficients are shown in Figure 4.2, as a function of $\alpha$. The numerical results of the baseline lift coefficient are in very good agreement with those of experimental values. The $C_{L}$ behaves normally, with lift increase in the linear rate until AoA, $\alpha \approx 12^{\circ}$, has a slope of $d C_{L} / d \alpha=0.1055$ (per deg) and continues to increase but at a lower rate. It has the maximum lift coefficient $C_{\mathrm{Lmax}}$ $=1.67$ at $\mathrm{AoA} \alpha \approx 16^{\circ}$. This increase in lift at a lower rate above $\alpha=12^{\circ}$ indicates the flow separation caused by the adverse pressure gradient in the boundary layer. The rate of increase in lift decreased and drag increased due to separation, as shown in Figure 4.2 at $12^{\circ} \leq \alpha \leq 16^{\circ}$. The flow separation starts at the trailing edge, and the further increase in $\alpha$ increases separation upstream. Past $\alpha=16^{\circ}$, the baseline stall caused a dramatic loss of lift and rapid increase in drag.

The drag coefficient of baseline was lowest at $\alpha=0^{\circ}, C_{D} \sim 0.0065$. The $C_{D}$ increased in quadratic fashion with the increase in $\alpha$ until the flow separation occurred, and thereafter, it increased at a discontinued rate. The drag on the baseline suddenly rose after the stalling angle ( $\alpha$ $\approx 16^{\circ}$ ). The results show a very good agreement. Usually the $C_{L}$ values are easy to predict because they are mainly due to pressure difference on the upper and lower surfaces of the wing. Typically the $C_{D}$ values show poor agreement in turbulent flows, since they are mainly caused by skin friction. However, the values shown here have good agreement; therefore, the numerical results of the baseline from Fluent were validated with the experimental results. 


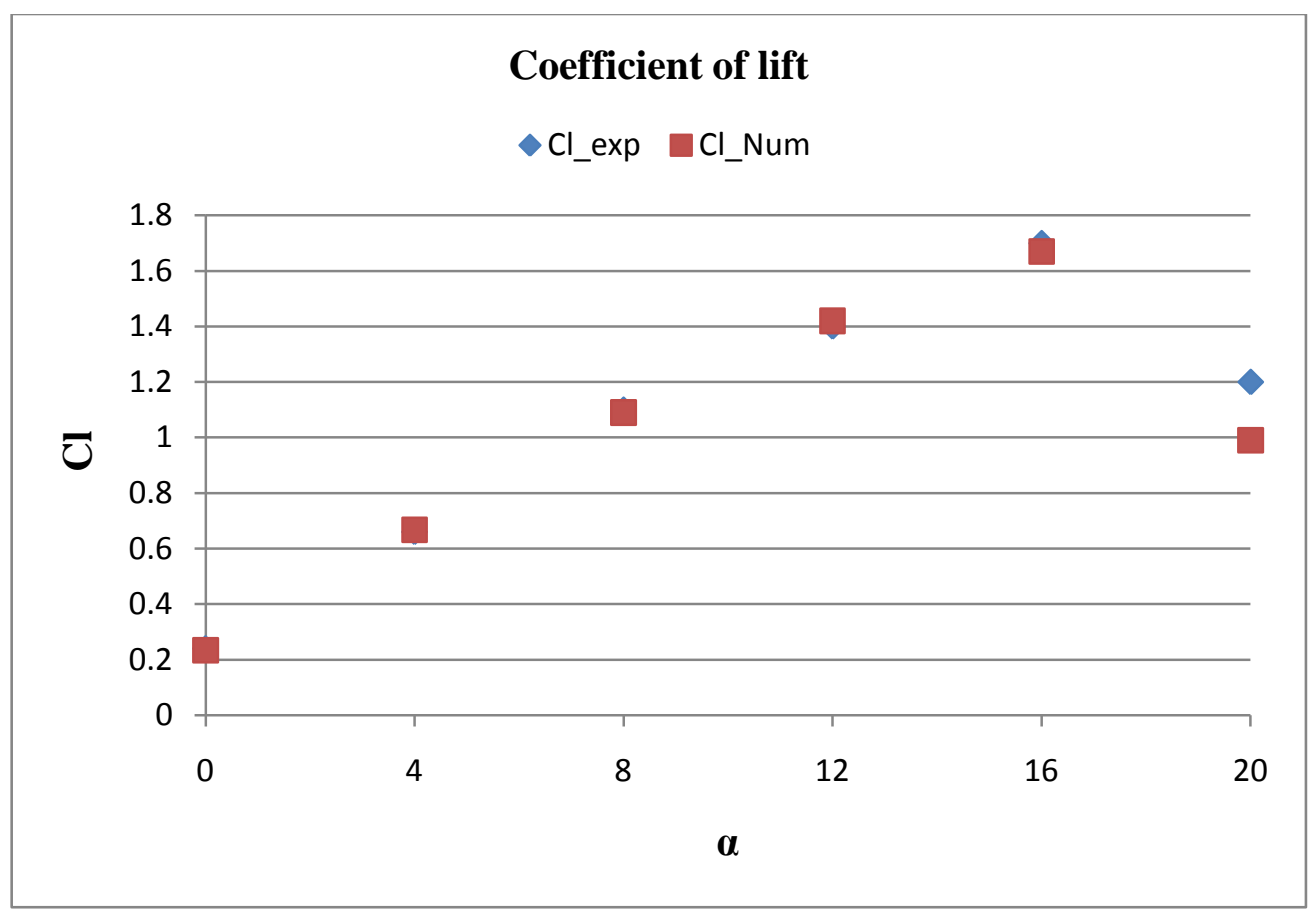

Figure 4.1 Lift coefficient of baseline as function of $\alpha$

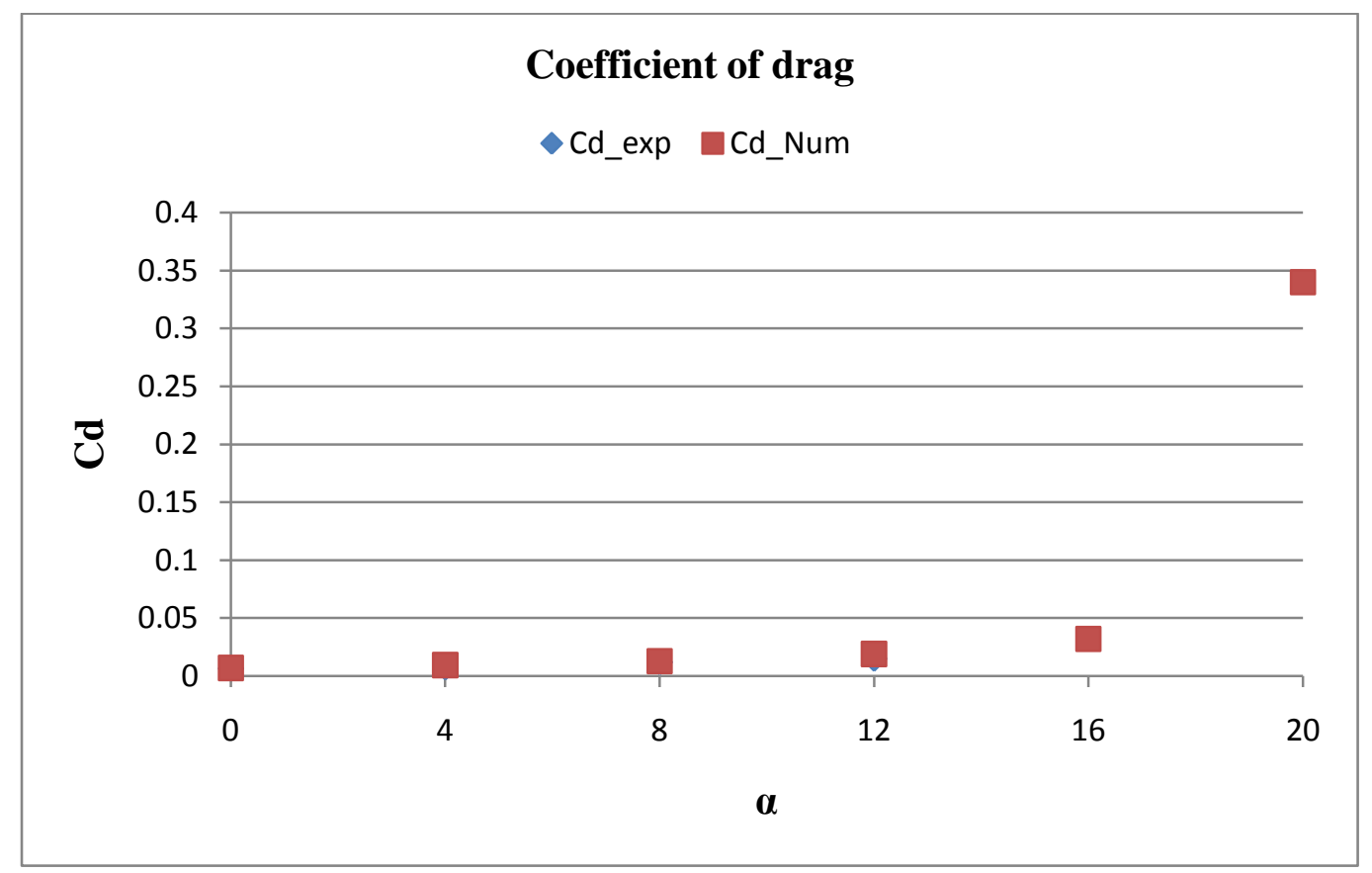

Figure 4.2 Drag coefficient of baseline as function of $\alpha$ 


\section{CHAPTER 5}

\section{RESULTS AND DISCUSSION}

This chapter presents the numerical results obtained through simulations for wings with various modified leading edges. The simulations produced an adequate amount of data, which was processed to uncover the effects of leading-edge protuberances on wings. Here the lift and drag characteristics of all wings with leading-edge protuberances are compared with those of the baseline, under the same conditions for evaluating the performance of each wing.

\subsection{Effects of Protuberance Amplitude}

The effects of protuberance amplitude on the performance of the wings with leading-edge protuberances compared to the baseline are shown in Figures 5.1 to 5.4. All wings with protuberances had similar lift coefficients from $0^{\circ} \leq \alpha \leq 12^{\circ}$ with a linear rise in $C_{L}$ as a function of $\alpha$. All wings with protuberances showed the separation effect after $\alpha \approx 12^{\circ}$.

The lift coefficient $\left(\mathrm{C}_{\mathrm{L}}\right)$ of the wing with the shortest wavelength and smallest amplitude (2A), shown in Figure 5.1 (a), followed the same trend as the baseline until $\alpha \approx 12^{\circ}$. At $12^{\circ}$, the $\mathrm{C}_{\mathrm{L}}$ began to drop with $\alpha$ and reached a point where the lift was almost equal to that of the baseline, with $\mathrm{C}_{\mathrm{L}} \approx 0.83$. Albeit the $2 \mathrm{~A}$ wing produced lower lift than that of the baseline in the pre-stall regime, the value of $\mathrm{C}_{\mathrm{L}}$ was more than the baseline $\mathrm{C}_{\mathrm{L}}$, past the stalling angle. Therefore, the $2 \mathrm{~A}$ wing generated more lift after the stalling angle and had a less-dramatic stall effect.

As in the case of increased amplitude of the protuberance with the same wavelength (2B), shown in Figure 5.1 (a), a different characteristic was observed. This wing also had a similar effect of linear rise with $\alpha$, as the baseline, but 2B generated less lift at a lower AoA when compared to that of the small protuberance amplitude wing (2A). After crossing the AoA $\alpha \approx$ 
$12^{\circ}$, the lift dropped at the lower rate than the baseline wing. The $2 \mathrm{~B}$ wing continued to generate $25 \%$ more lift than the baseline wing at $\alpha \approx 16^{\circ}$, where the lift dropped off gradually but was still about $15 \%$ greater than the baseline at $\alpha \approx 20^{\circ}$. Therefore, the $2 \mathrm{~B}$ wing also generated more lift than the baseline past the stalling angle.

The data for wings 4A and 4B with a $0.5 \mathrm{c}$ wavelength, shown in Figure 5.3, exhibited very similar behavior to the wings with a shorter wavelength, which implies that the lift was more dependent on the amplitude of protuberances. The $\mathrm{C}_{\mathrm{L}}$ for the wing with smallest leading edge protuberances (4A) had similar values to the $\mathrm{C}_{\mathrm{L}}$ of the baseline up to $\alpha \approx 12^{\circ}$, and it dropped off past this angle, becoming almost identical to the $C_{L}$ values of baseline. The $C_{L}$ for the wing with the largest leading-edge protuberances (4B) rose linearly up to $\alpha \approx 12^{\circ}$ and gradually dropped off, having lift of $48 \%$ and $38 \%$ more than that of the baseline, at $\alpha \approx 16^{\circ}$ and $20^{\circ}$, respectively.

The drag coefficient $\left(\mathrm{C}_{\mathrm{D}}\right)$ of wings with $0.25 \mathrm{c}$ and $0.5 \mathrm{c}$ wavelength can be seen in Figures 5.1 (b) and $5.3(\mathrm{~b})$, respectively. The $C_{D}$ values of the baseline rose in quadratic fashion with $\alpha$, showing the rapid increase in drag at the stalling angle, and continued to increase past the stalling angle. In both cases, as shown in Figures 5.1 (b) and 5.3 (b), the $C_{D}$ values of wings with protuberances showed a similar effect until the stalling angle; past the stalling angle, these wings generated less drag and eventually became almost equal to that of the baseline. The interesting point to note here is that, as the amplitude of the protuberances increased, the significant increase in drag at the stalling angle was smaller. The wings with leading-edge protuberances had more drag, only in a pre-stall regime. However, in a post-stall regime, the drag coefficient values in the four cases were close to the $C_{D}$ values of the baseline, and past the stalling angle at a high AoA, 
drag became almost identical in all cases. At high angles of attack, the drag was almost independent of leading-edge geometry because all wings appeared blunt.

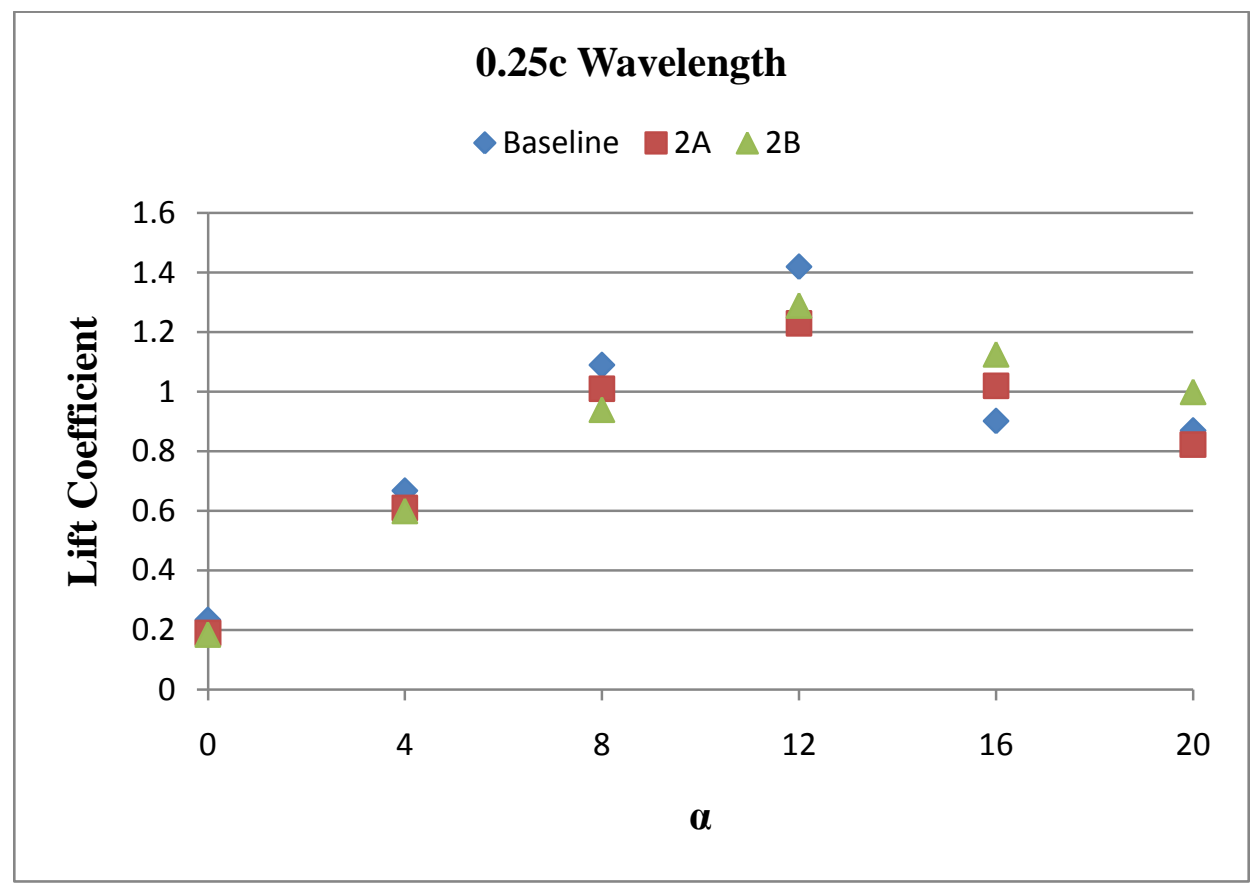

(a)

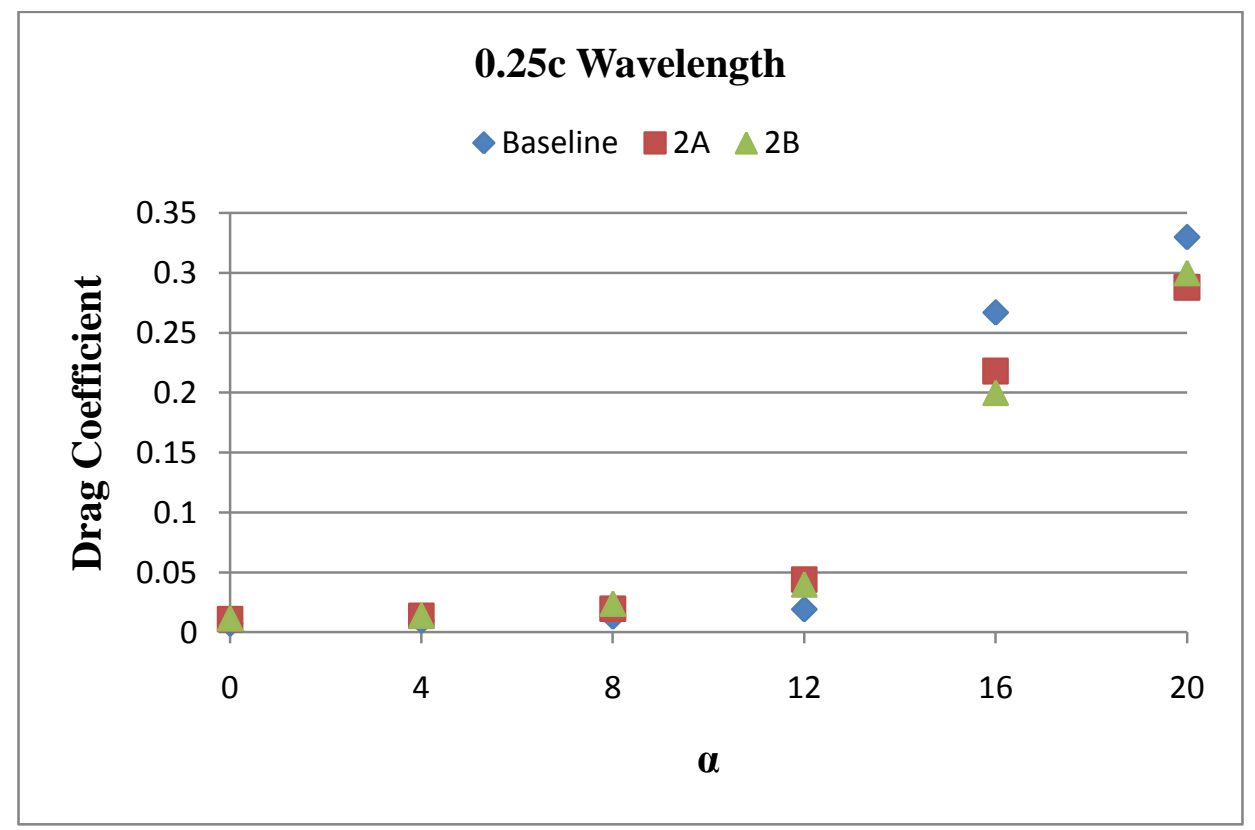

(b)

Figure 5.1 (a) Lift and (b) Drag coefficients of wings with $0.25 \mathrm{c}$ wavelength as function of $\alpha$ 


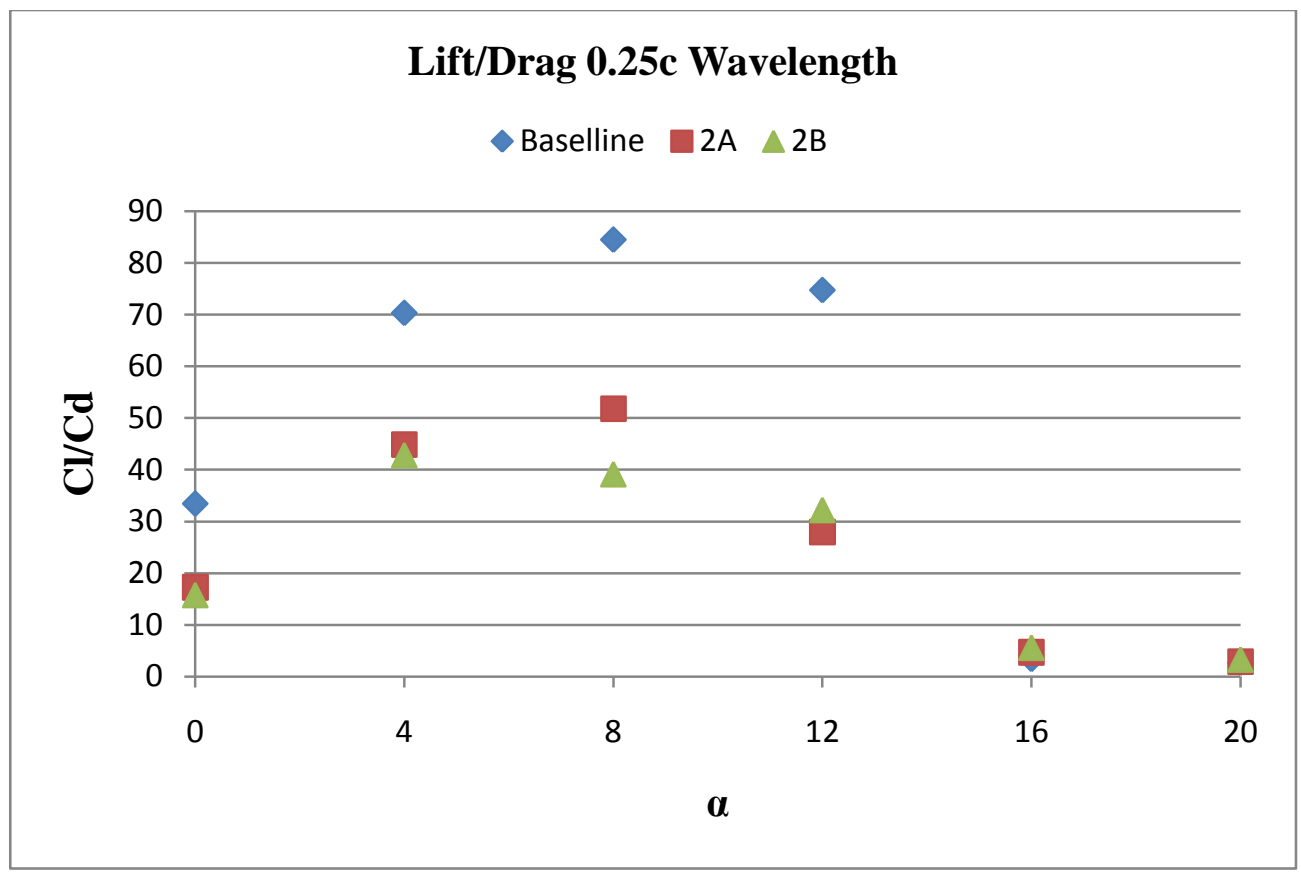

Figure 5.2 Lift-to-drag ratio of wings with $0.25 \mathrm{c}$ wavelength as a function of $\alpha$

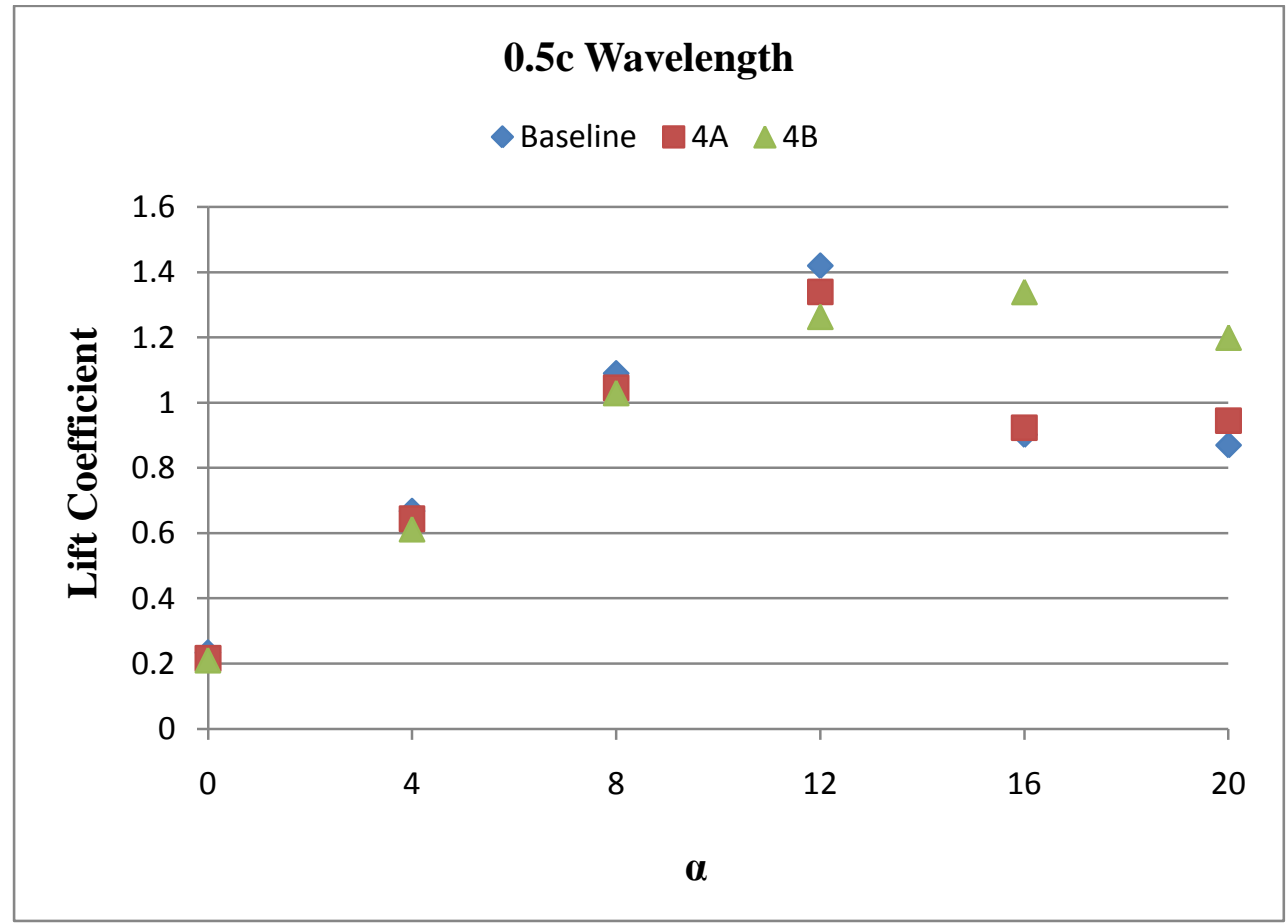

(a)

Figure 5.3 (a) Lift and (b) Drag coefficients of wings with $0.5 \mathrm{c}$ wavelength as a function of $\alpha$ 


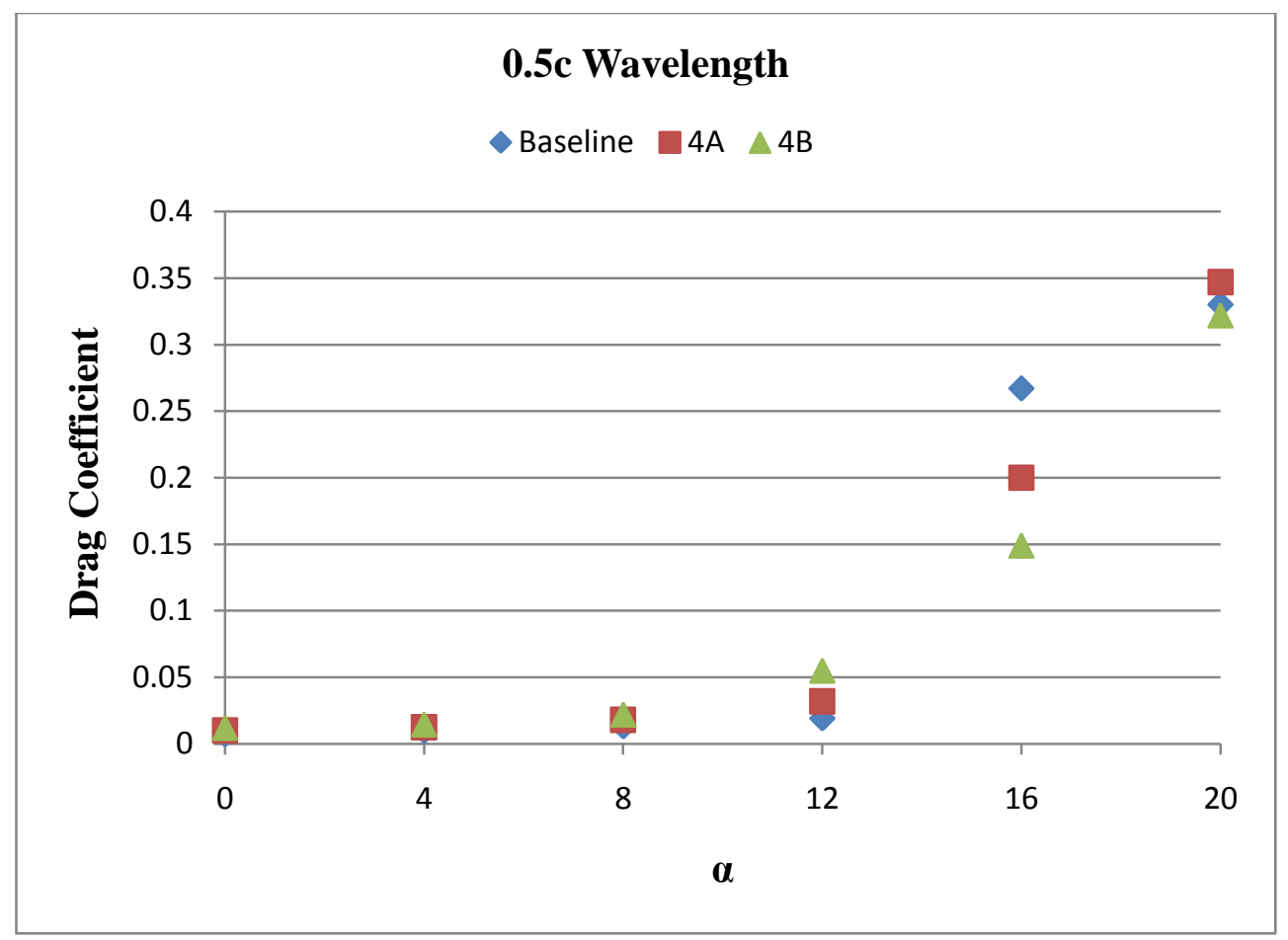

(b)

Figure 5.3 (a) Lift and (b) Drag coefficients of wings with $0.5 \mathrm{c}$ wavelength as a function of $\alpha$ (continued)

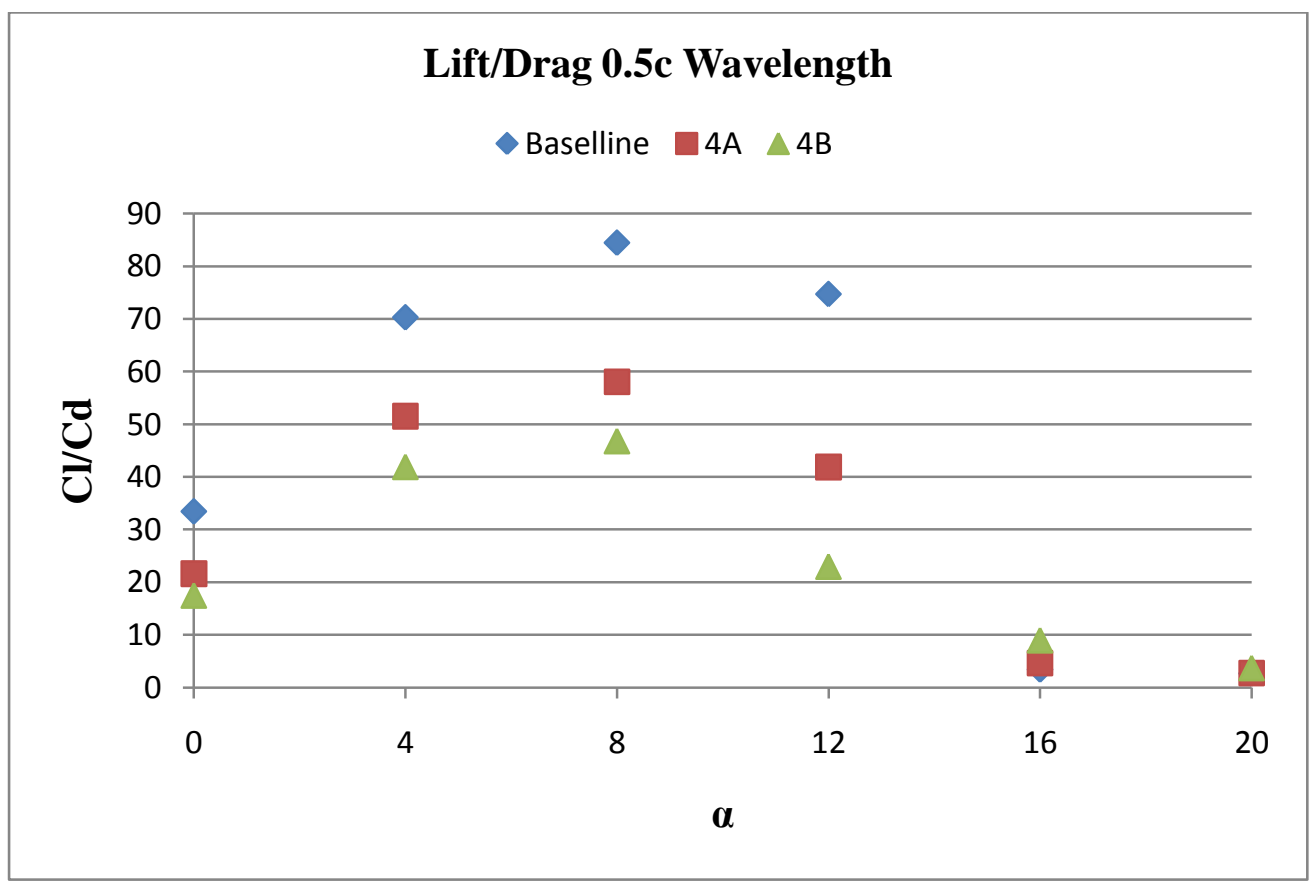

Figure 5.4 Lift-to-drag ratio of wings with $0.5 \mathrm{c}$ wavelength as a function of $\alpha$ 


\subsection{Load Characteristics}

Figure 5.5 shows the overall effect of leading-edge protuberances on the load characteristics of the wings. The lift and drag forces on the 4B wing normalized by the lift and drag forces on the baseline are presented in this figure. The $4 \mathrm{~B}$ wing produced $11 \%$ less lift than the baseline at its lowest value in the pre-stall regime, whereas the lift generated is as much as $48 \%$ higher than baseline in the post-stall regime. The drag on the $4 \mathrm{~B}$ wing in the pre-stall regime was up to $180 \%$ higher but in the post-stall regime the drag can be $44 \%$ less than baseline; gradually the difference becomes minimized and the values get closer to baseline above $\alpha \geq 16^{\circ}$. Therefore, the post-stall regime is the most effective angle of attack where the protuberances of the leading edge should be located on the baseline. After the stalling effect on the baseline, the lift can be as much as $48 \%$ higher and the drag can be $44 \%$ less, or there is no drag penalty.

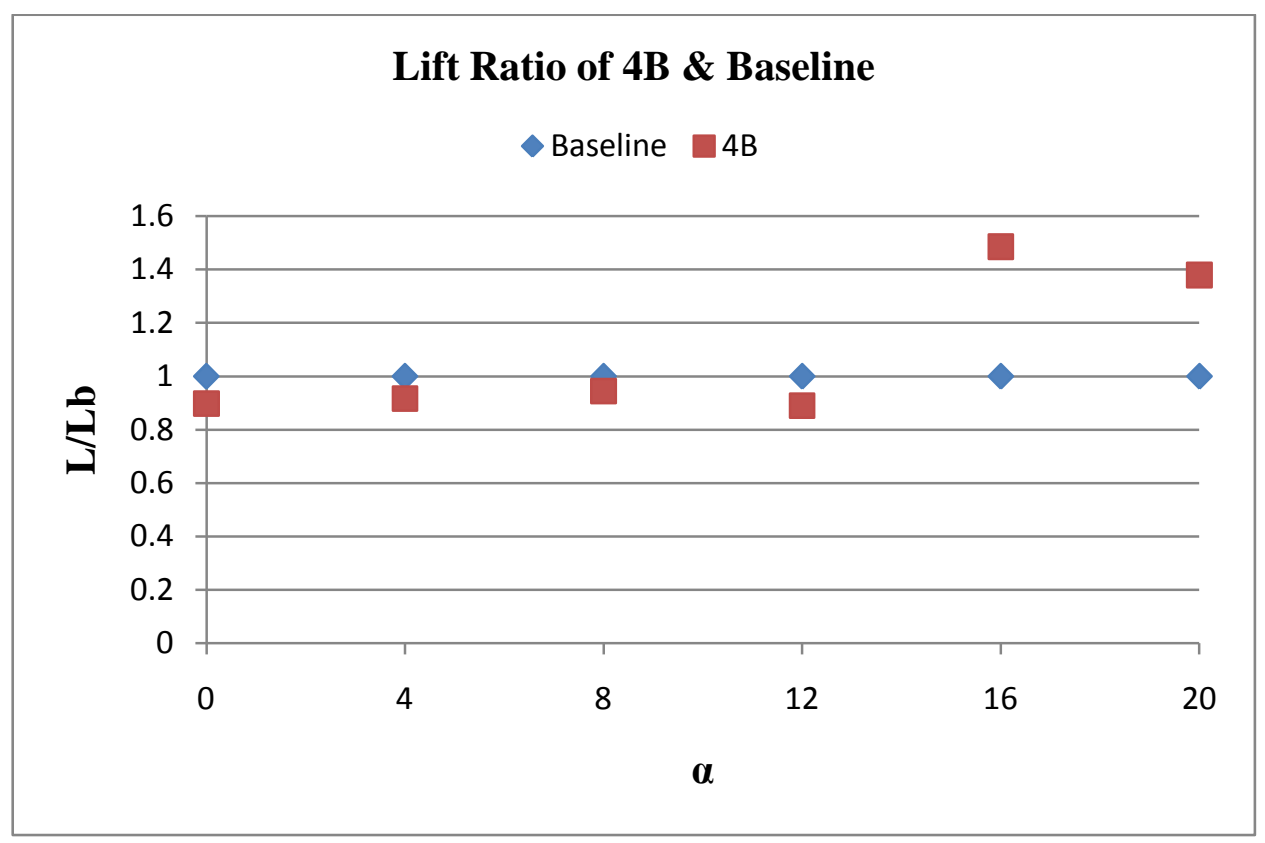

(a)

Figure 5.5 (a) Lift and (b) Drag coefficients of 4B wing normalized by baseline values 


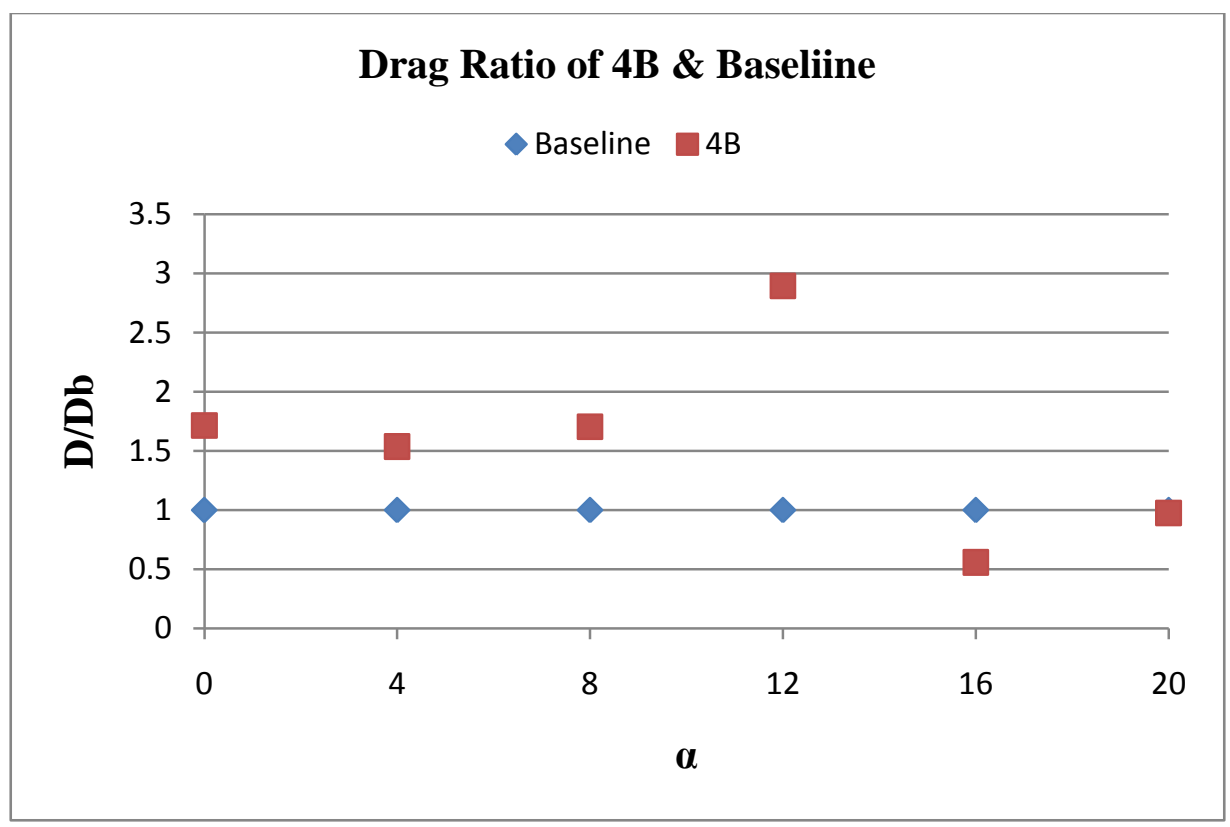

(b)

Figure 5.5 (a) Lift and (b) Drag coefficients of 4B wing normalized by baseline values (continued)

The aerodynamic characteristics, maximum $\mathrm{C}_{\mathrm{L}}, \alpha$ at maximum $\mathrm{C}_{\mathrm{L}}$, minimum $\mathrm{C}_{\mathrm{D}}$, maximum $\mathrm{L} / \mathrm{D}, \alpha$ at maximum $\mathrm{L} / \mathrm{D}$, and lift coefficient slope, within the linear range for all wings, can be seen in Table 5.1. The slope of the lift coefficient is lower than the baseline for all wings with leading-edge protuberances. All wings with leading-edge protuberances had a lower maximum lift coefficient than the baseline, which indicates that having the protuberances at the leading edge of the wing produces less maximum lift but delays the stall.

TABLE 5.1

AERODYNAMIC CHARACTERISTICS OF ALL WINGS

\begin{tabular}{|c|c|c|c|c|c|c|}
\hline Wing & Max C $_{\mathbf{L}}$ & $\begin{array}{c}\alpha \text { at Max } C_{\mathbf{L}} \\
(\mathbf{d e g})\end{array}$ & $\operatorname{Min}_{\mathbf{D}}$ & $\begin{array}{c}\text { Max } \\
\text { L/D }\end{array}$ & $\begin{array}{c}\alpha \text { at Max L/D } \\
(\mathbf{d e g})\end{array}$ & $\begin{array}{c}\mathbf{d} \mathbf{C}_{\mathbf{L}} / \mathbf{d \alpha} \\
(\mathbf{p e r} \mathbf{d e g})\end{array}$ \\
\hline Baseline & 1.42 & 12 & 0.007 & 84.49 & 8 & 0.1055 \\
\hline 2A & 1.23 & 12 & 0.011 & 51.8 & 8 & 0.10 \\
\hline 4A & 1.34 & 12 & 0.01 & 58.05 & 8 & 0.1002 \\
\hline 2B & 1.29 & 12 & 0.0117 & 42.85 & 4 & 0.085 \\
\hline 4B & 1.34 & 16 & 0.012 & 46.82 & 4 & 0.1045 \\
\hline
\end{tabular}




\subsection{Effects of Protuberance Wavelength}

The effect of wavelength on wings with leading-edge protuberances compared to the baseline are presented in Figures 5.6 (a) and 5.7 (a), which is similar to data presented earlier. The effect of wavelength of protuberance is minor when compared with the effect of protuberance amplitude. Among the wings with protuberances, the increase in maximum lift coefficient $\left(\mathrm{Max}_{\mathrm{L}}\right)$ was observed with the increase in wavelength.

Figures 5.6 (b) and 5.7 (b) show the drag coefficients for two different wavelengths. The effect of wavelength on drag coefficient was observed to be greater for the $0.05 \mathrm{c}$ protuberance amplitude than the $0.025 \mathrm{c}$ protuberance amplitude.

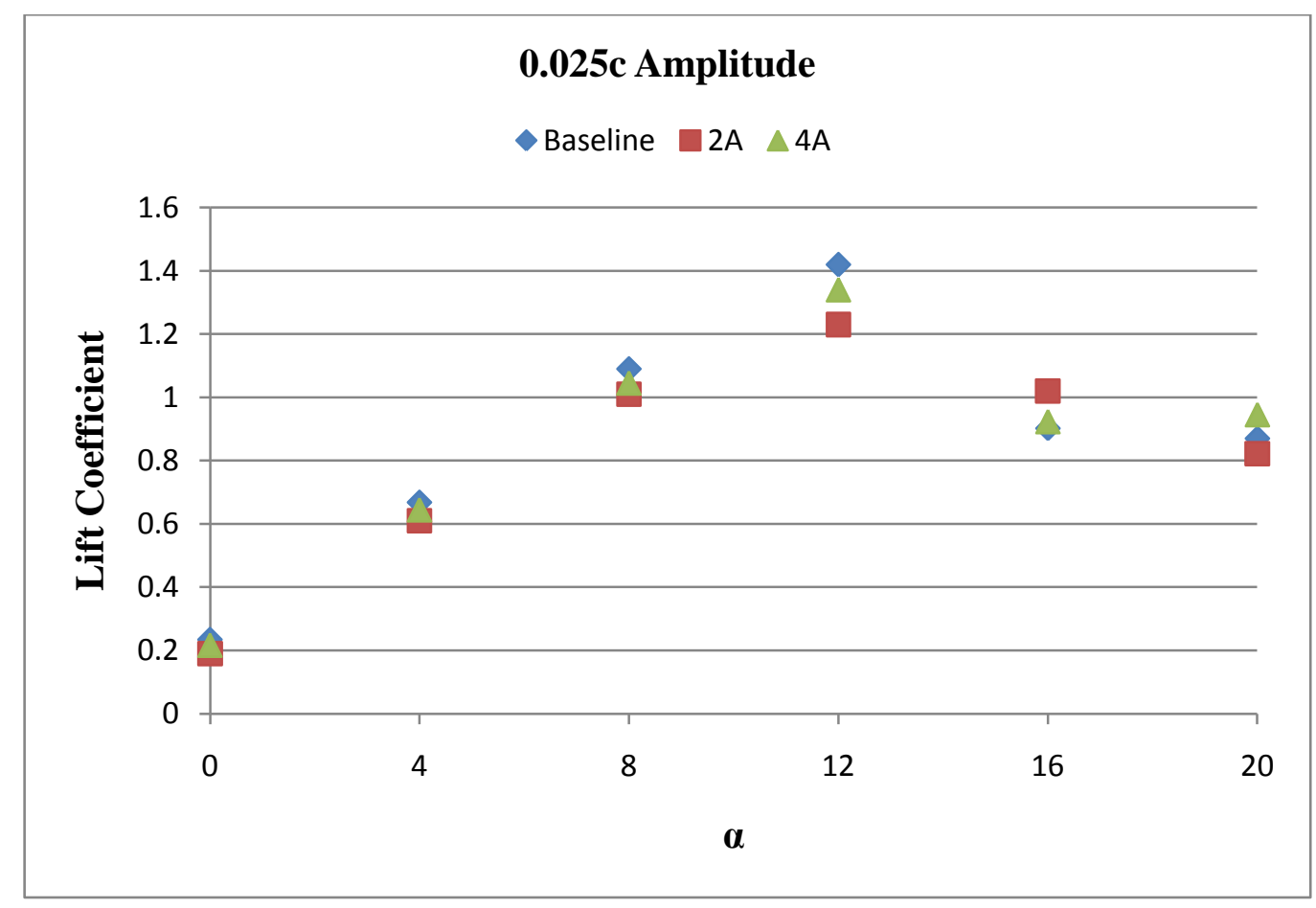

(a)

Figure 5.6 (a) Lift and (b) Drag coefficients of wings with $0.025 \mathrm{c}$ amplitude as a function of $\alpha$ 


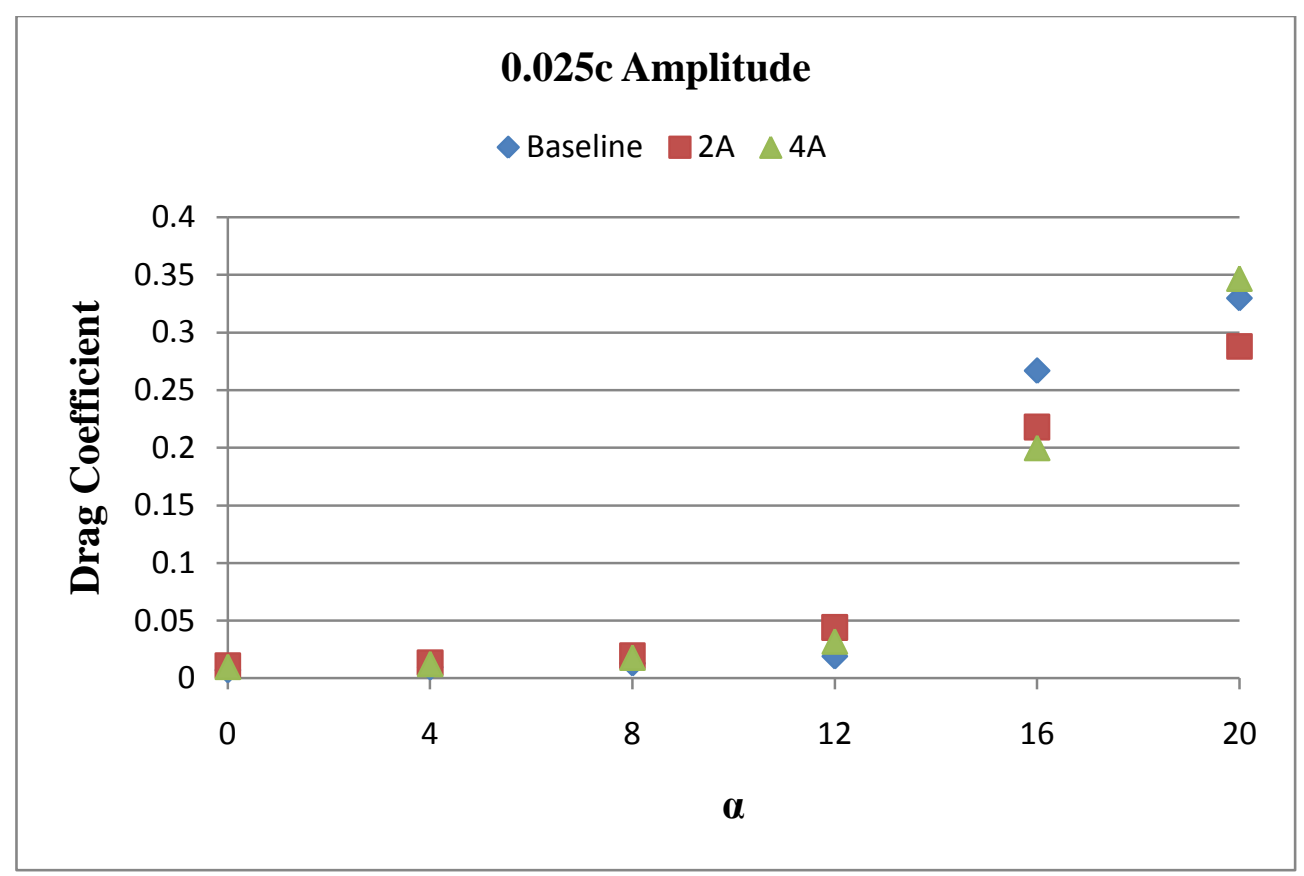

(b)

Figure 5.6 (a) Lift and (b) Drag coefficients of wings with $0.025 \mathrm{c}$ amplitude as a function of $\alpha$ (continued)

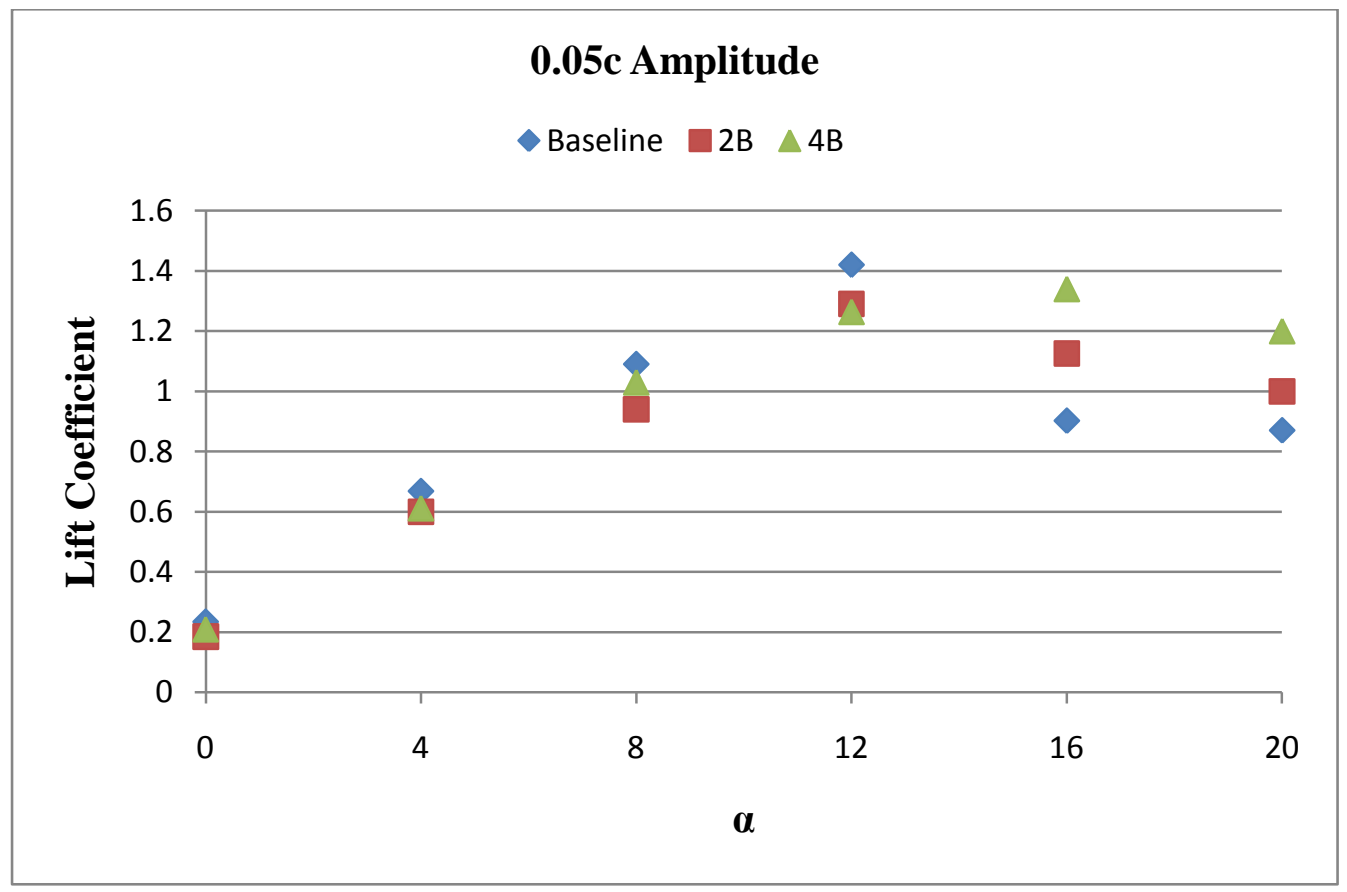

(a)

Figure 5.7 (a) Lift and (b) Drag coefficients of wings with $0.05 \mathrm{c}$ amplitude as a function of $\alpha$ 


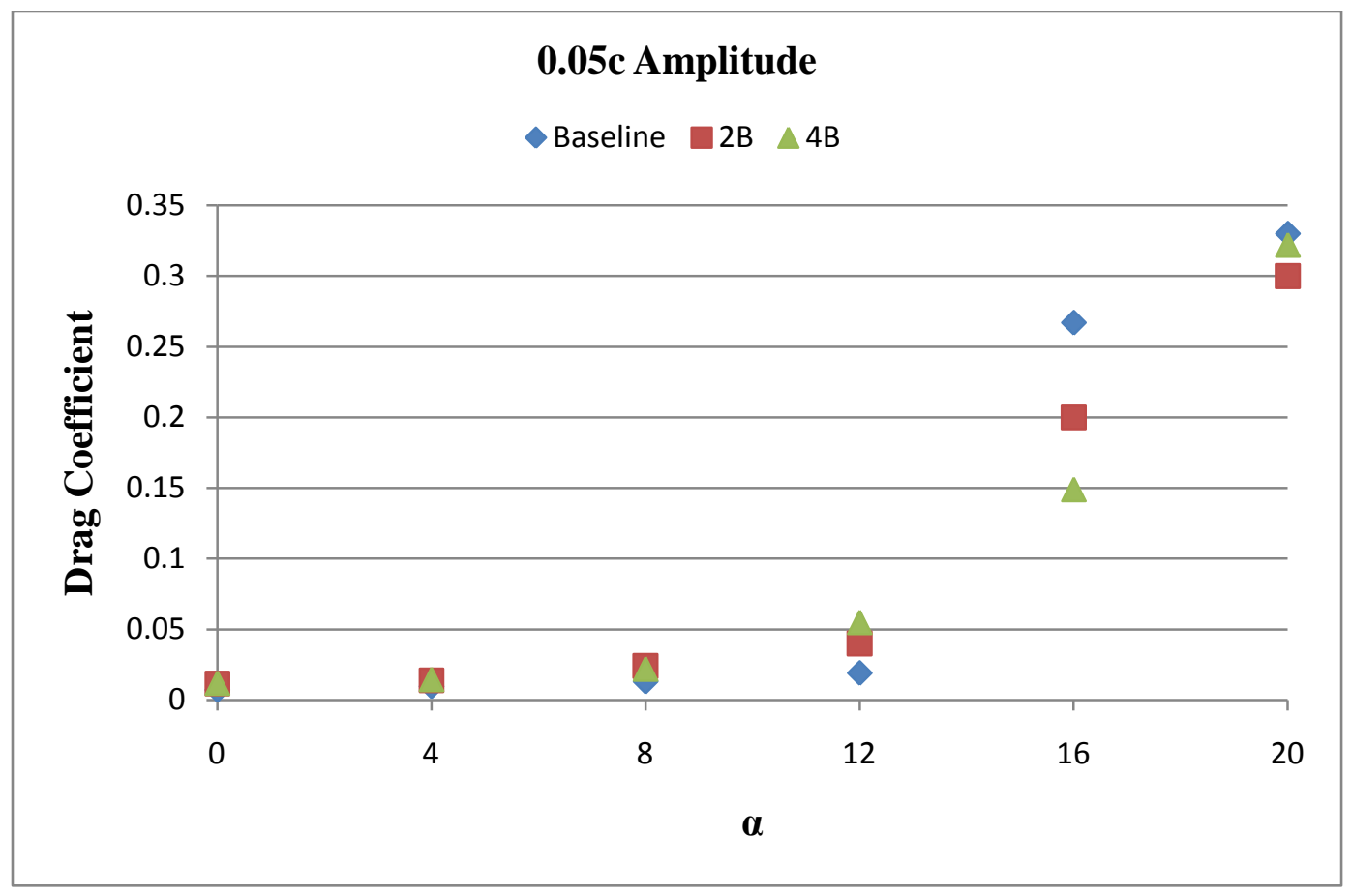

(b)

Figure 5.7 (a) Lift and (b) Drag coefficients of wings with $0.05 \mathrm{c}$ amplitude as a function of $\alpha$ (continued)

\subsection{Detailed Results of Simulations}

The flow dynamics of all wings are presented in this section. The improved performance of wings with leading-edge protuberances and how wavelength and amplitude affects the flow can be better understood by analyzing and comparing the flow on the baseline with modified wings. As shown earlier, the differences are most noticeable in the post-stall regime; therefore, $\alpha$ $=16^{\circ}$ was considered for analysis.

\subsubsection{Contours of Pressure and Velocity}

Figure 5.8 presents the pressure contours of the baseline at various sections along the $\mathrm{Z}$ direction, and x-velocity contours are shown in Figure 5.9. The high-pressure region exists below the wing, and the low-pressure region is on top of it. Due to the pressure difference, the flow from the bottom surface to the top surface at the trailing edge creates a low-pressure region. This 
low-pressure region is much lower than the pressure on the top surface, which creates a favorable pressure gradient in the front part but an adverse pressure gradient in the rear part, as shown in Figure 5.8. This adverse pressure gradient slows down the velocities inside the boundary layer which causes the recirculation region close to the top surface of wing. The recirculation region continues to grow upstream as more air is accelerated from bottom to top surface of wing and leaves vortex foot print as shown in Figure 5.9 (b) with blue color at rear top surface. Later it separates from the surface to form a vortex which grows even after leaving the trailing edge.

The pressure contours on wings with leading-edge protuberances $(4 \mathrm{~A}, 2 \mathrm{~A}, 4 \mathrm{~B}$, and $2 \mathrm{~B})$ at similar sections are presented in Figures 5.10, 5.12, 5.14, and 5.16, respectively. The x-velocity contours are depicted in Figures 5.11, 5.13, 5.15, and 5.17, respectively.

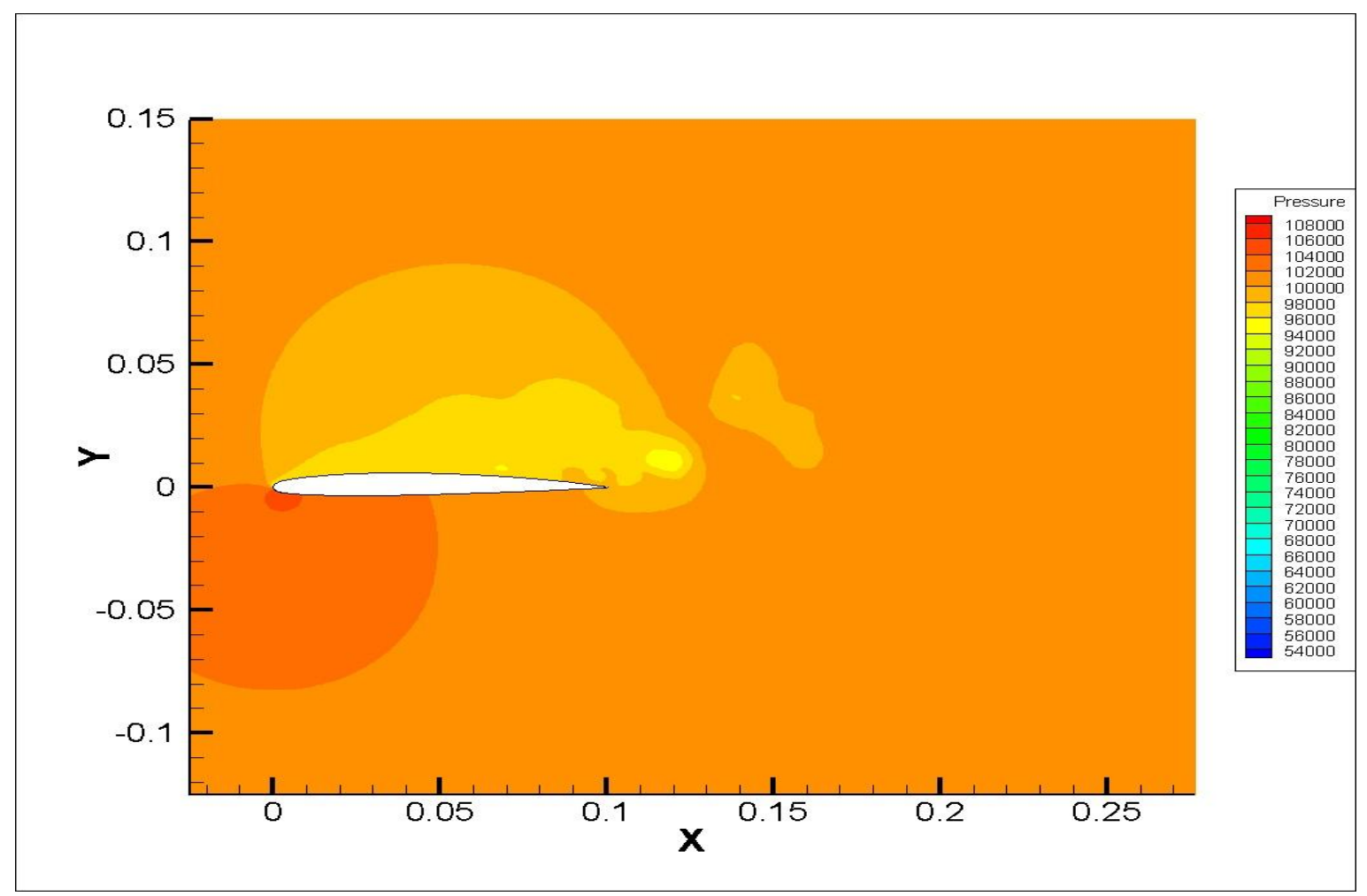

(a)

Figure 5.8 Pressure contours of baseline at $\mathrm{z}=$ (a) $0.025 \mathrm{~m}$, (b) $0.05 \mathrm{~m}$, and (c) $0.075 \mathrm{~m}$ 


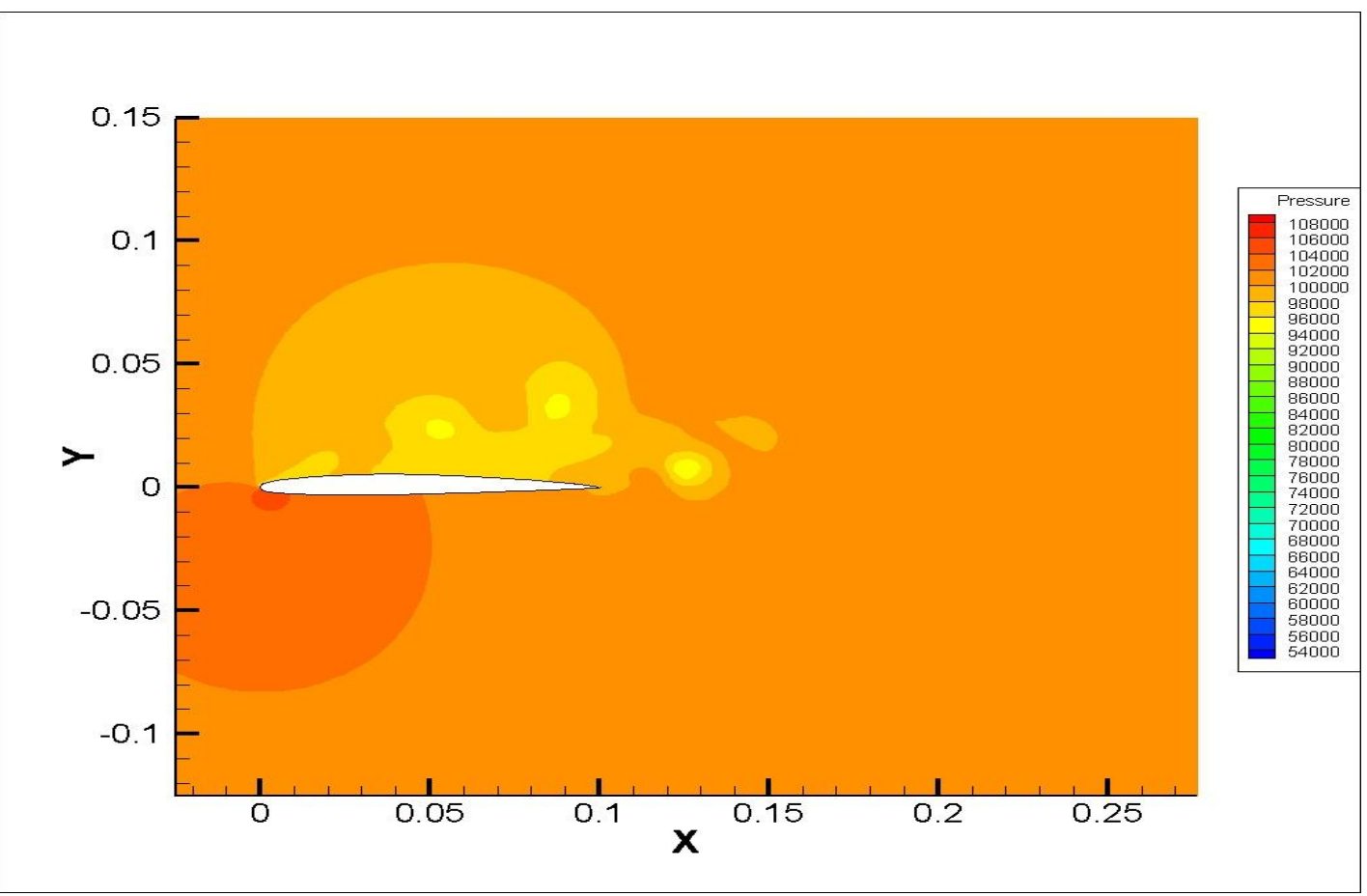

(b)

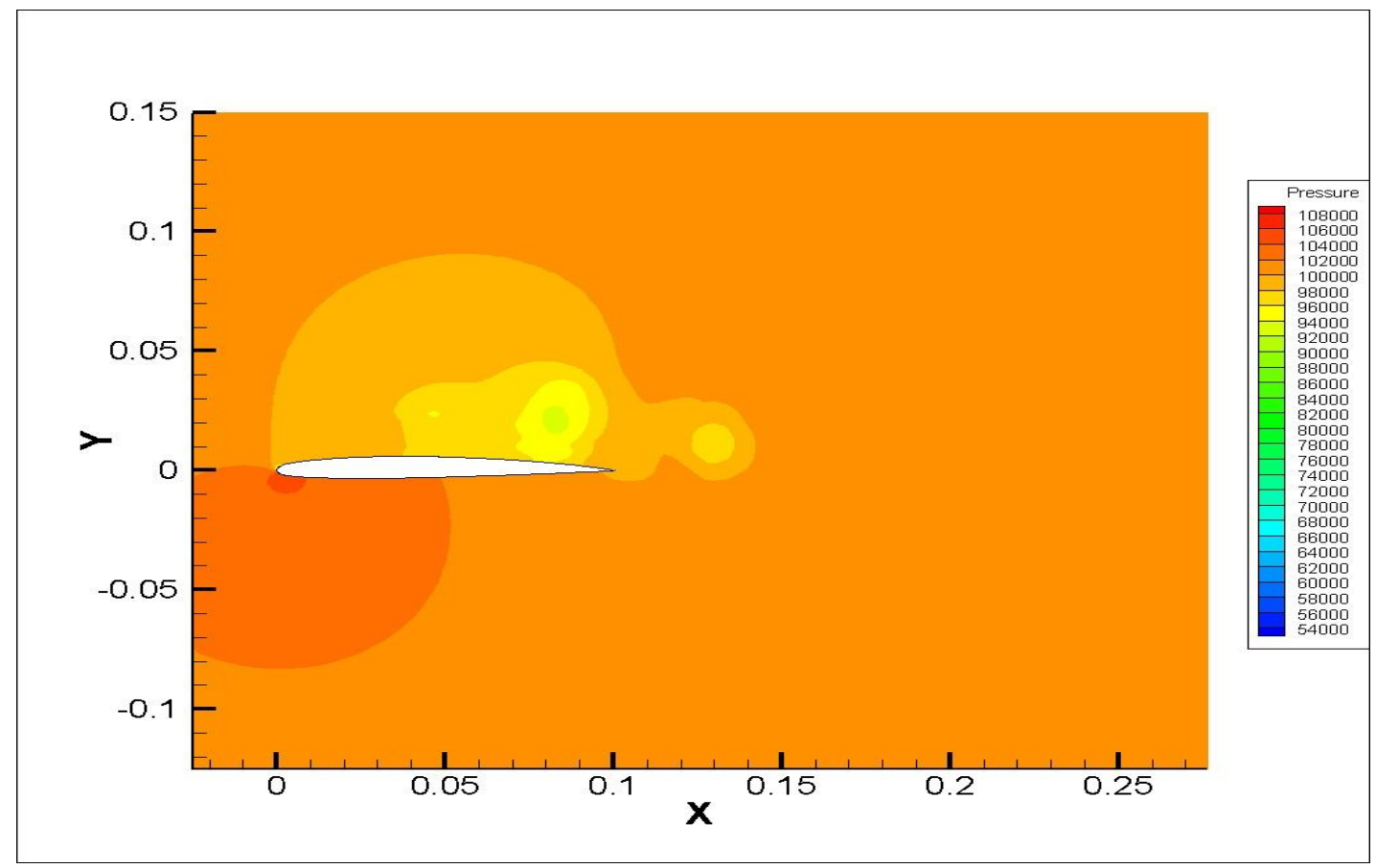

(c)

Figure 5.8 Pressure contours of baseline at $\mathrm{z}=$ (a) $0.025 \mathrm{~m}$, (b) $0.05 \mathrm{~m}$, and (c) $0.075 \mathrm{~m}$ 


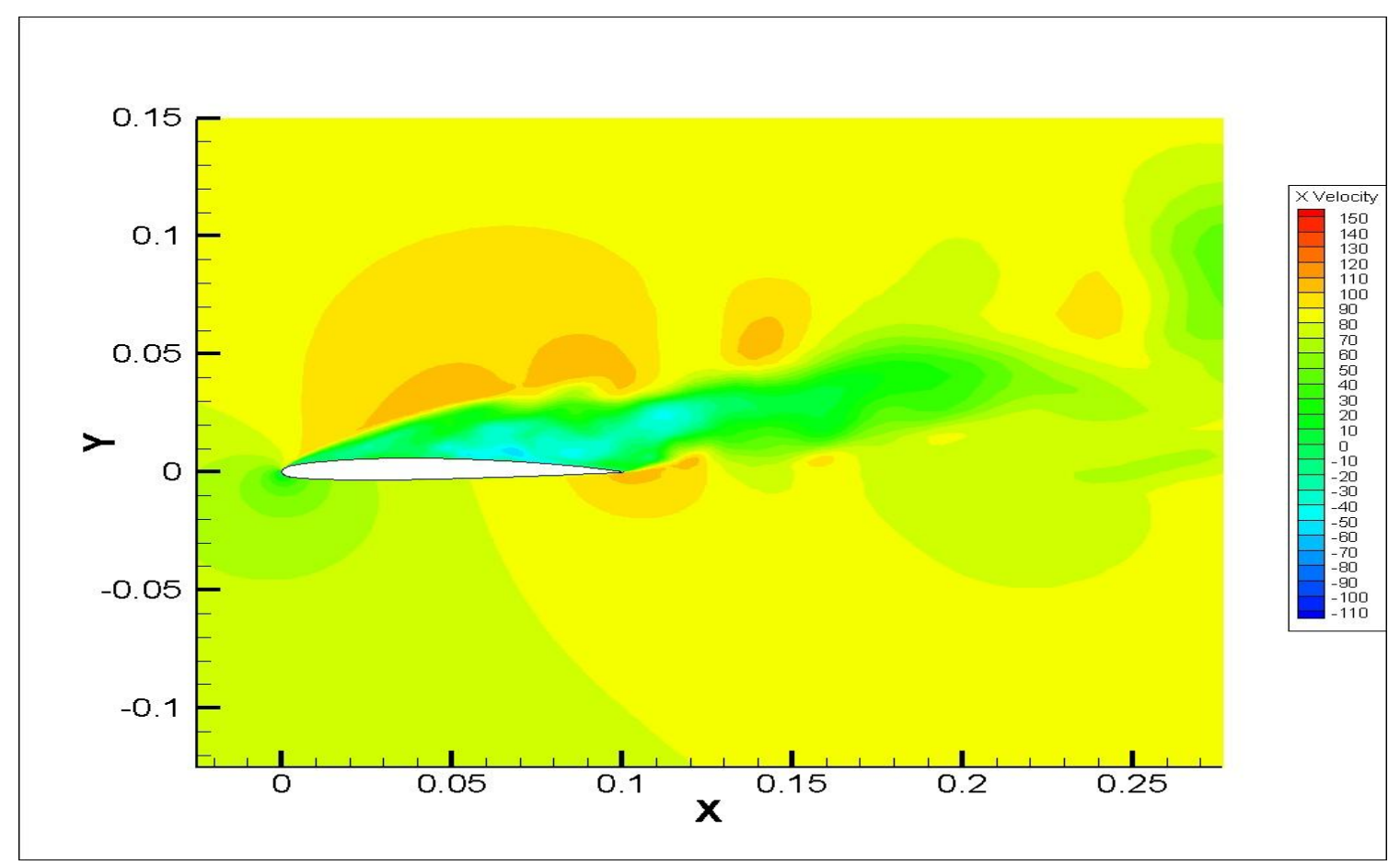

(a)

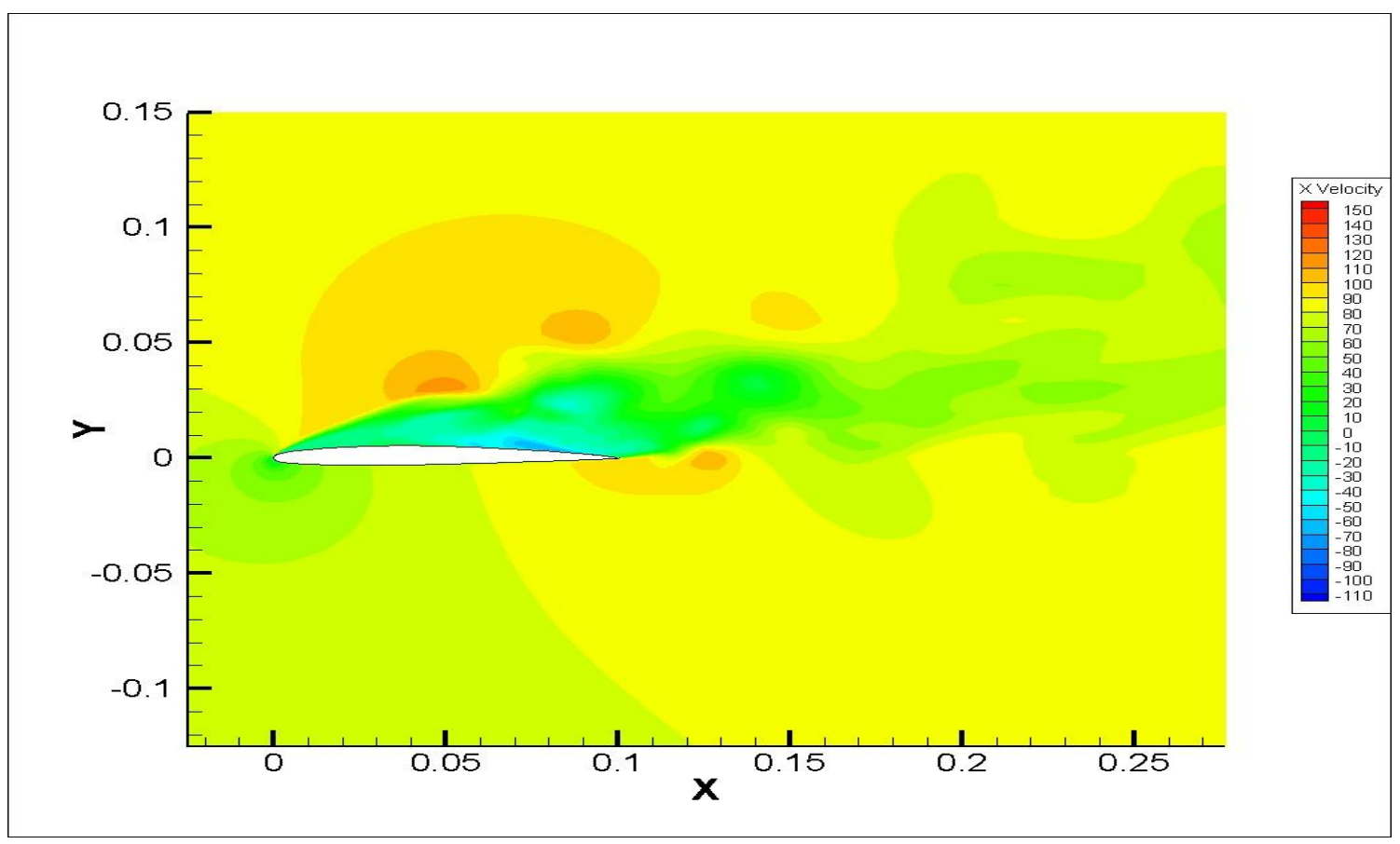

(b)

Figure 5.9 Velocity contours of baseline at $\mathrm{z}=$ (a) $0.025 \mathrm{~m}$, (b) $0.05 \mathrm{~m}$, and (c) $0.075 \mathrm{~m}$ 


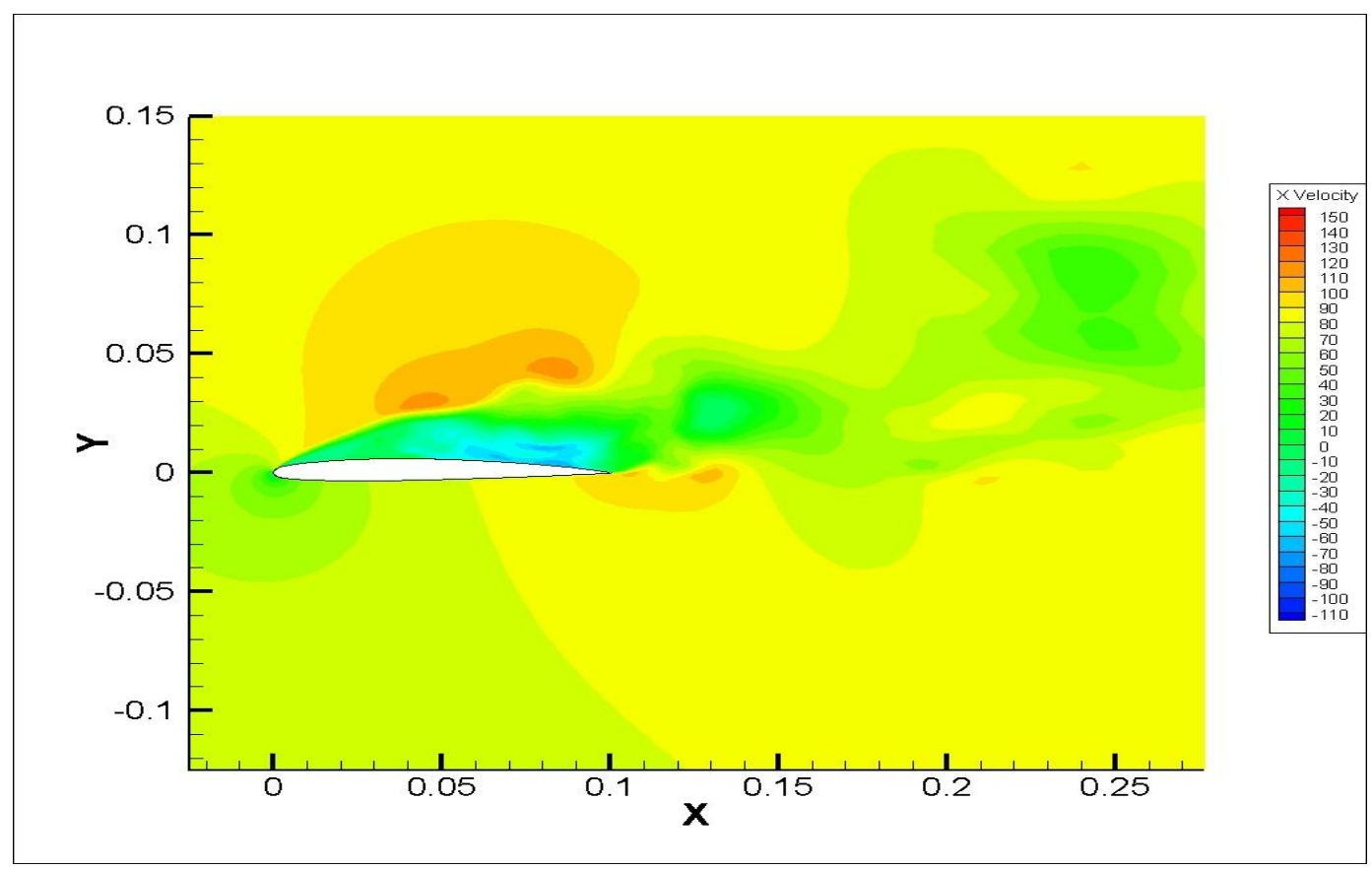

(c)

Figure 5.9 Velocity contours of baseline at $\mathrm{z}=$ (a) $0.025 \mathrm{~m}$, (b) $0.05 \mathrm{~m}$, and (c) $0.075 \mathrm{~m}$ (continued)

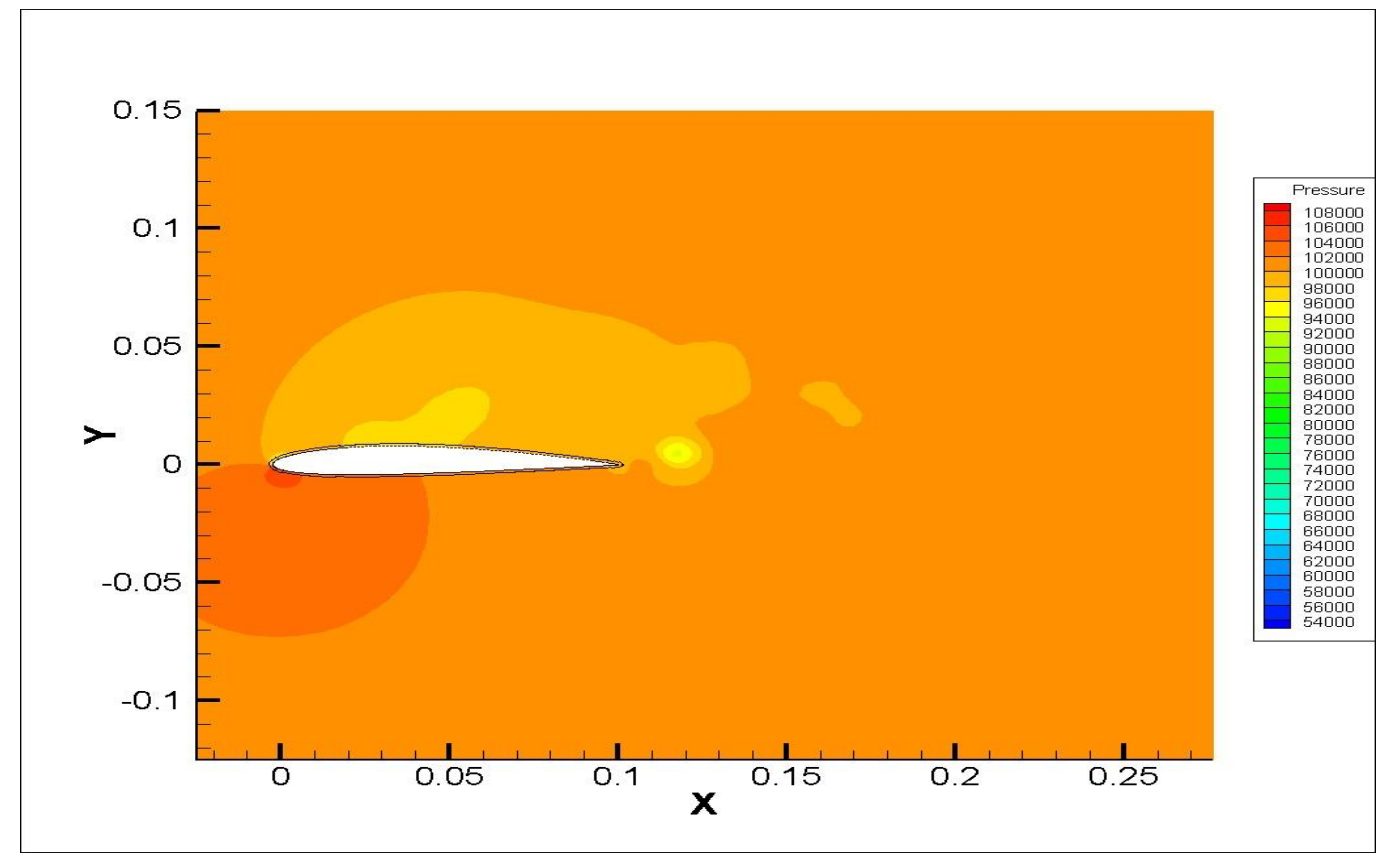

(a)

Figure 5.10 Pressure contours of $4 \mathrm{~A}$ wing at $\mathrm{z}=$ (a) $0.025 \mathrm{~m}$, (b) $0.05 \mathrm{~m}$, and (c) $0.075 \mathrm{~m}$ 


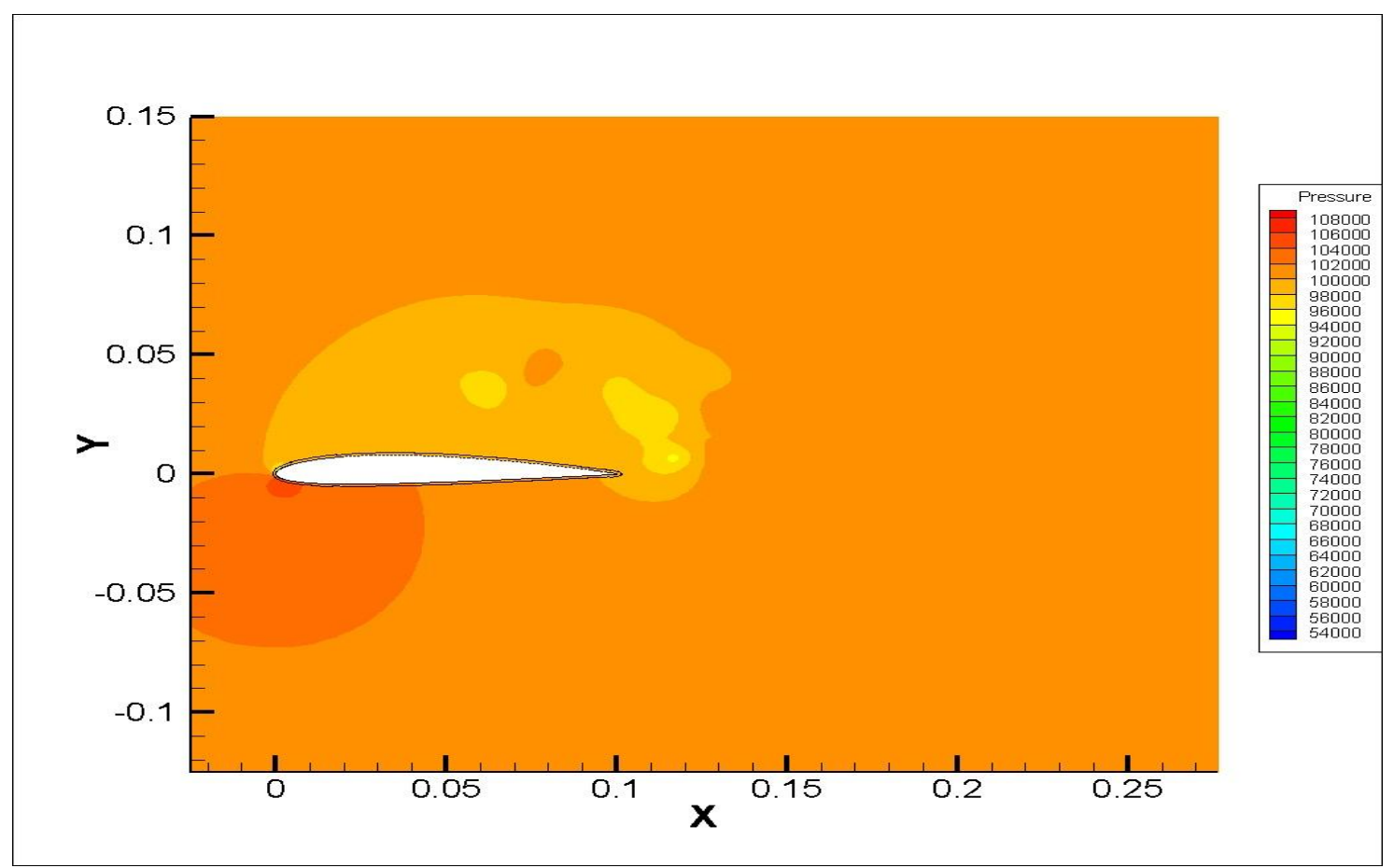

(b)

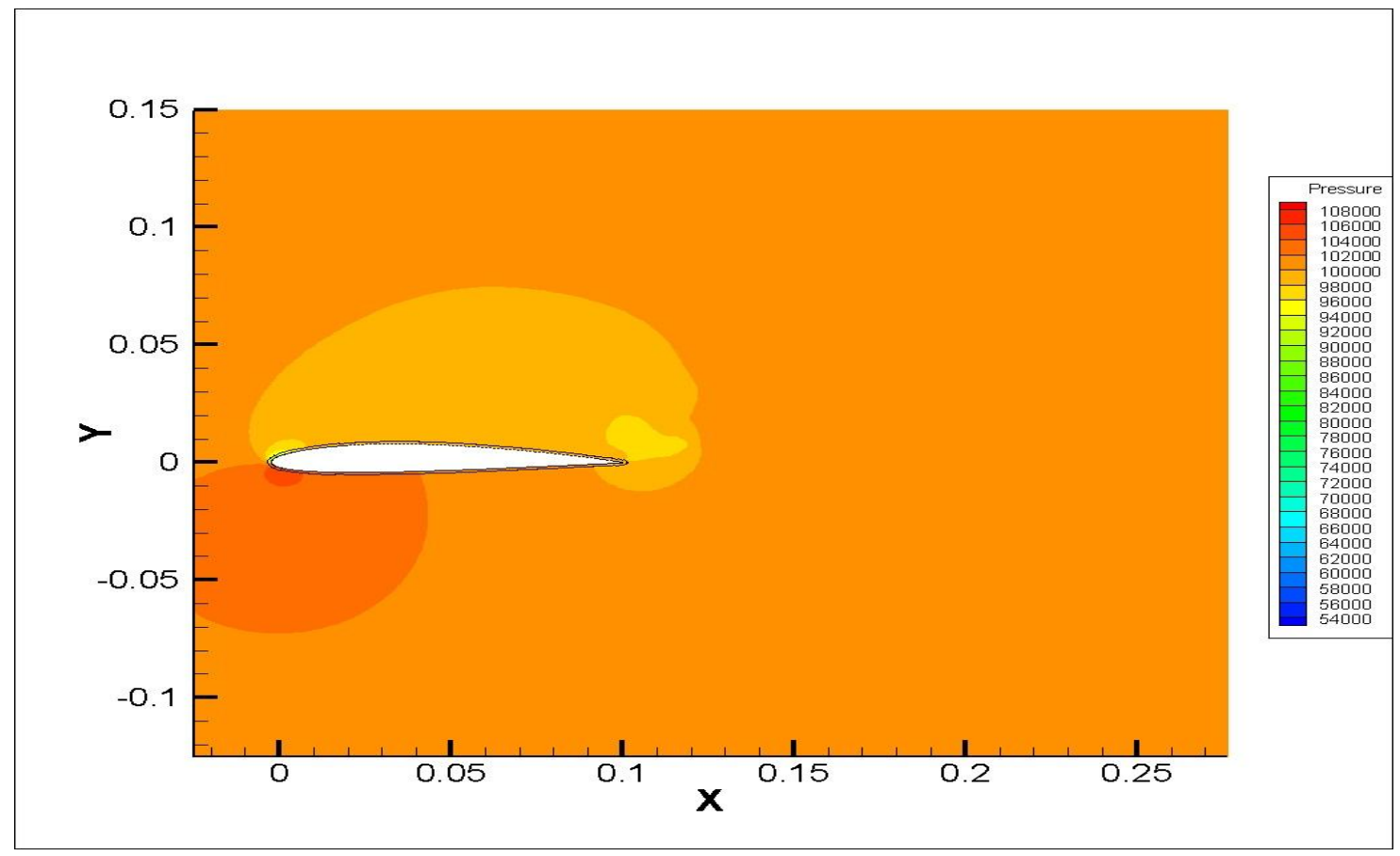

(c)

Figure 5.10 Pressure contours of $4 \mathrm{~A}$ wing at $\mathrm{z}=$ (a) $0.025 \mathrm{~m}$, (b) 0.05 , and (c) $0.075 \mathrm{~m}$ (continued) 


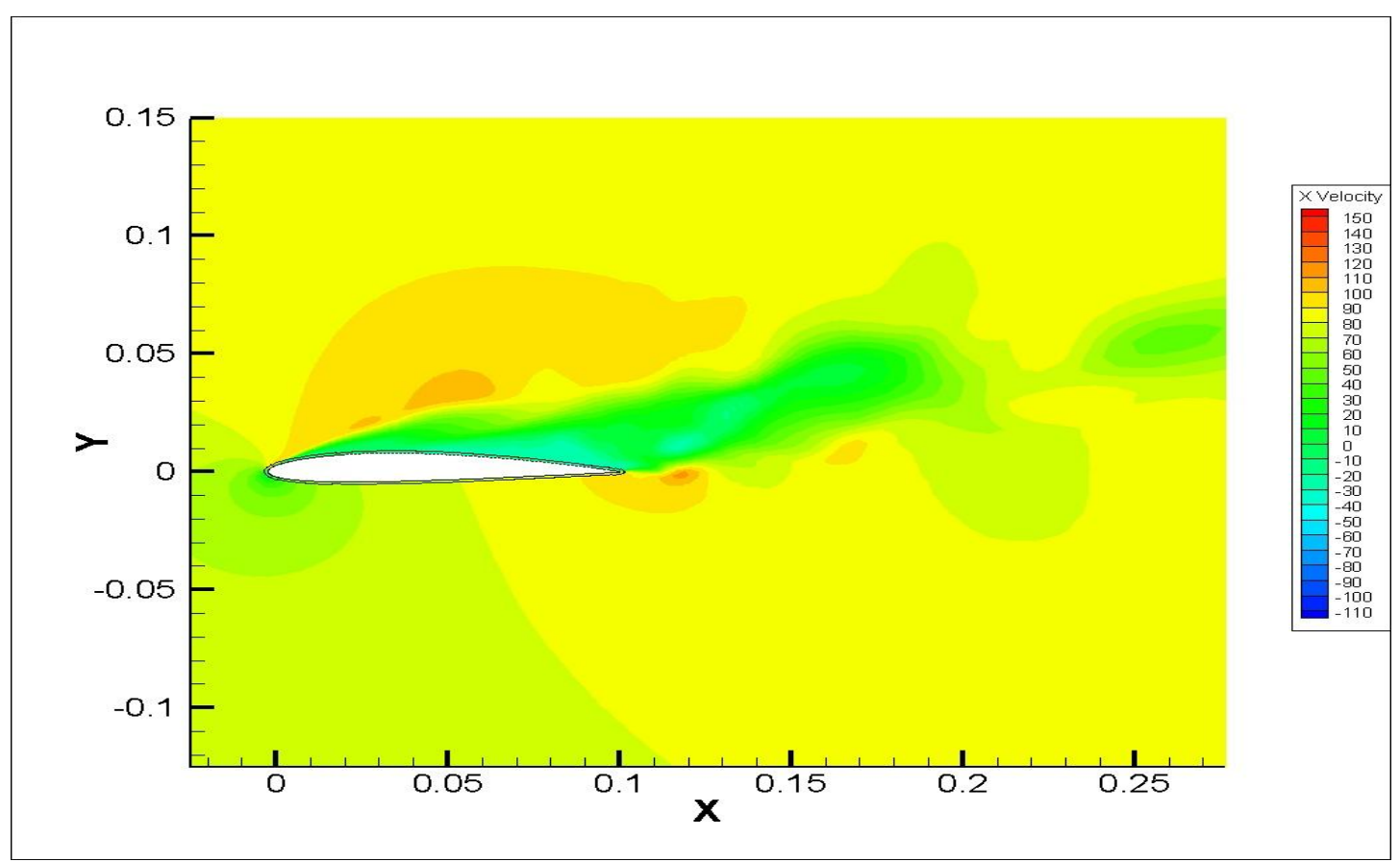

(a)

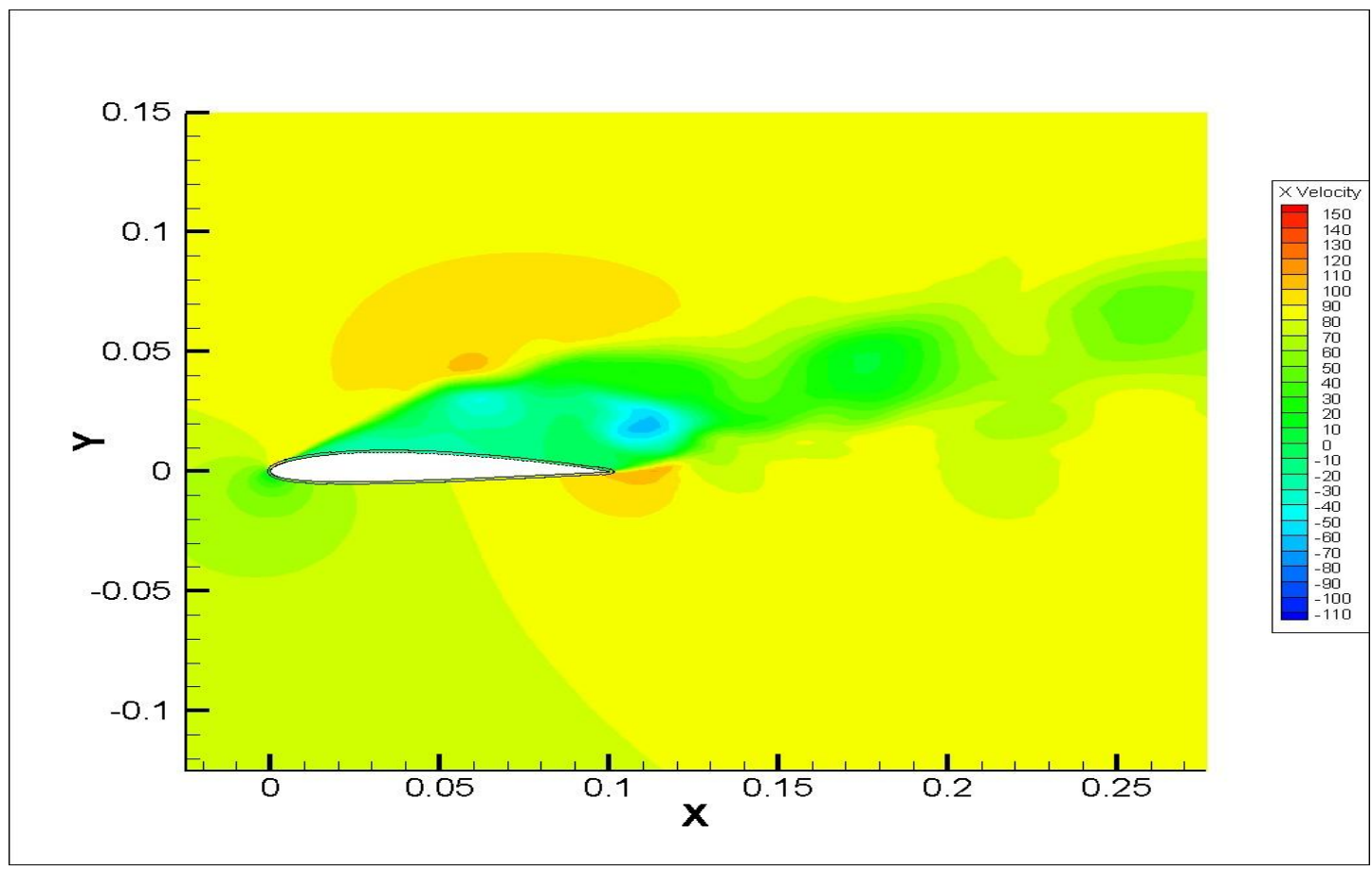

(b)

Figure 5.11 Velocity contours of $4 \mathrm{~A}$ wing at $\mathrm{z}=$ (a) $0.025 \mathrm{~m}$, (b) $0.05 \mathrm{~m}$, and (c) $0.075 \mathrm{~m}$ 


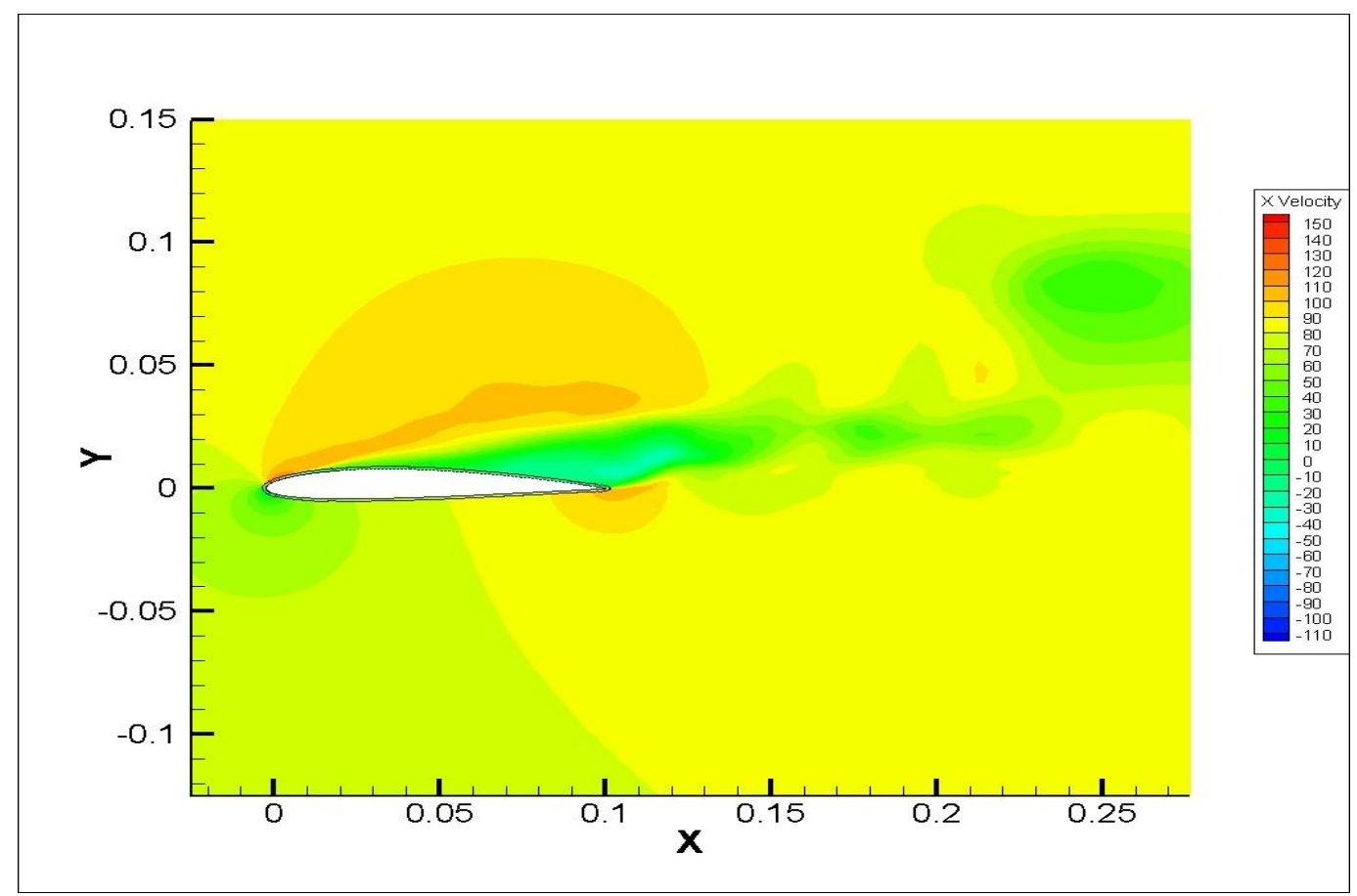

(c)

Figure 5.11 Velocity contours of 4A wing at $\mathrm{z}=$ (a) $0.025 \mathrm{~m}$, (b) 0.05 , and (c) $0.075 \mathrm{~m}$ (continued)

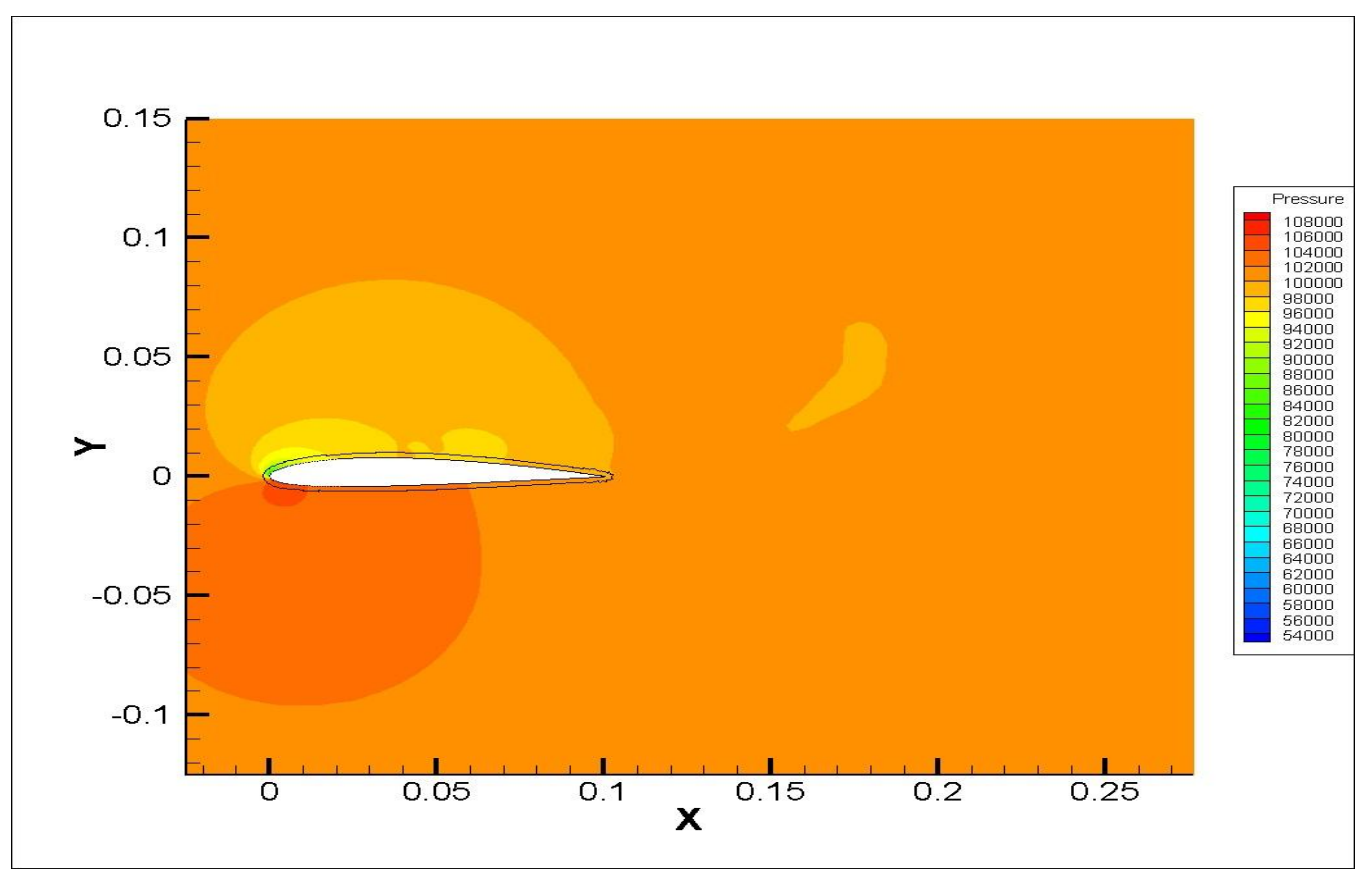

(a)

Figure 5.12 Pressure contours of $2 \mathrm{~A}$ wing at $\mathrm{z}=$ (a) $0.025 \mathrm{~m}$, (b) $0.05 \mathrm{~m}$, and (c) $0.075 \mathrm{~m}$ 


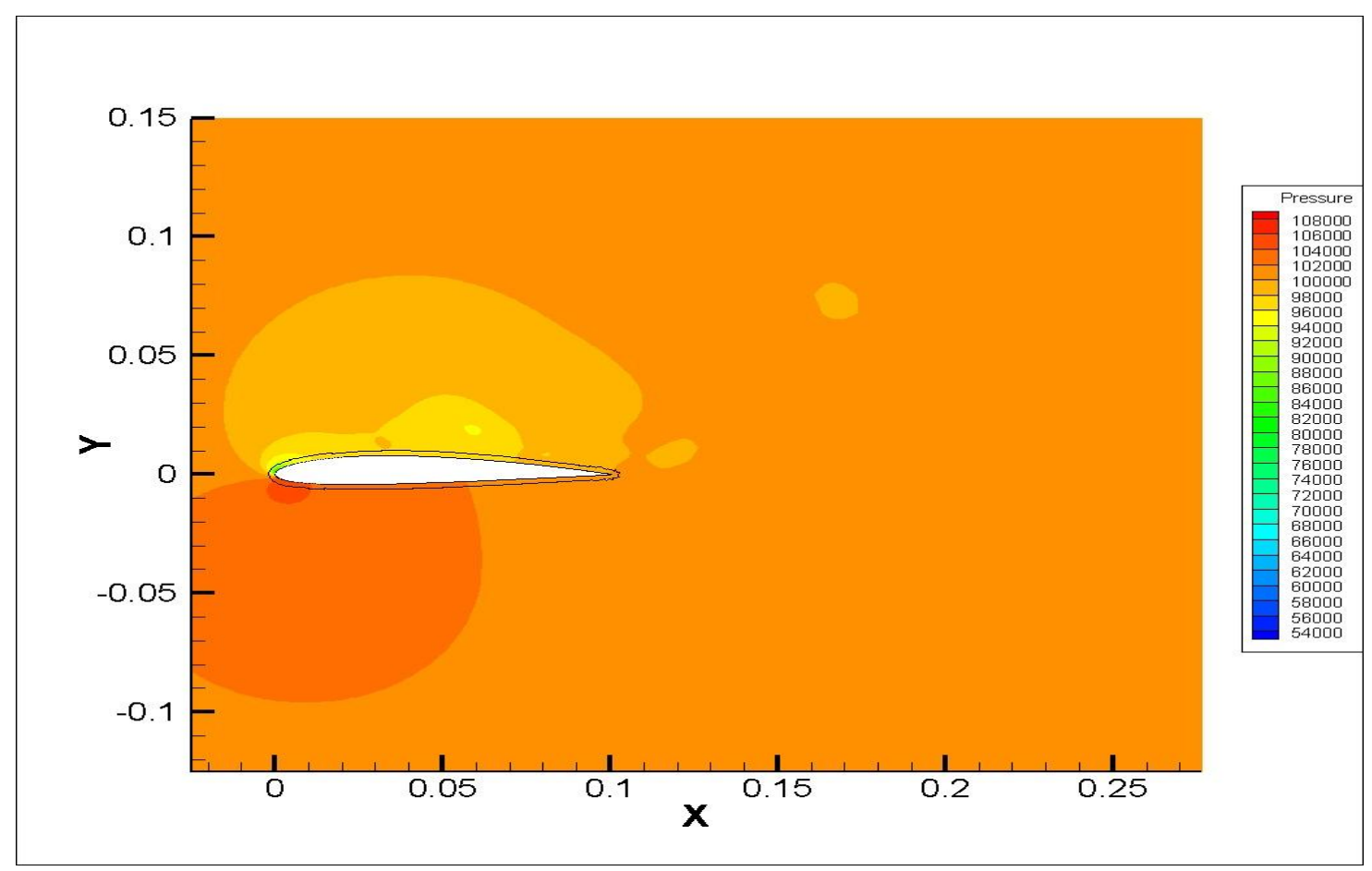

(b)

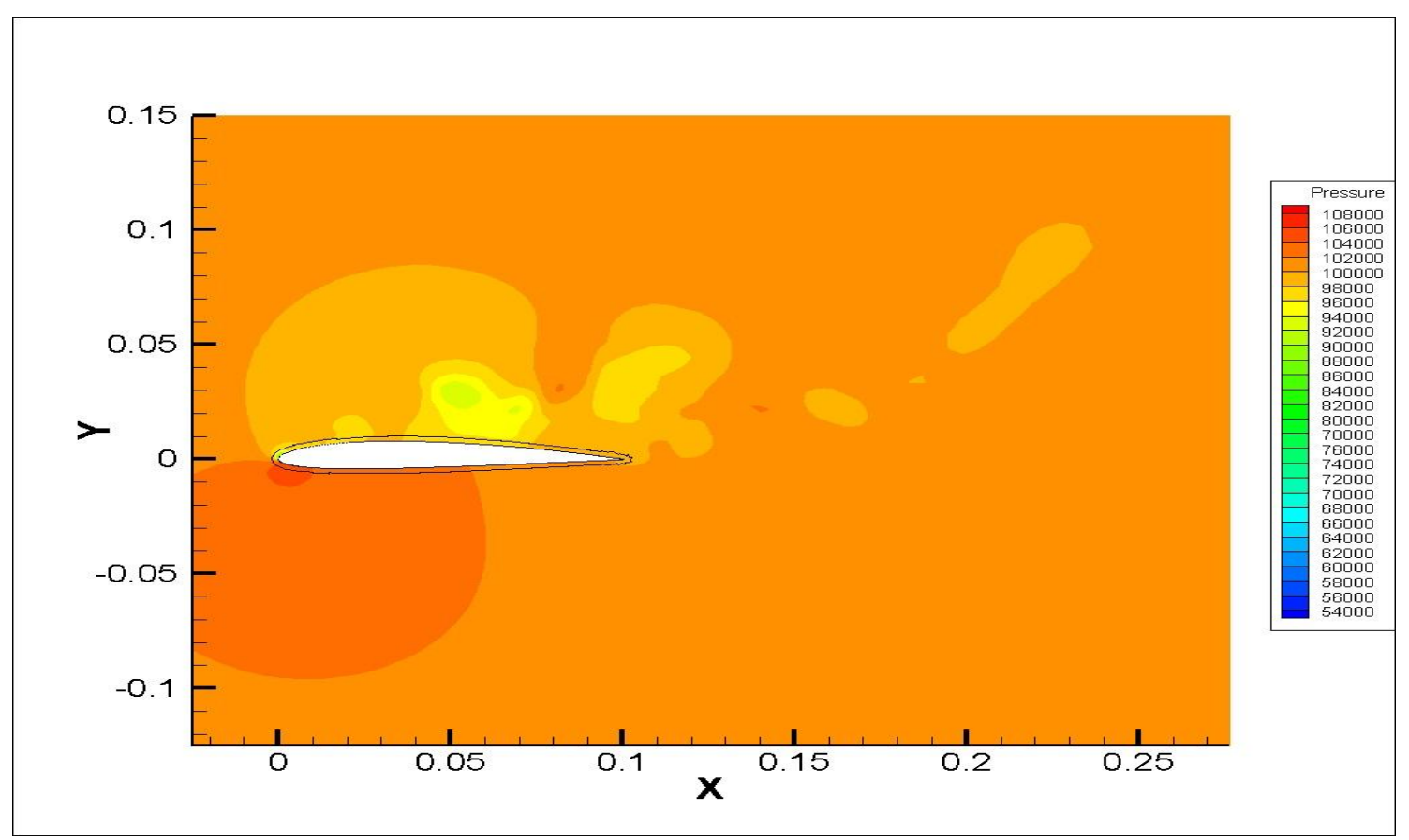

(c)

Figure 5.12 Pressure contours of $2 \mathrm{~A}$ wing at $\mathrm{z}=$ (a) $0.025 \mathrm{~m}$, (b) 0.05 , and (c) $0.075 \mathrm{~m}$ (continued) 


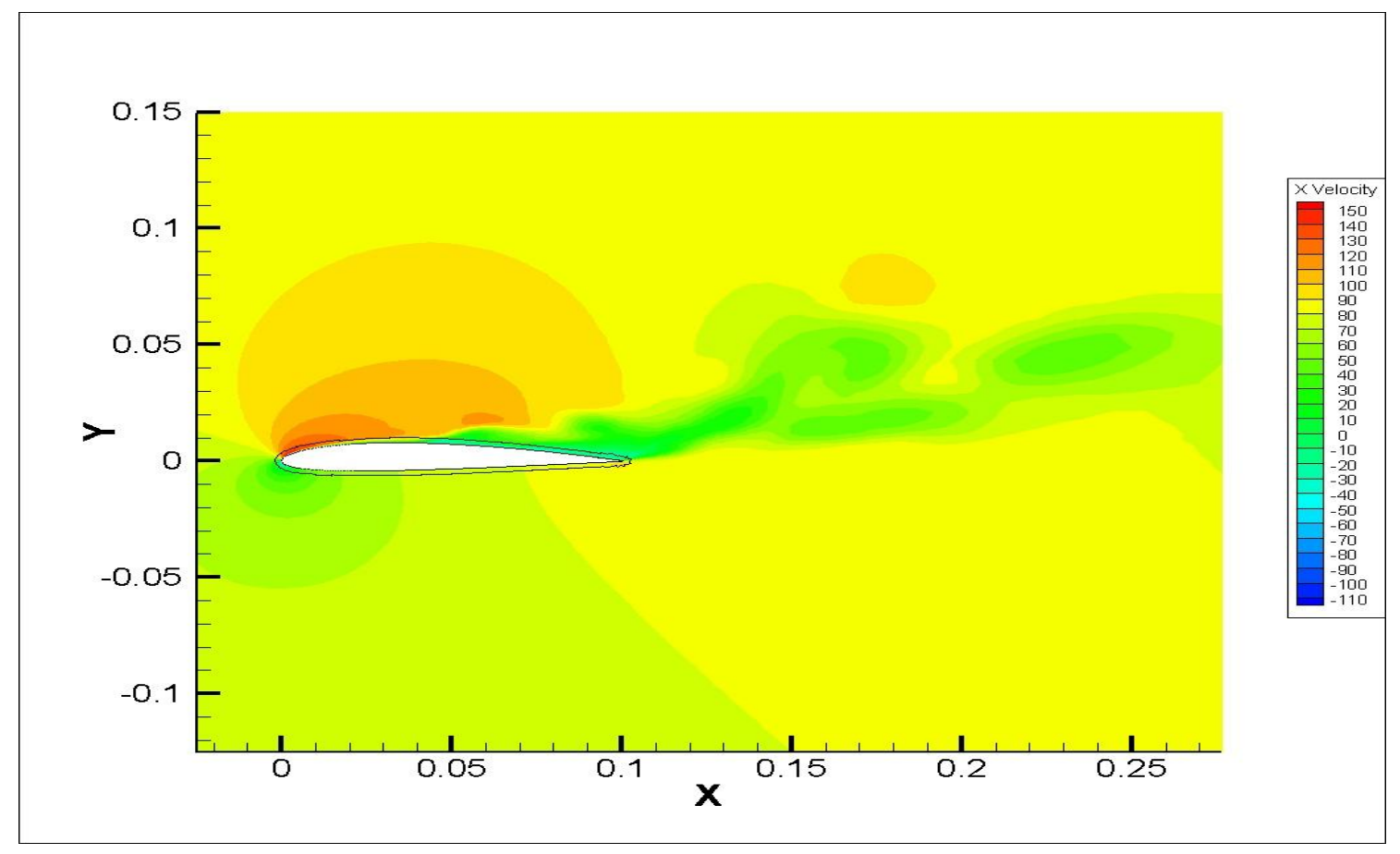

(a)

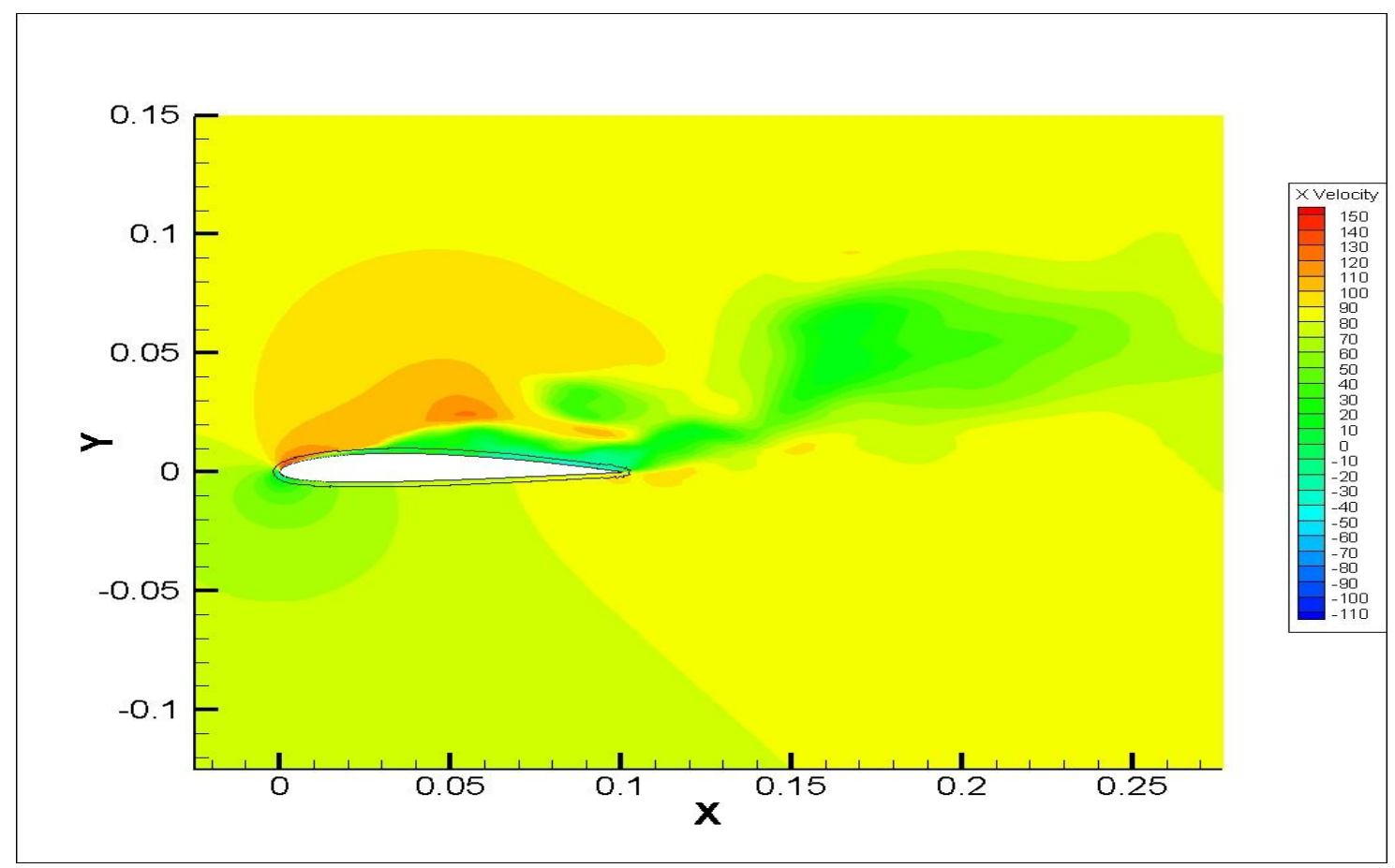

(b)

Figure 5.13 Velocity contours of 2A wing (a) $0.025 \mathrm{~m}$, (b) 0.05 , and (c) $0.075 \mathrm{~m}$ 


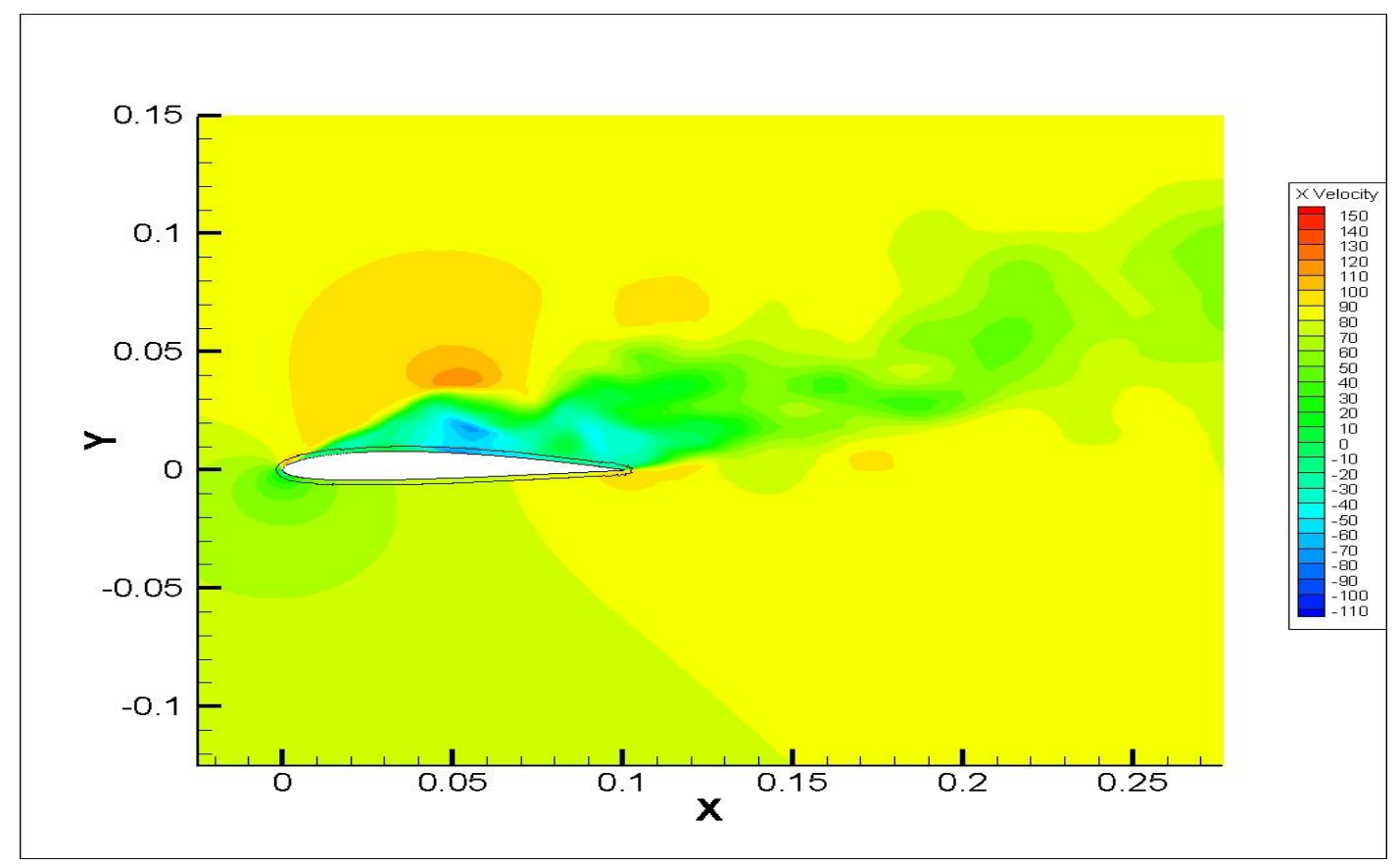

(c)

Figure 5.13 Velocity contours of $2 \mathrm{~A}$ wing (a) $0.025 \mathrm{~m}$, (b) 0.05 , and (c) $0.075 \mathrm{~m}$ (continued)

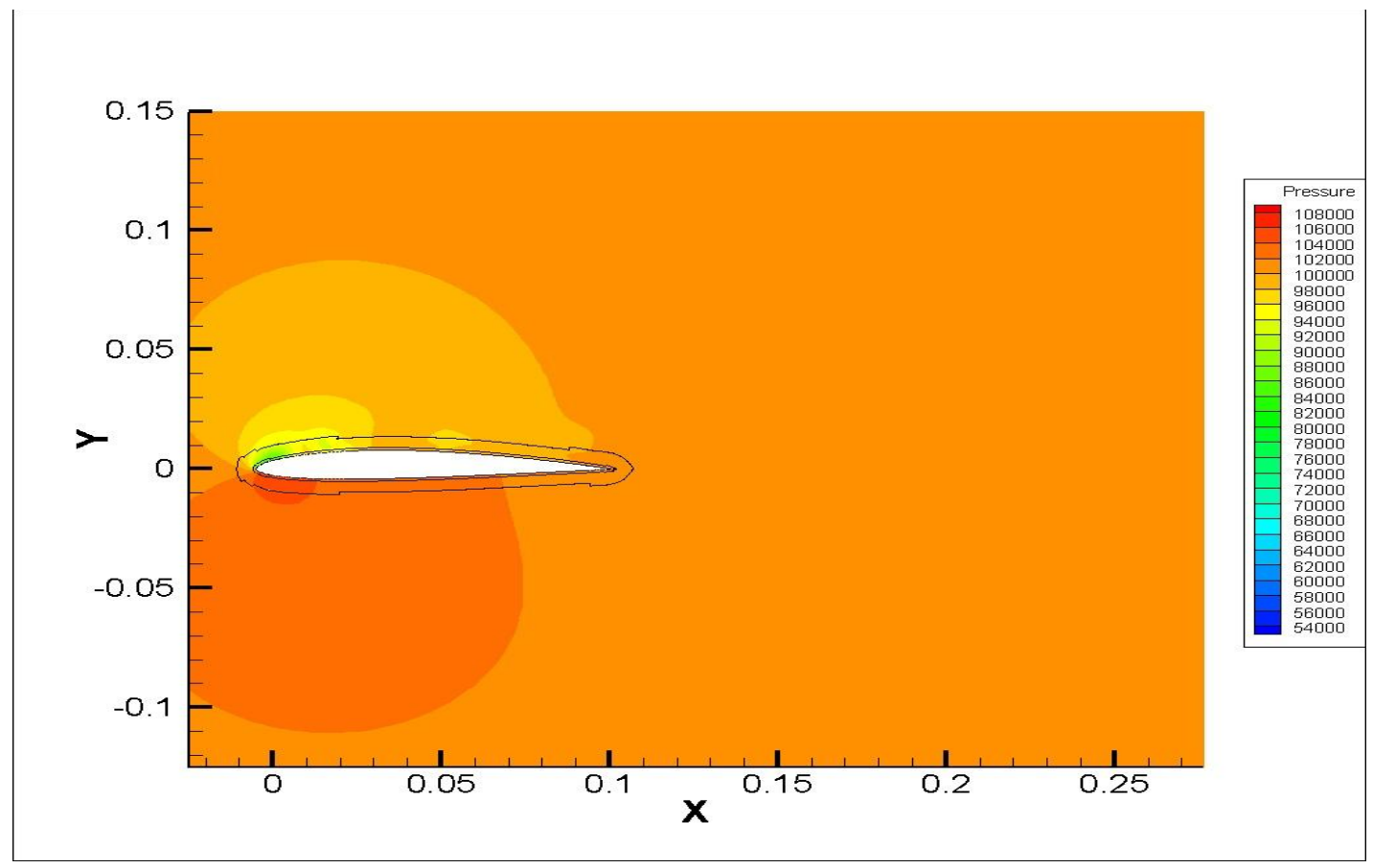

(a)

Figure 5.14 Pressure contours of $4 \mathrm{~B}$ wing at $\mathrm{z}=$ (a) $0.025 \mathrm{~m}$, (b) 0.05 , and (c) $0.075 \mathrm{~m}$ 


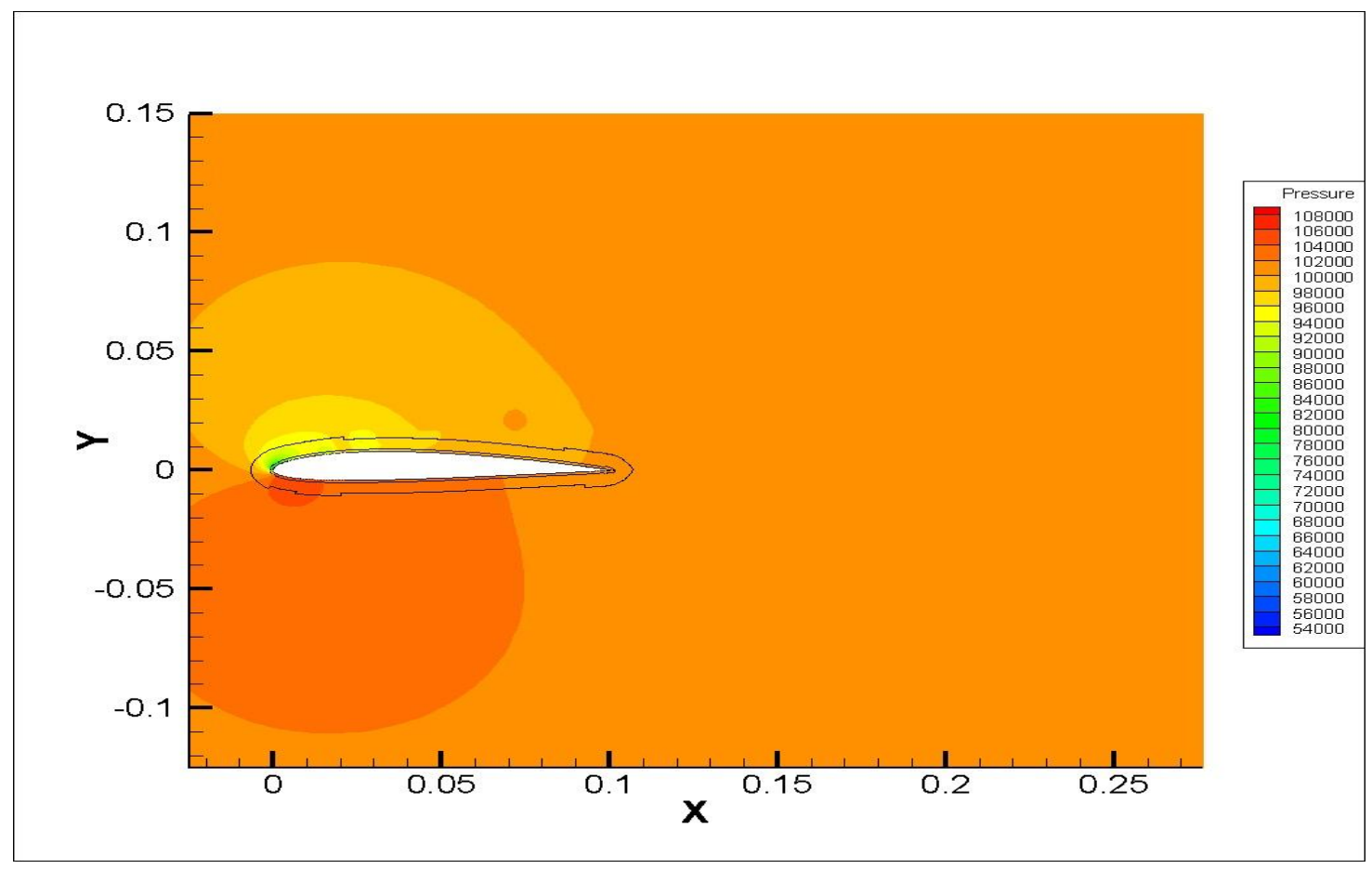

(b)

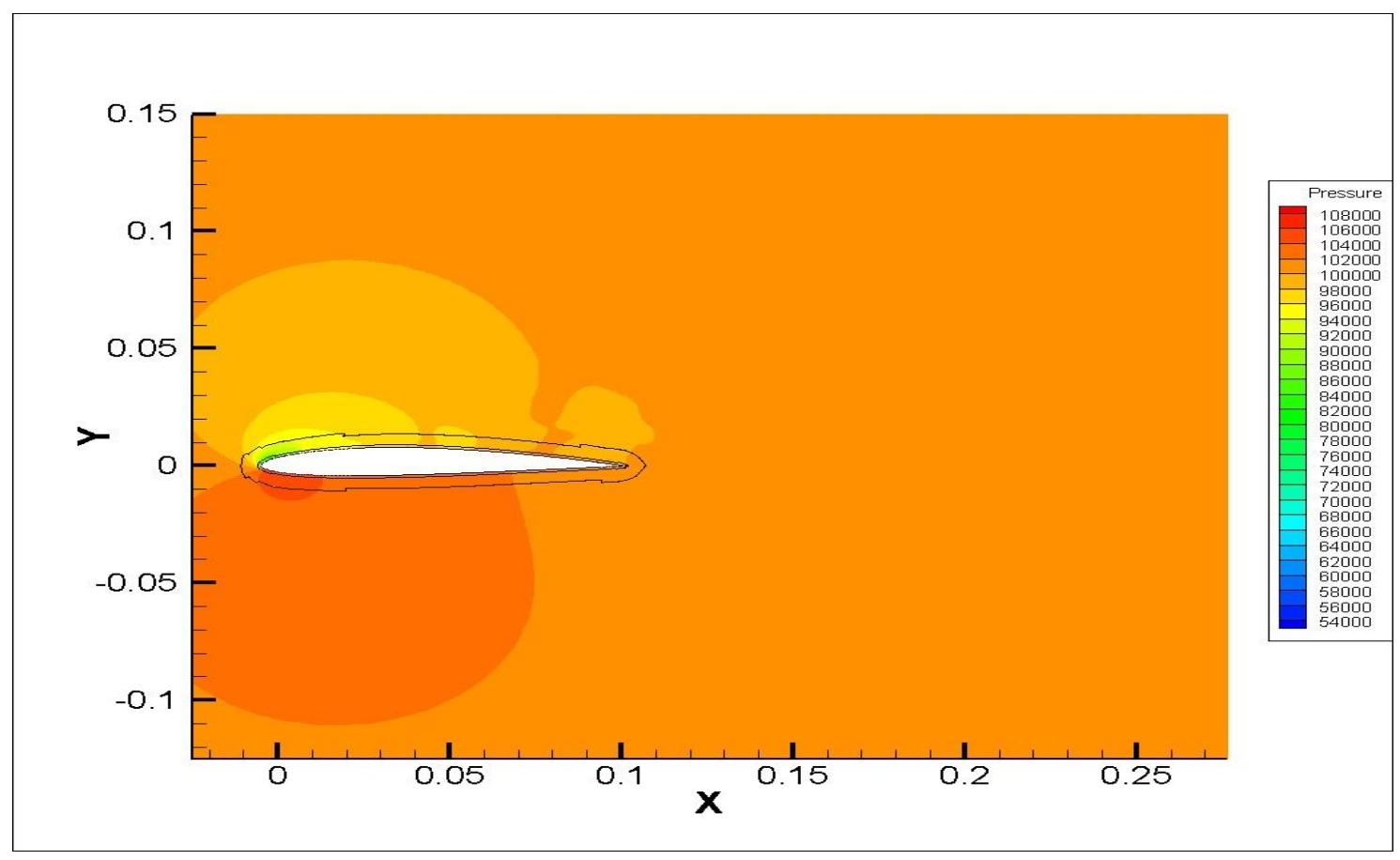

(c)

Figure 5.14 Pressure contours of 4B wing at $\mathrm{z}=$ (a) $0.025 \mathrm{~m}$, (b) 0.05 , and (c) $0.075 \mathrm{~m}$ (continued) 


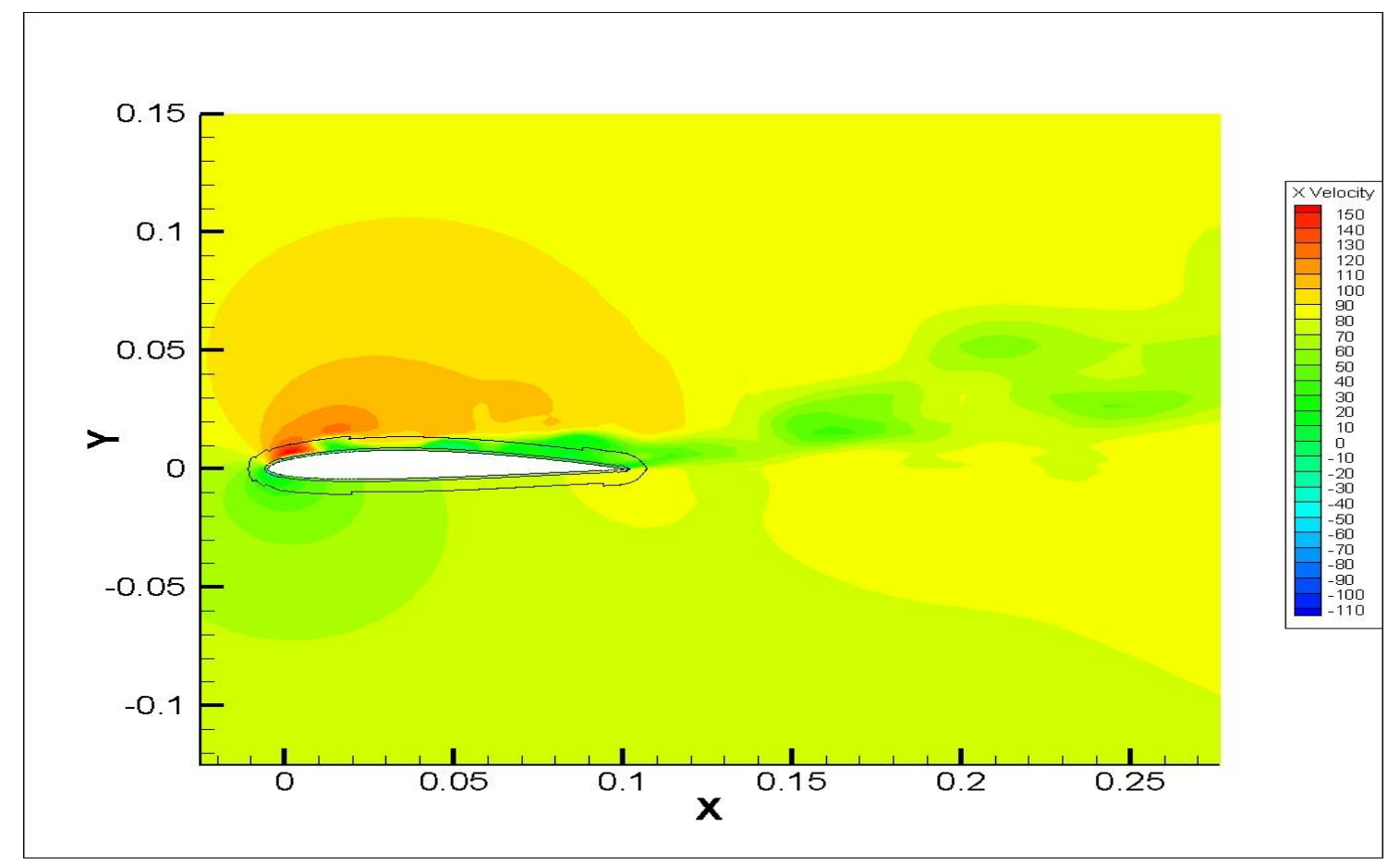

(a)

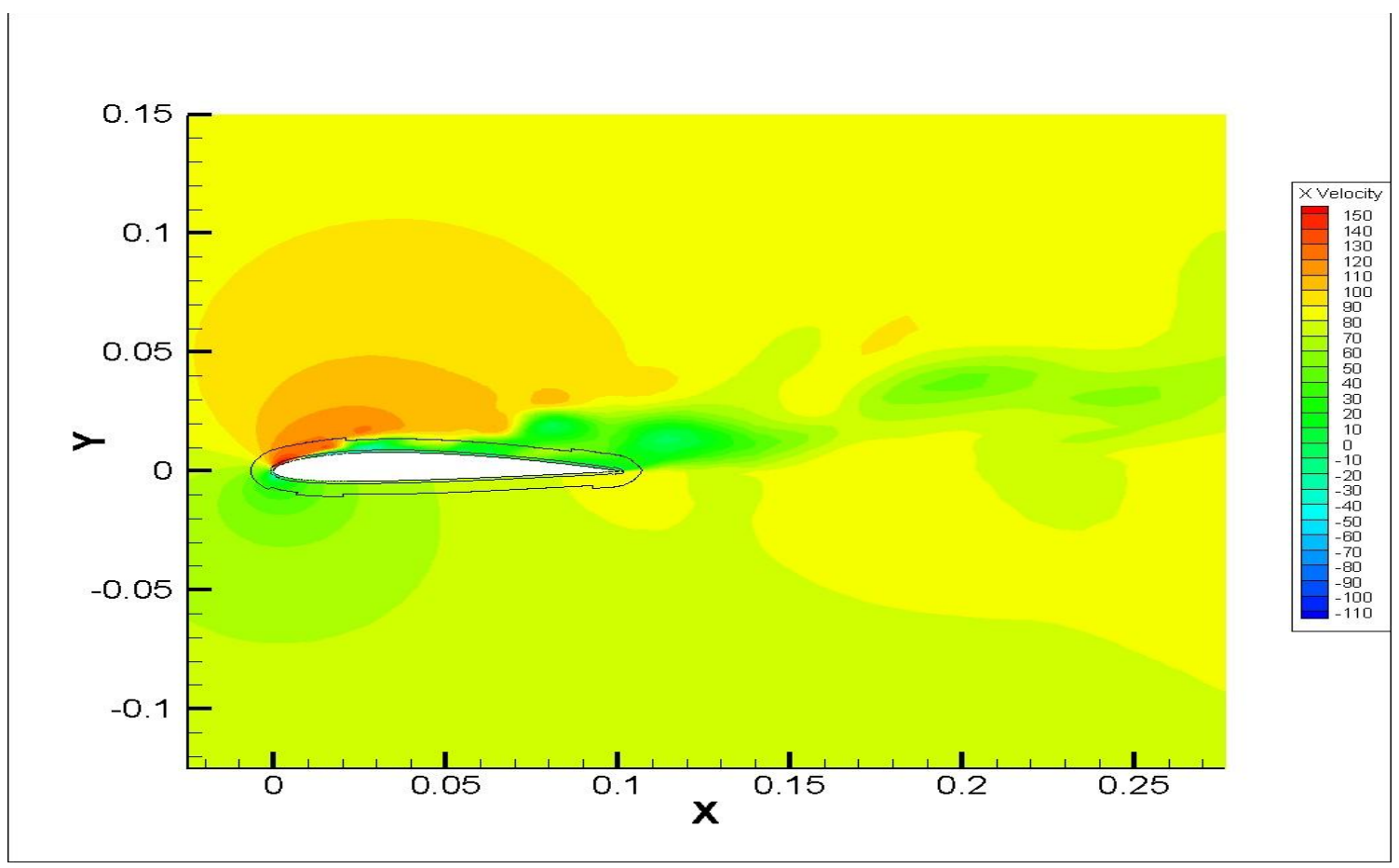

(b)

Figure 5.15 velocity contours of $4 \mathrm{~B}$ wing at $\mathrm{z}=$ (a) $0.025 \mathrm{~m}$, (b) 0.05 , and (c) $0.075 \mathrm{~m}$ 


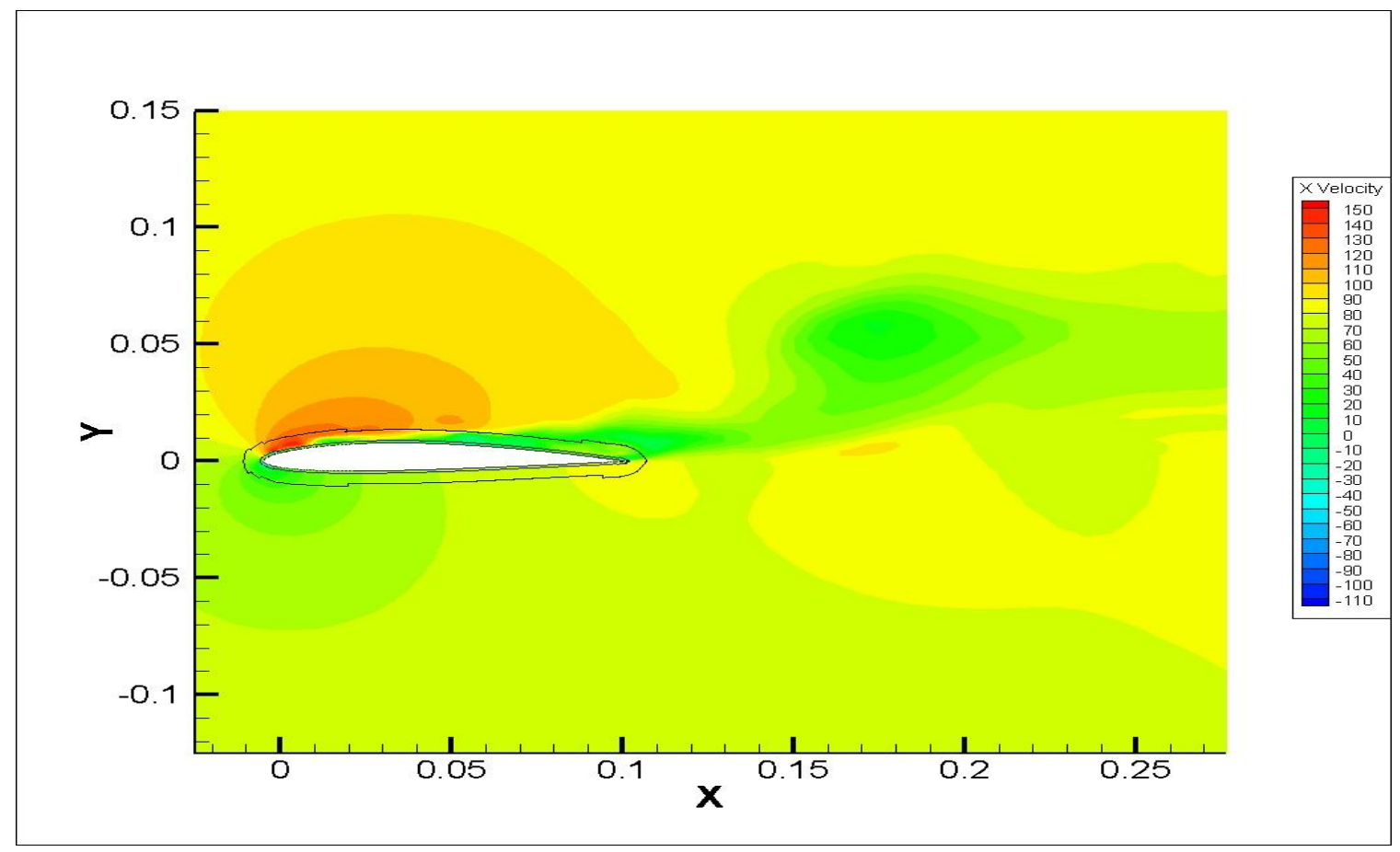

(c)

Figure 5.15 velocity contours of $4 \mathrm{~B}$ wing at $\mathrm{z}=$ (a) $0.025 \mathrm{~m}$, (b) 0.05 , and (c) $0.075 \mathrm{~m}$ (continued)

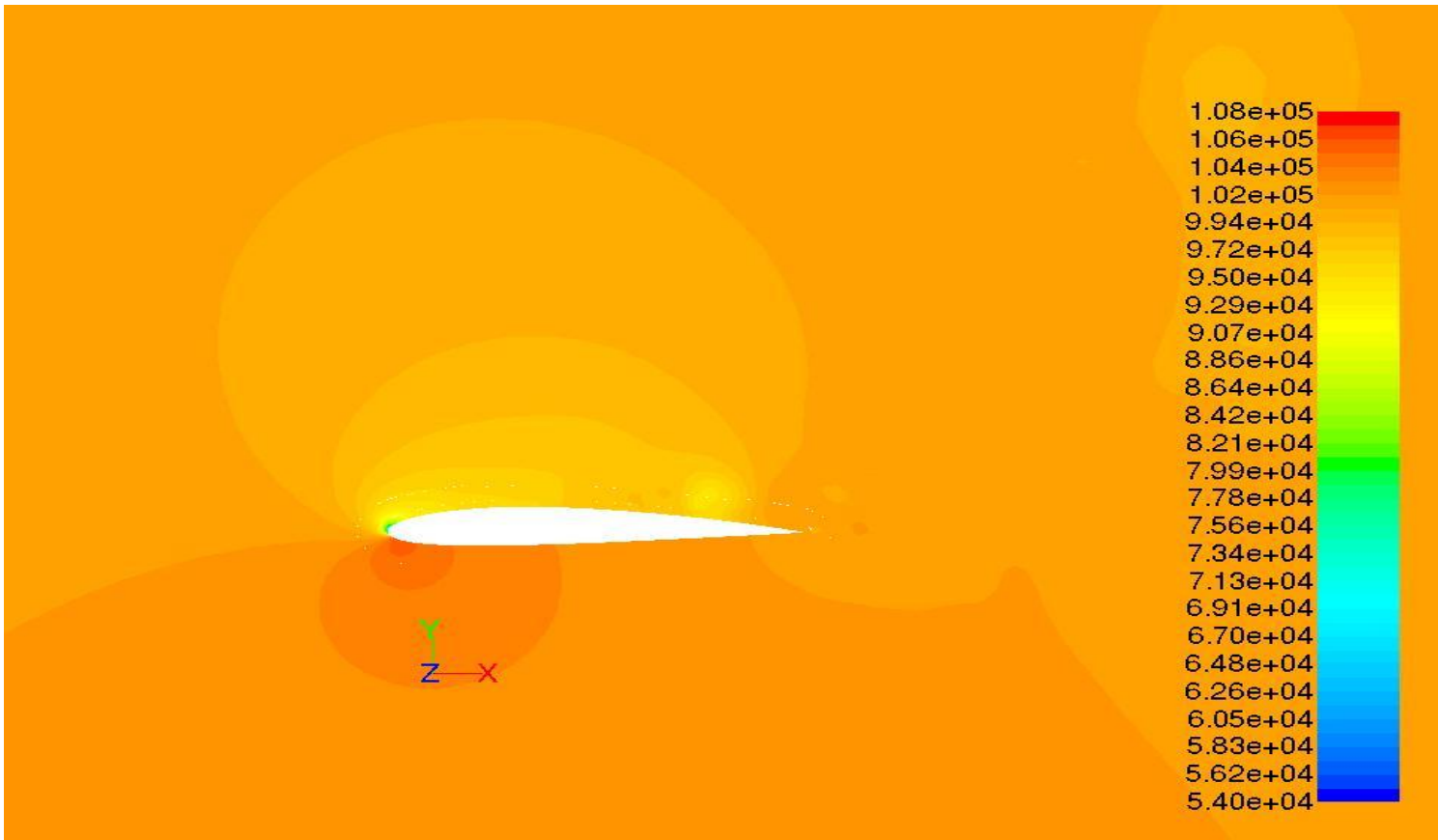

(a)

Figure 5.16 Pressure contours of 2B wing at $\mathrm{z}=$ (a) $0.025 \mathrm{~m}$, (b) 0.05 , and (c) $0.075 \mathrm{~m}$ 
(b)

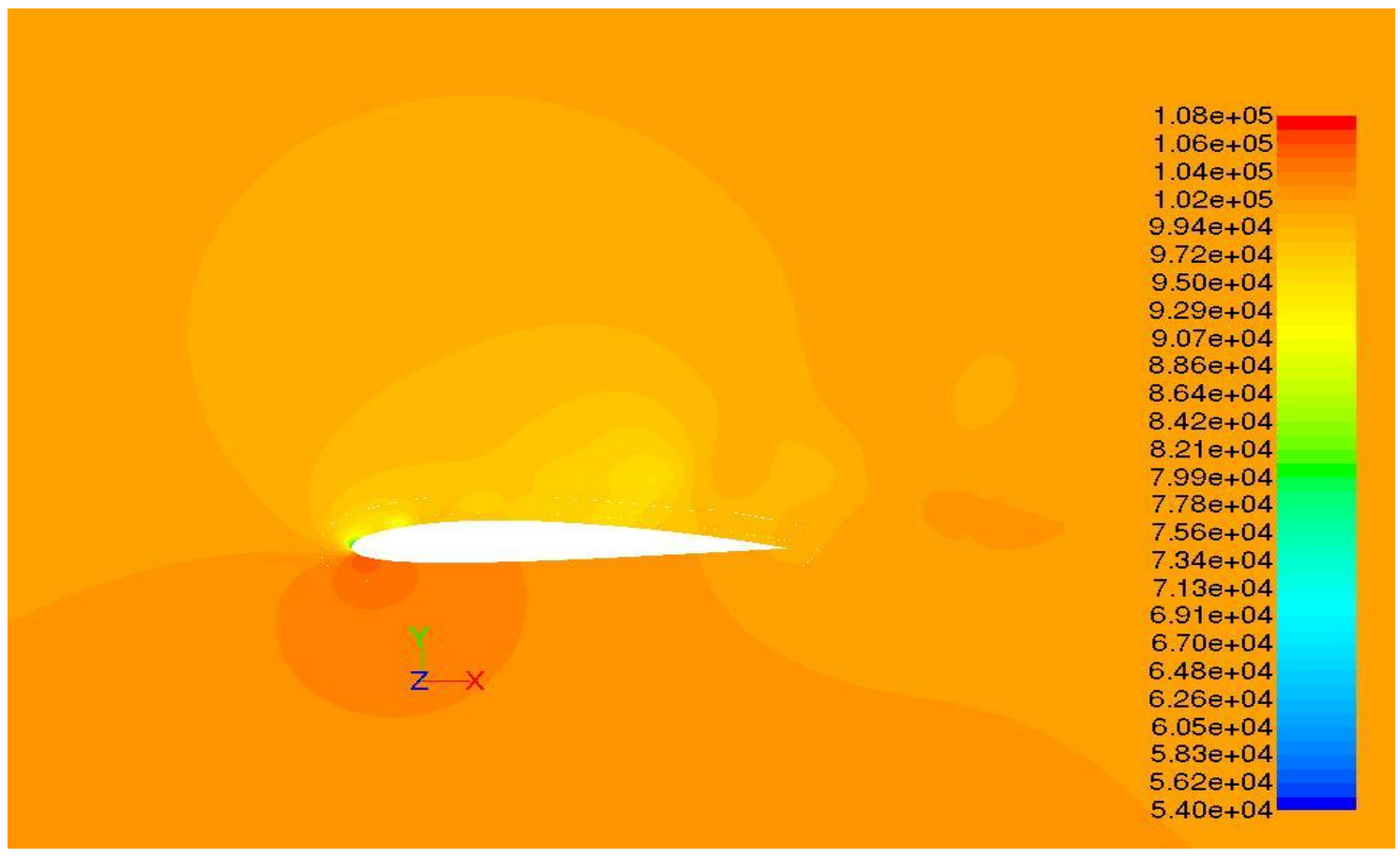

(c)

Figure 5.16 Pressure contours of $2 \mathrm{~B}$ wing at $\mathrm{z}=$ (a) $0.025 \mathrm{~m}$, (b) 0.05, and (c) $0.075 \mathrm{~m}$ (continued) 


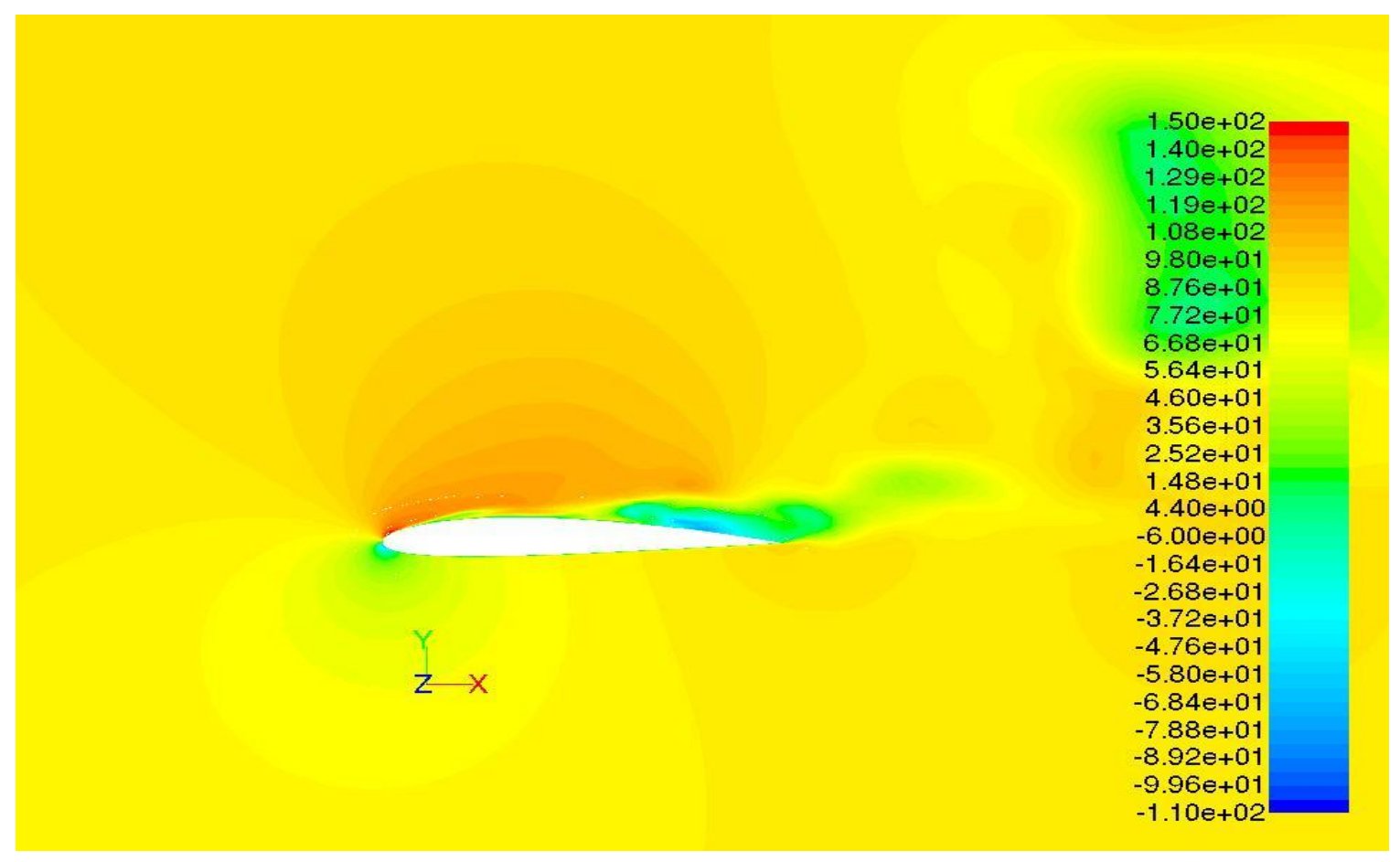

(a)

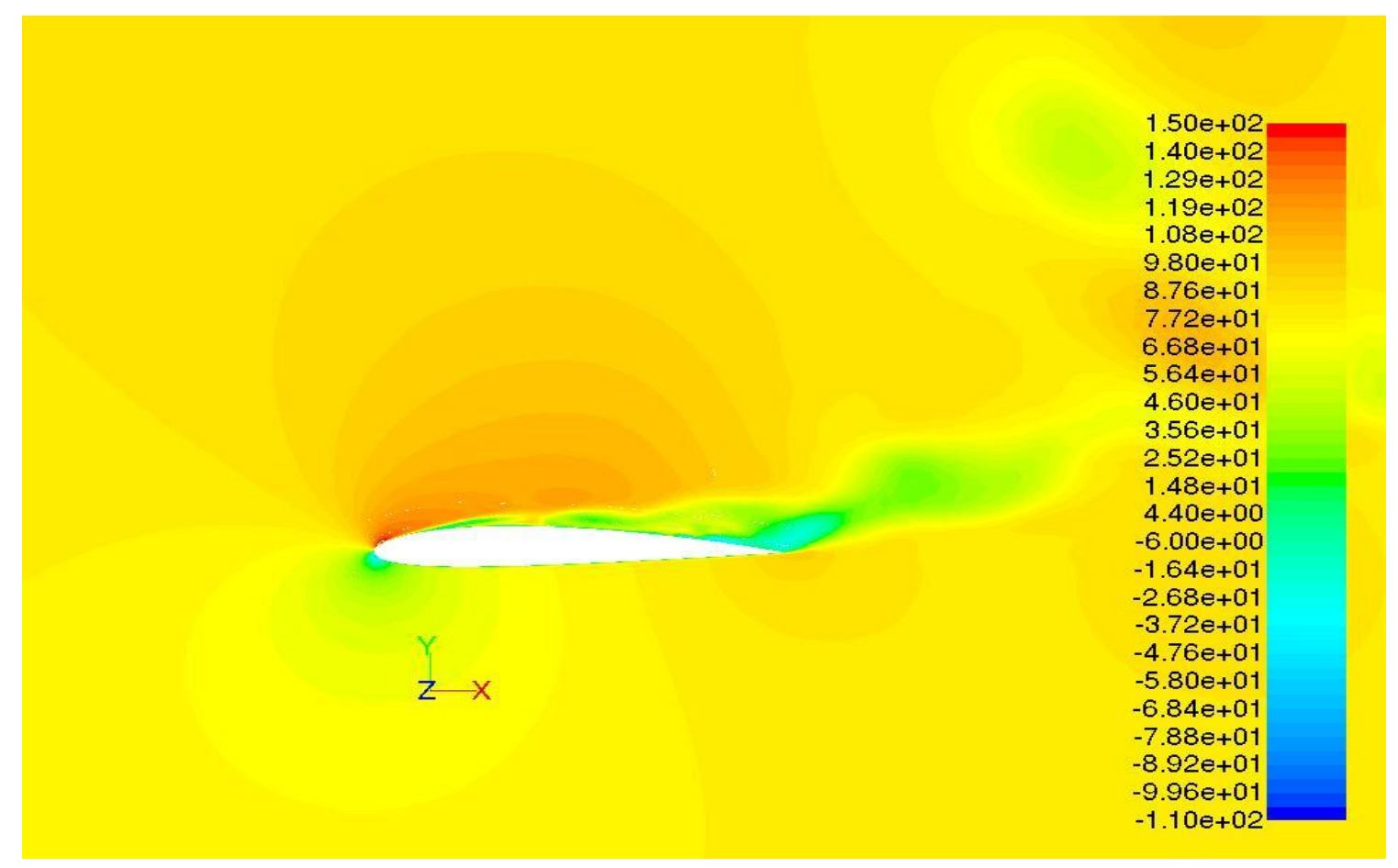

(b)

Figure 5.17 Velocity contours of $2 \mathrm{~B}$ wing at $\mathrm{z}=$ (a) $0.025 \mathrm{~m}$, (b) 0.05 , and (c) $0.075 \mathrm{~m}$ 


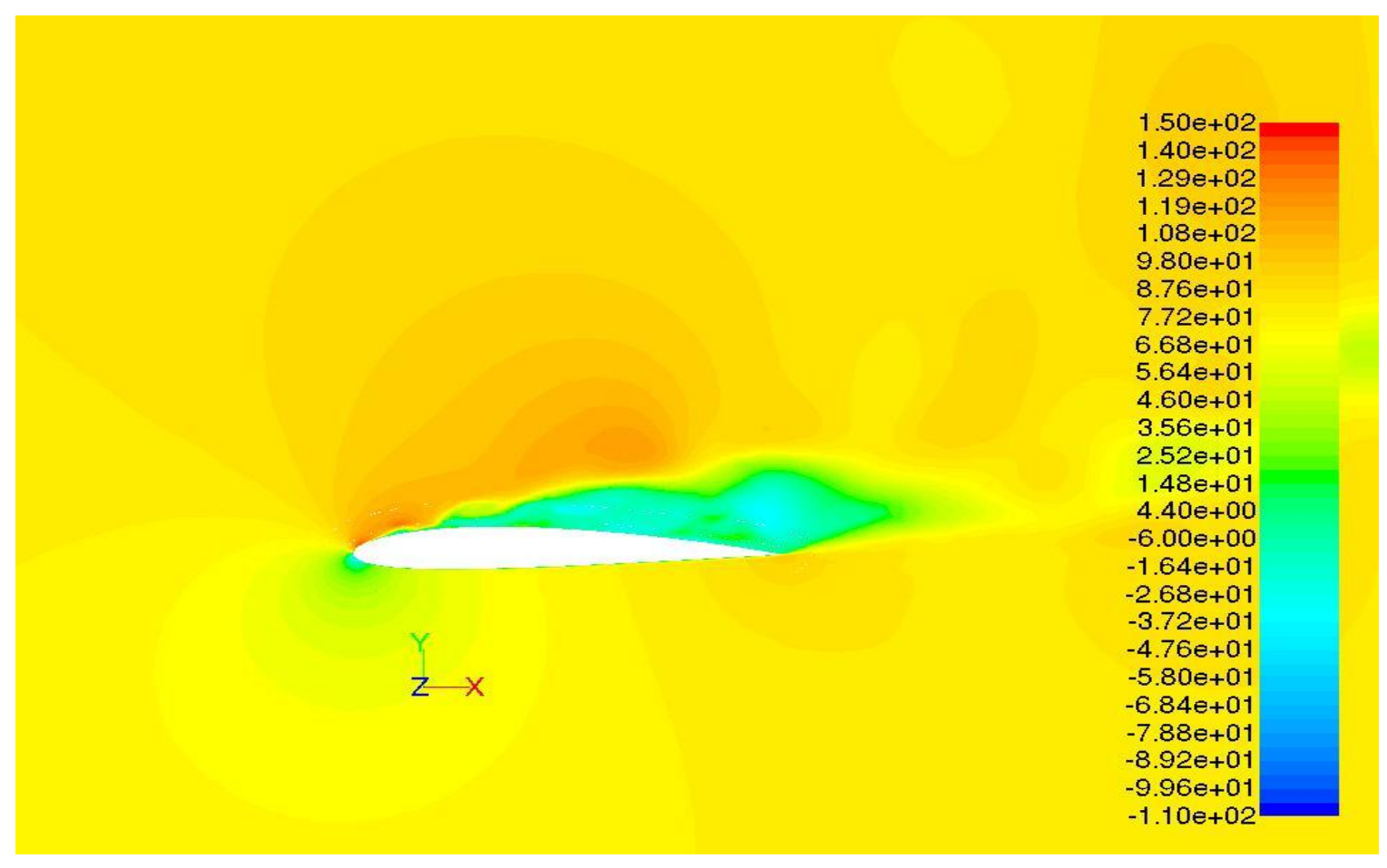

(c)

Figure 5.17 Velocity contours of 2B wing at $\mathrm{z}=$ (a) $0.025 \mathrm{~m}$, (b) 0.05 , and (c) $0.075 \mathrm{~m}$ (continued)

\subsubsection{Vorticity}

To comprehend the better performance of modified aircraft wings the analysis of vorticity on their surface is important. Figure 5.18 depicts the contours of vorticity magnitude on the wings. Although the same color scheme is applied to all wings, the modified wings depict a different pattern than the baseline. Apparently the variation in color can be observed at the leading edge of the modified wings, unlike the baseline. All modified wings have higher vorticity at the protuberances, which act as spanwise vortex generators. 


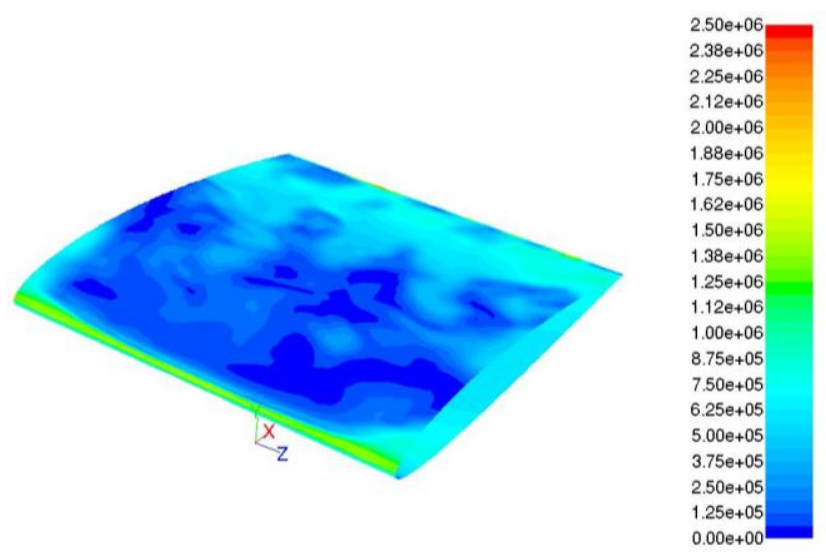

(a) Baseline

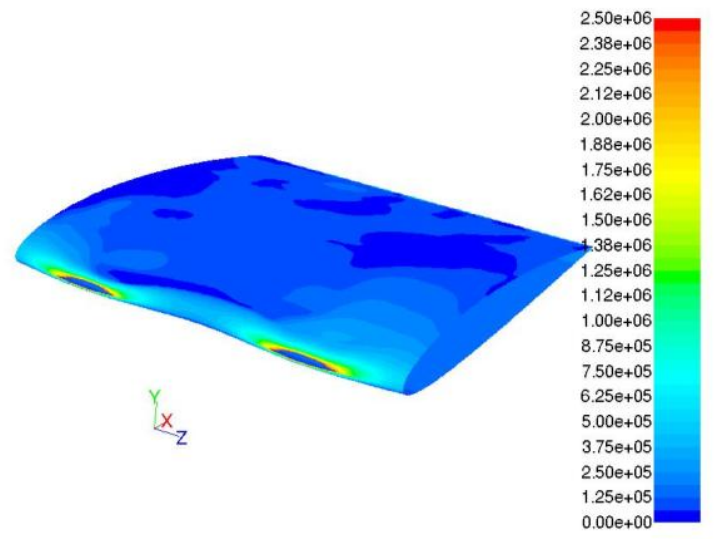

(b) $4 \mathrm{~A}$

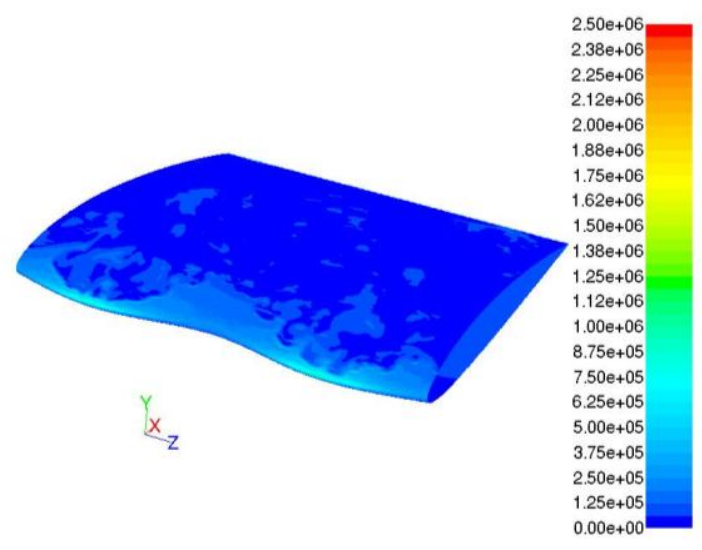

(d) $4 \mathrm{~B}$

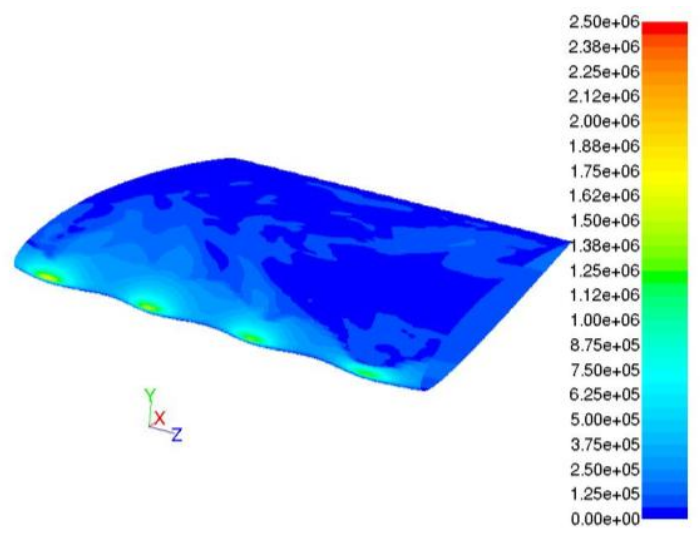

(c) $2 \mathrm{~A}$

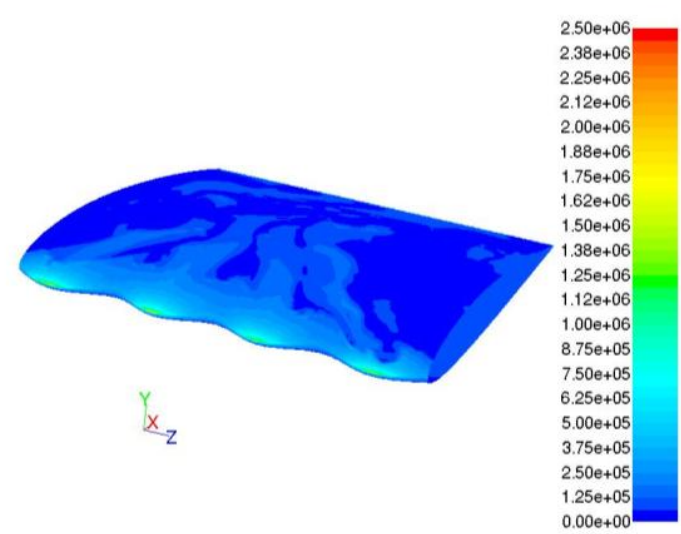

(e) $2 \mathrm{~B}$

Figure 5.18 Contours of vorticity magnitude of all wings 
An iso-surface of vorticity magnitude is presented in Figures 5.19 (a) to (e), all of which have similar values. Excluding both ends of all wings, the focus is on the mid-span. The midsection of the baseline, as shown in Figure 5.19 (a), illustrates the vortical structures through the span, indicating that the flow is separated in this region, whereas in the case of modified wings, the vortices are aligned with the protuberances, and the baseline shows no such structures. The vortices aligned with protuberances are most likely to have an effect on the stability characteristics of the boundary layer.

The vorticity magnitude slices in the chord-wise direction of the baseline and a modified wing are compared in Figure 5.20. In Figure 5.20 (a) and (b), the first slice is at $\mathrm{x}=0.05 \mathrm{~m}$ and the second slice is at $x=0.126 \mathrm{~m}$. The vertical gap in the first slice indicates the thickness of the wing's cross section, and the second slice is behind the trailing edge of the wing. It can be clearly seen in the first slices, as shown in Figure 5.20 (b), that the modified wing has higher values of vorticity over the surface than the baseline, shown in Figure 5.20 (a). These eddies re-energize the boundary layer by carrying the high momentum flow near the wall. Thus, the flow over the wings with leading edge protuberances possesses much more momentum in this region, which delays the separation. The increase in drag due to turbulent boundary layer is small when compared to the increase in drag due to separation, which occurs with a laminar boundary layer. Therefore, modified wings delay the stall by ceasing the rapid increase in drag at higher angles of attack. 


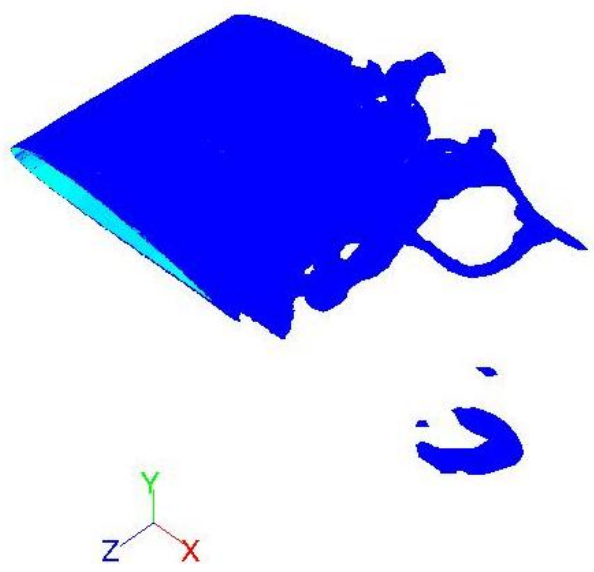

(a) Baseline

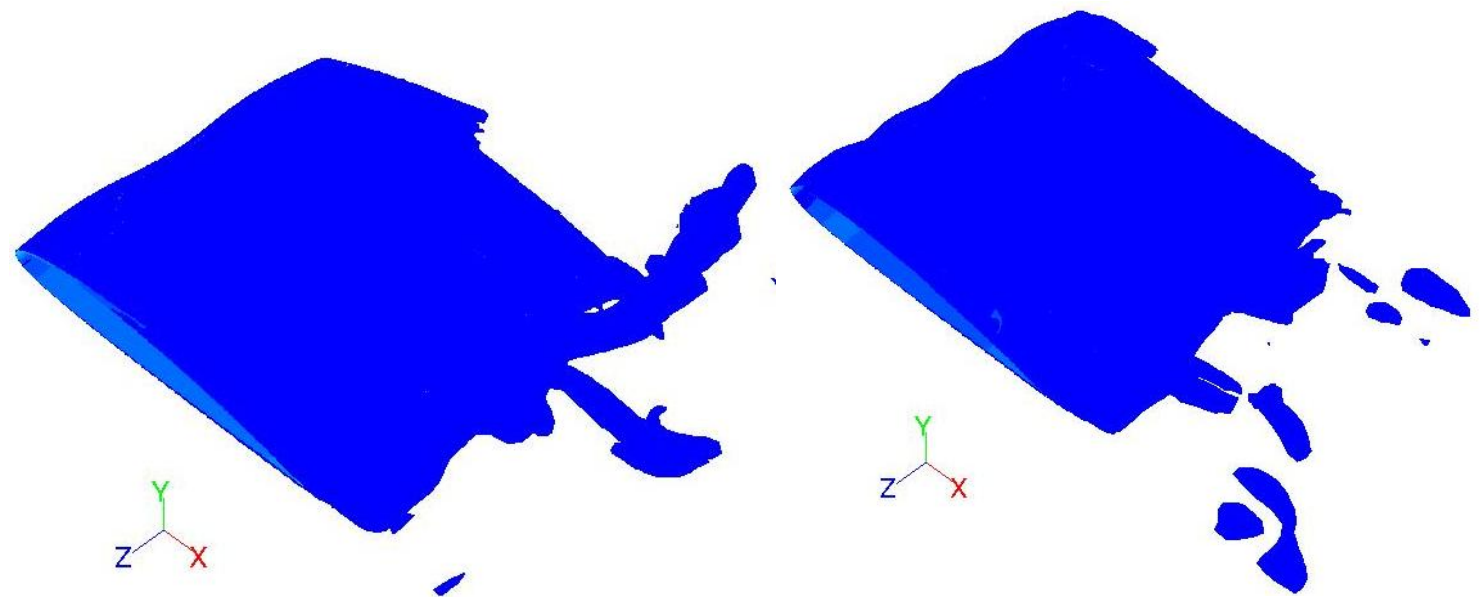

(b) $4 \mathrm{~A}$

(c) $2 \mathrm{~A}$
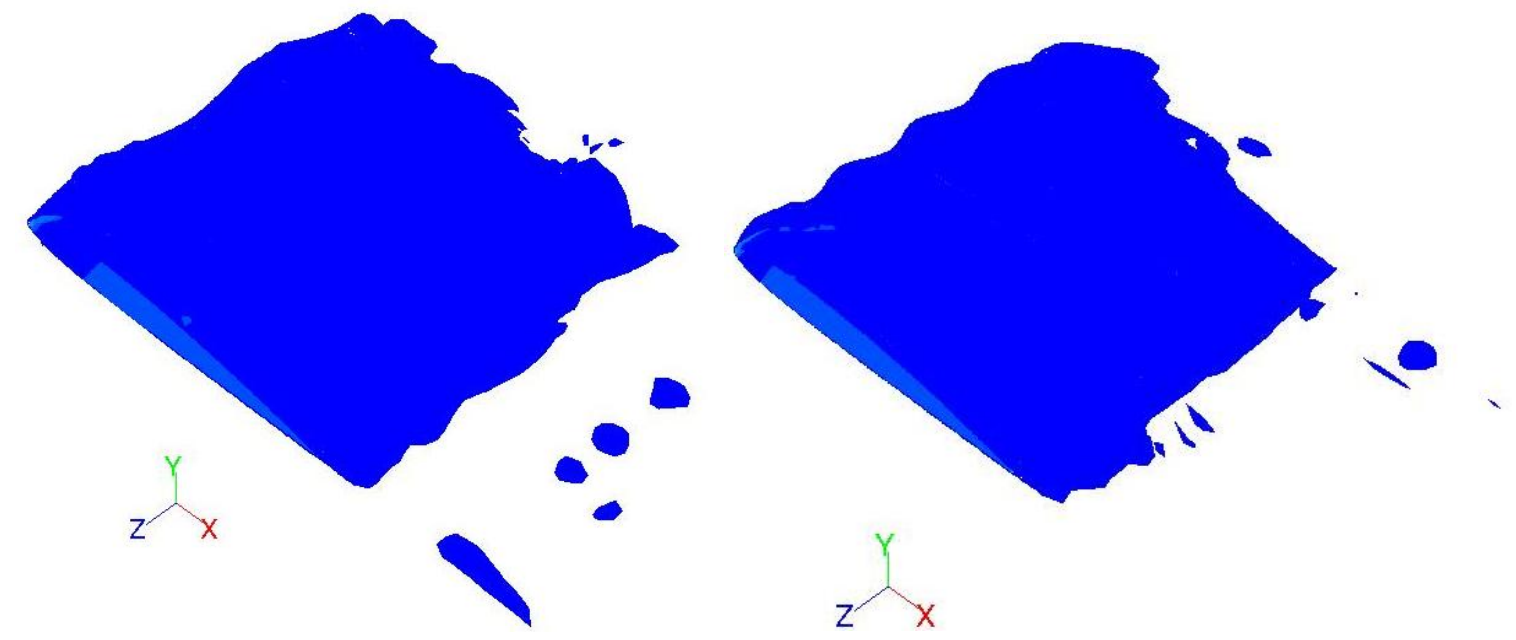

(d) $4 \mathrm{~B}$

(e) $2 \mathrm{~B}$

Figure 5.19 Instantaneous vorticity magnitude iso-surface on all wings 


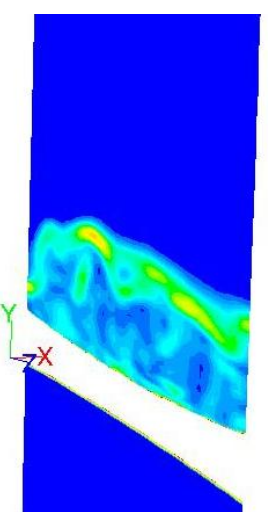

(a) Baseline

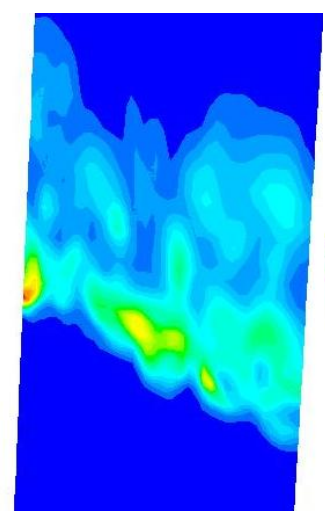

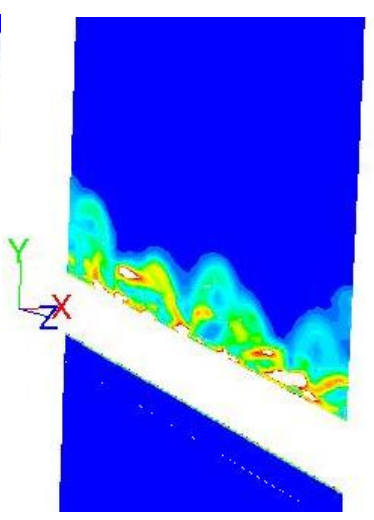

(b) Modified wing (4B)

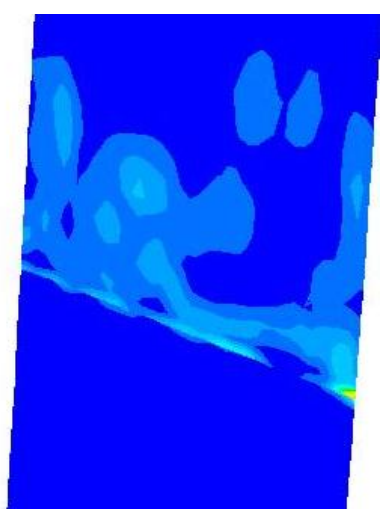

Figure 5.20 Vorticity magnitude slices in chord-wise direction at $\mathrm{x}=0.05 \mathrm{~m}$ and $0.126 \mathrm{~m}$

The near surface flow field over the top side of wing $2 \mathrm{~A}$ was examined to visualize the vortices aligned with protuberances. Streamlines over the surface of wing $2 \mathrm{~A}$ at $\alpha=12^{\circ}$, depicted in Figure 5.21, shows the flow emerging from leading edge moves downstream and diffuses as it reaches the trailing edge of wing. The flow pattern is not periodic from peak to peak and valley to valley, but it's bi-periodic. The first half of the wing in spanwise direction is reflected about center axis. The flow on either side of center valley has counter-rotating vortices, as shown in Figure 5.22; a slice of streamlines along chord-wise direction at $x=0.08 \mathrm{~m}$. The divergence of flow in center valley indicates the flow interaction between neighboring valleys. Essentially, the vortices in one valley become sufficiently strong to change the patterns of neighboring valley through interactions between the vortices. Most likely this divergence in center valley grows wider and vortices move upstream with increase in AoA. Thus, the presence of protuberances along the leading edge of wing, introduces spanwise flow in form of stream-wise vortices. These vortices result in low pressure along the surface of wing and are responsible for higher lift at high AoA. 


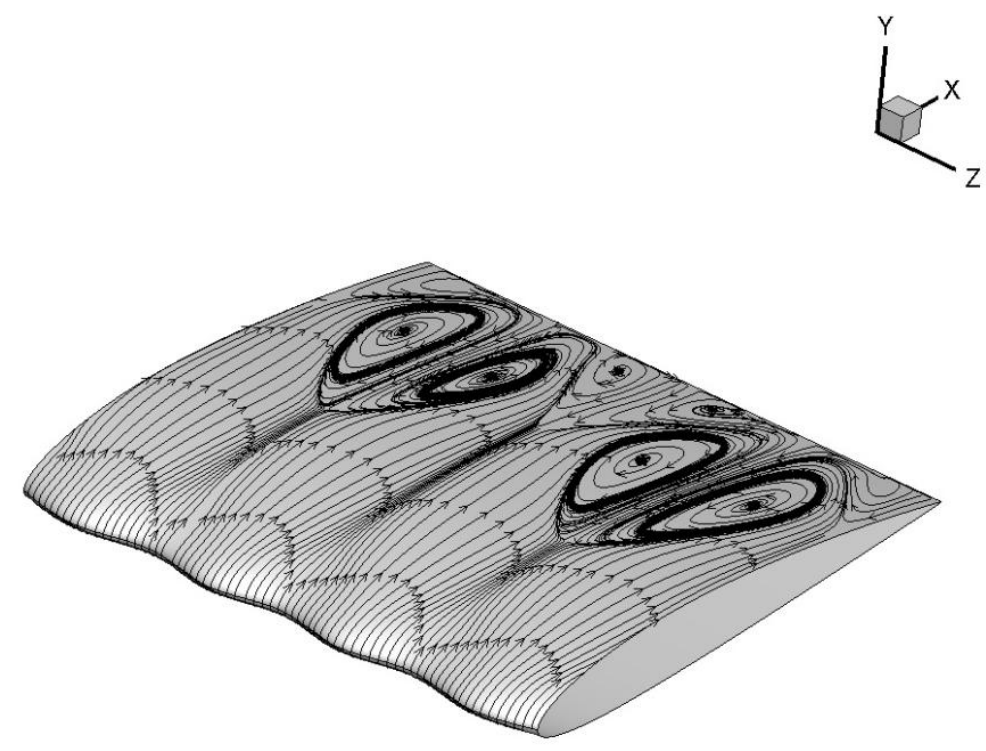

Figure 5.21 Streamlines over the surface of wing 2A

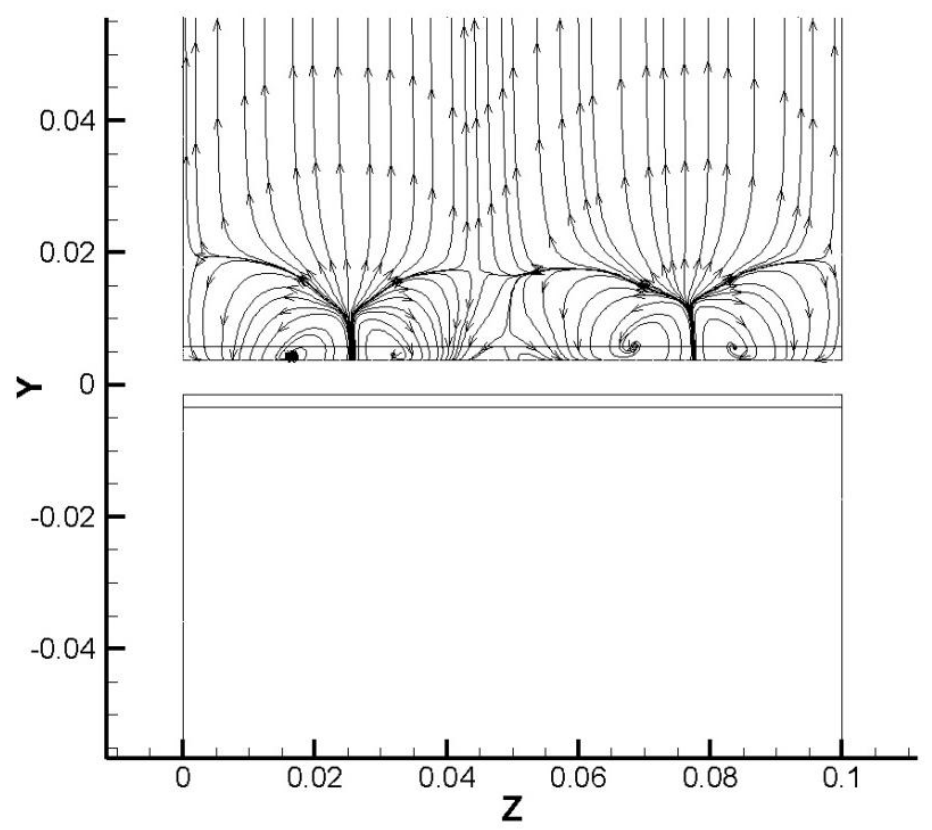

Figure 5.22 Slice of streamlines over wing $2 \mathrm{~A}$ in chord-wise direction at $\mathrm{x}=0.08 \mathrm{~m}$ 


\subsubsection{Pressure Contours on the Surface of Wings}

Pressure contours on the surface of the wings at $\alpha=16^{\circ}$ are shown in Figure 5.23. Figure 5.23 (a) illustrates the pressure contour on the baseline using the color scheme as shown. The stagnation region, which is red in color, can be observed just underneath the leading edge. Lower pressure on the upper surface than on the lower surface leads to the production of lift but tapers off at the trailing edge. The color of higher range at the trailing edge indicates high pressure, i.e., a low-velocity region indicating separation. Whereas all other wings, Figures 5.23 (b) to (e), show different patterns in color, the same color scheme is applied, and the contours are derived at the same $\alpha$ and time. It was found that at $\alpha \approx 16^{\circ}$, protuberances can increase lift up to $48 \%$ and reduce drag up to $44 \%$. Wings with leading-edge protuberances show variation in intensity of color along the leading edge, and the low pressure region (light blue in color at troughs) resides between the protuberances. When wings with the same wavelength are compared, i.e., 4A with $4 \mathrm{~B}$ and $2 \mathrm{~A}$ with $2 \mathrm{~B}$, respectively, the $4 \mathrm{~B}$ and $2 \mathrm{~B}$ wings have less pressure at the troughs and more color variation on the surface, which implies more turbulence in the boundary layer. Thus, the turbulent boundary layer remains attached to the surface longer because it has more energy than the laminar boundary layer, indicating that the wings with higher amplitude protuberances significantly delay separation and stall. Figures 5.24 to 5.28 show the instantaneous pressure isosurface on all wings with the same value of pressure. 


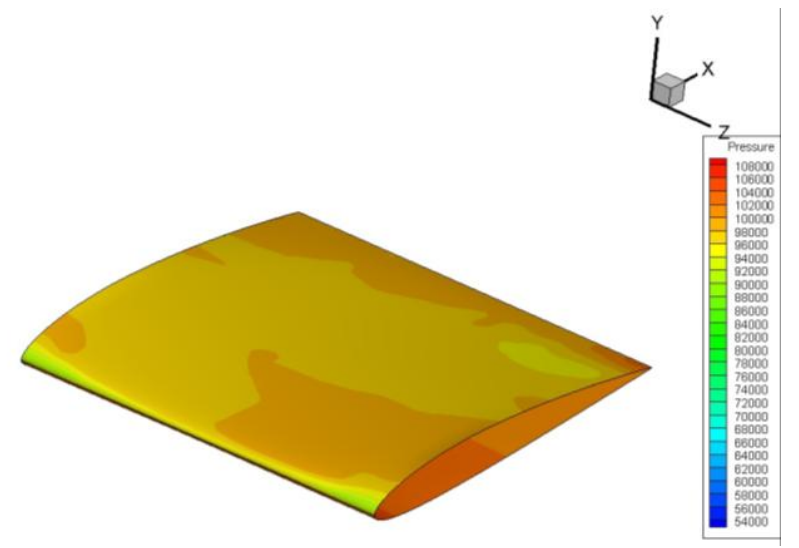

Baseline

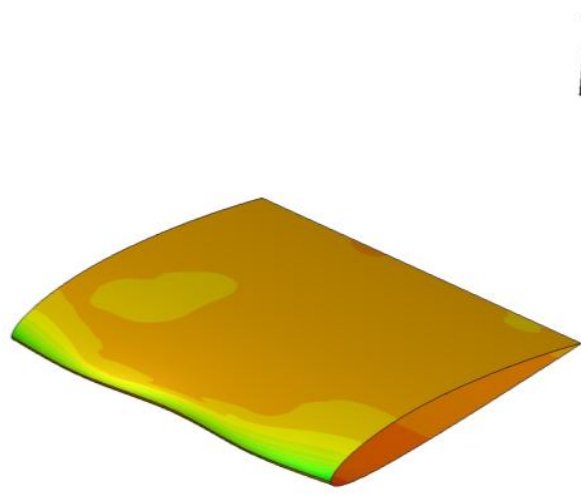

(b) $4 \mathrm{~A}$ wing

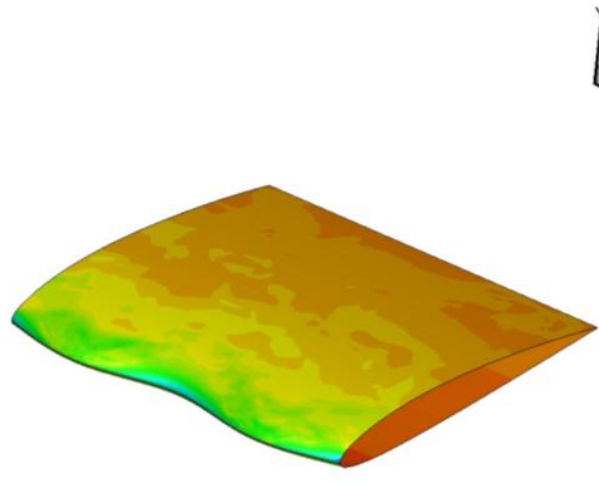

(d) 4B wing

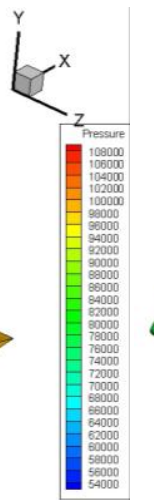

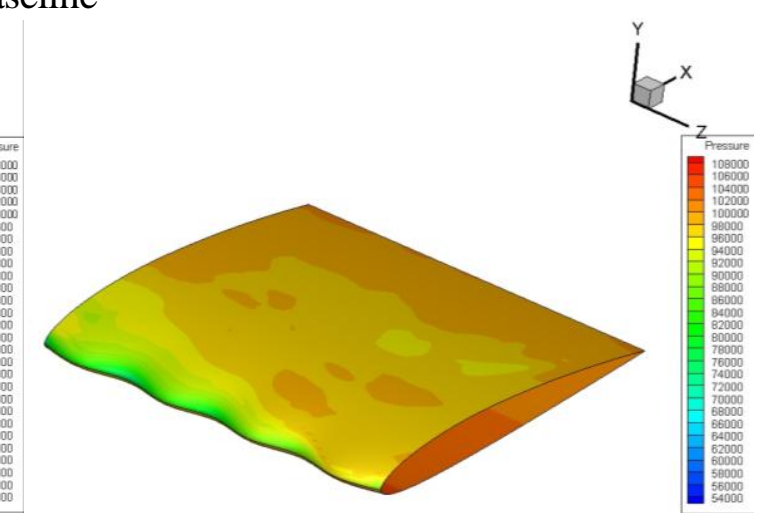

(c) $2 \mathrm{~A}$ wing
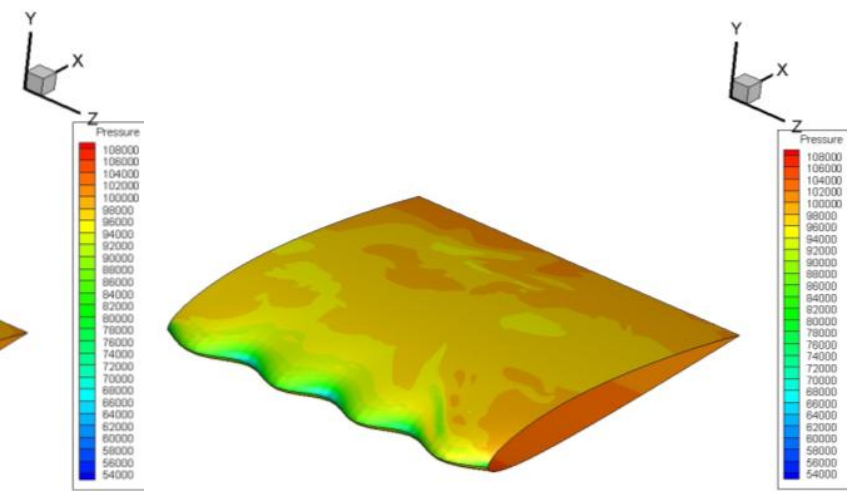

(e) 2B wing

Figure 5.23 Pressure contours on the surface of various wings 


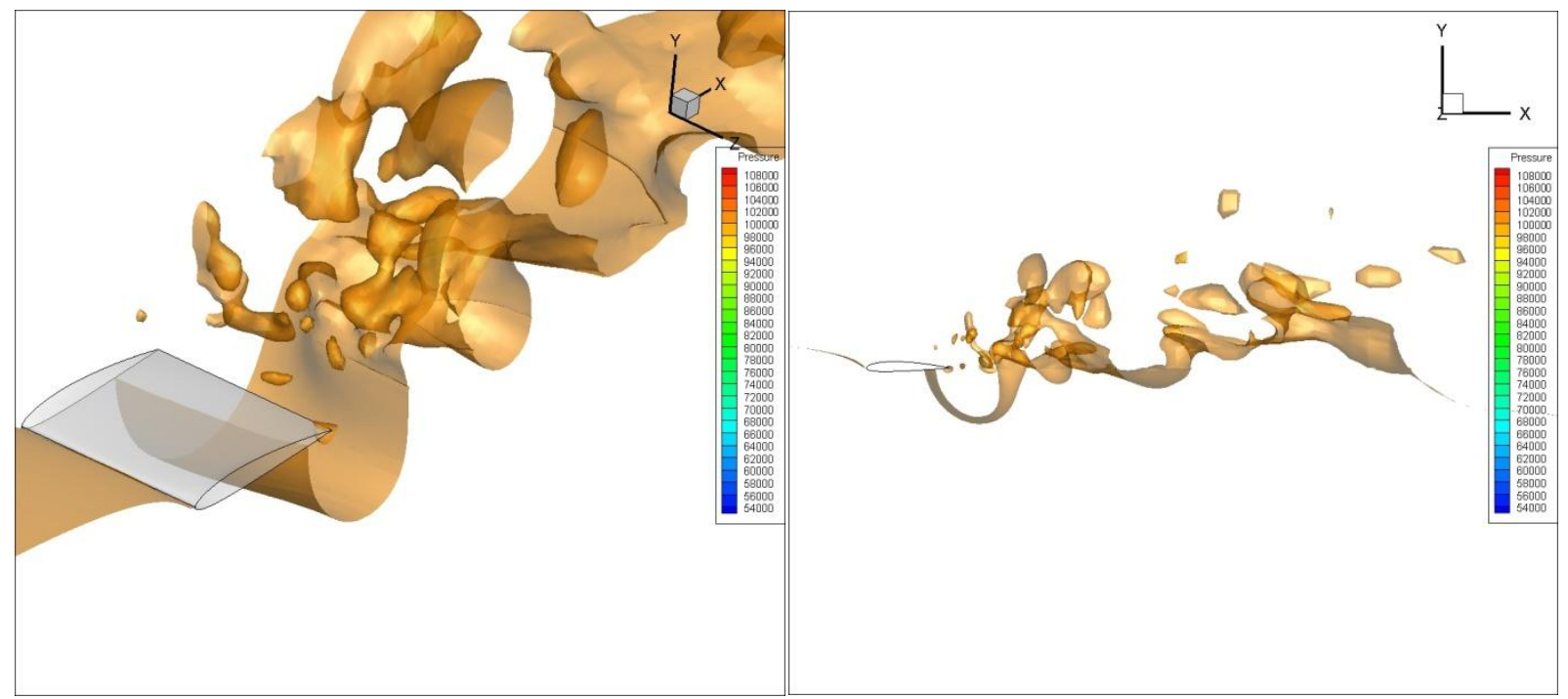

Figure 5.24 Instantaneous pressure iso-surface of baseline colored by pressure

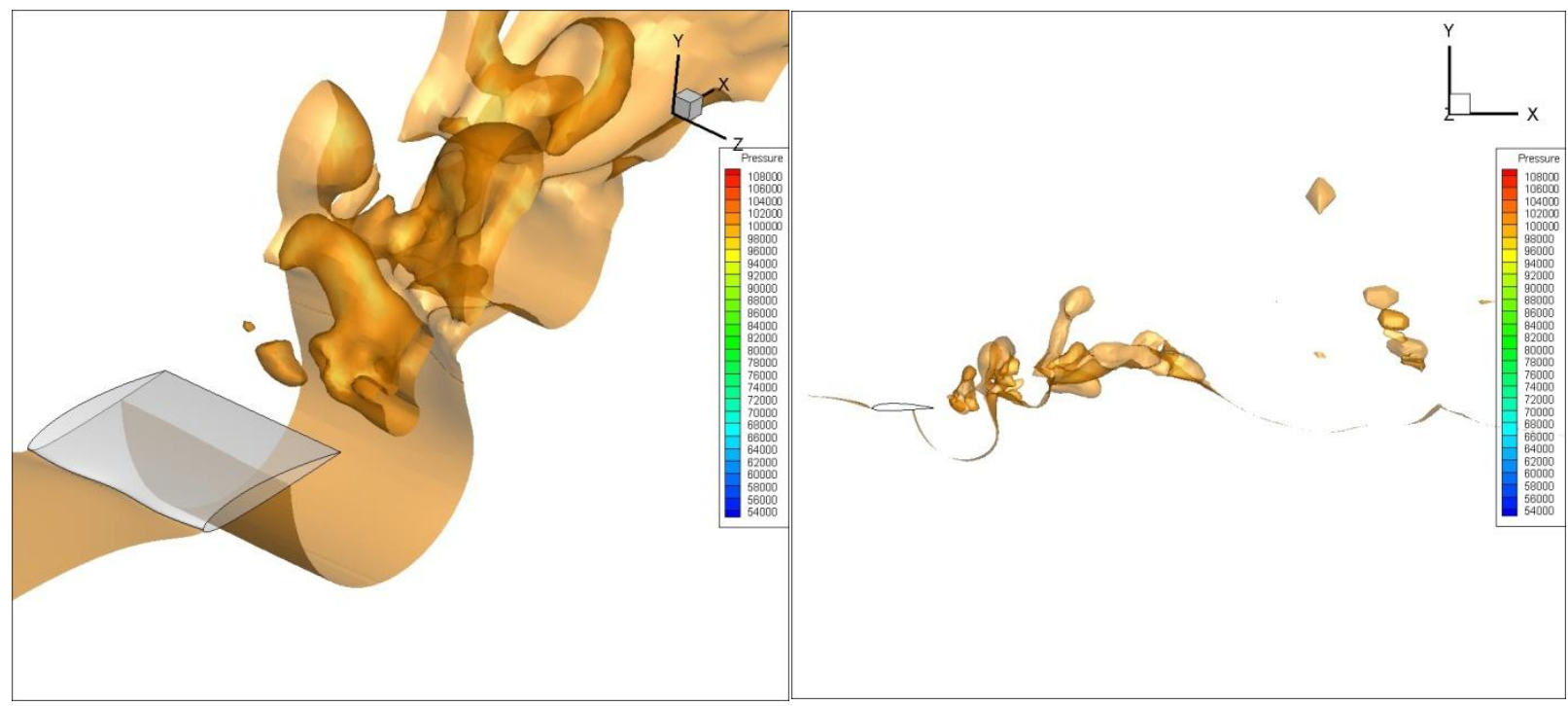

Figure 5.25 Instantaneous pressure iso-surface of 4A wing colored by pressure 


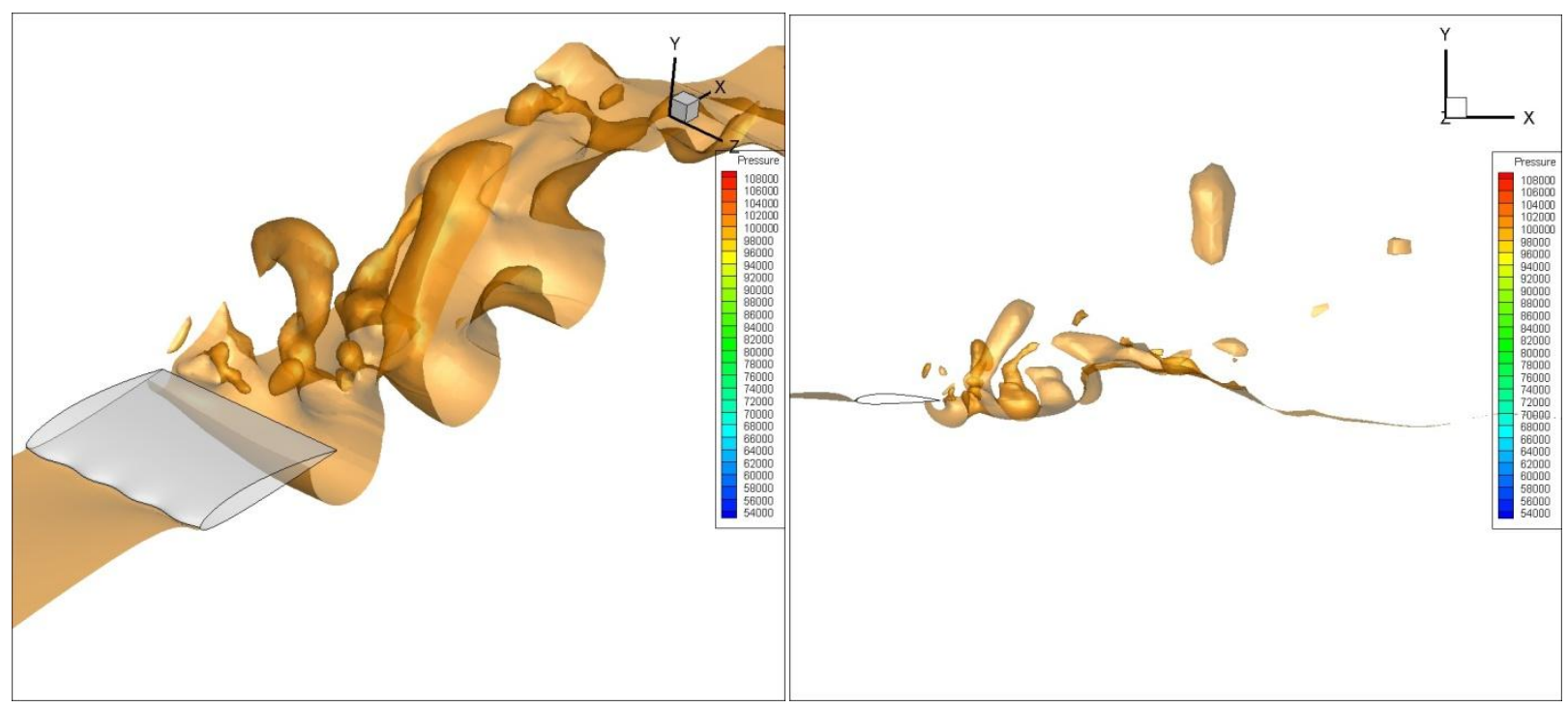

Figure 5.26 Instantaneous pressure iso-surface of $2 \mathrm{~A}$ wing colored by pressure

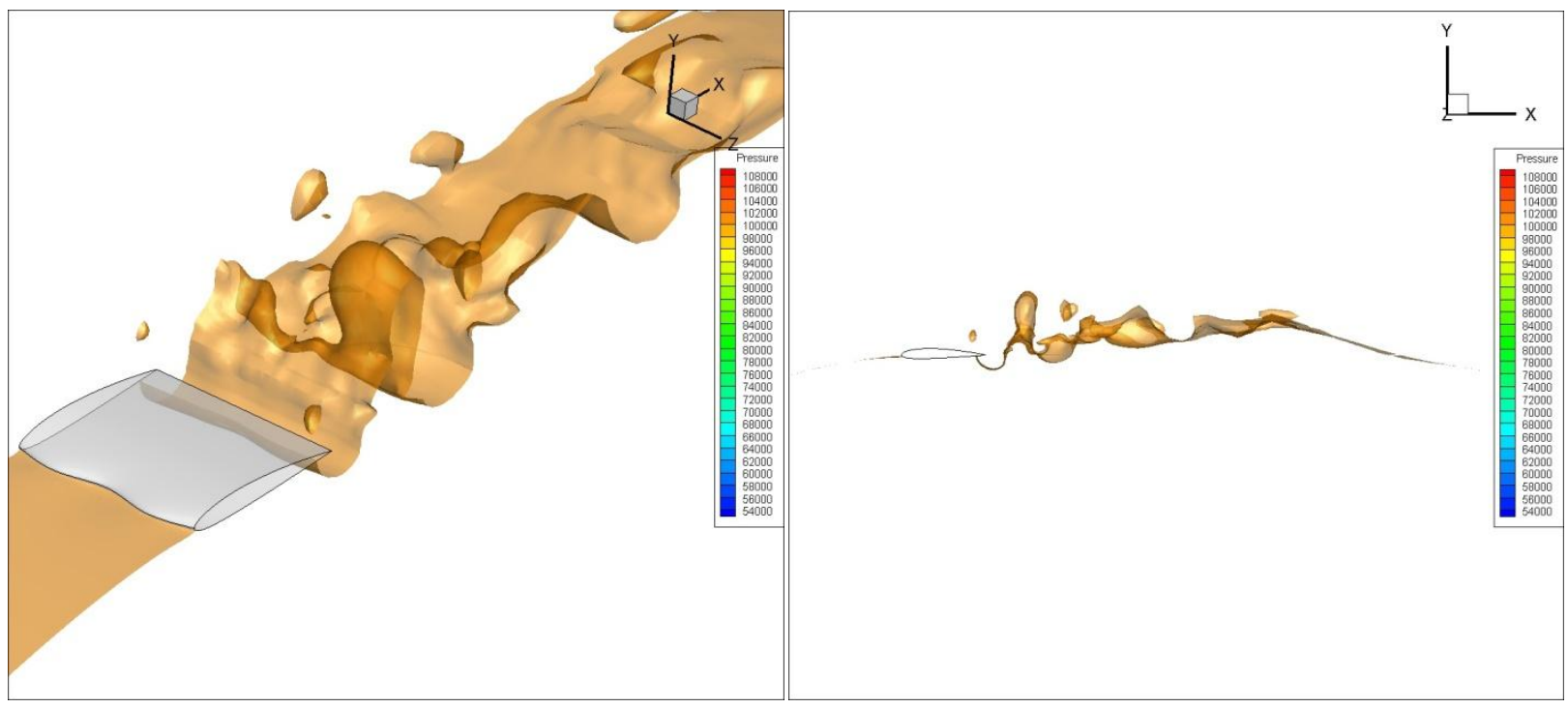

Figure 5.27 Instantaneous pressure iso-surface of 4B wing colored by pressure 


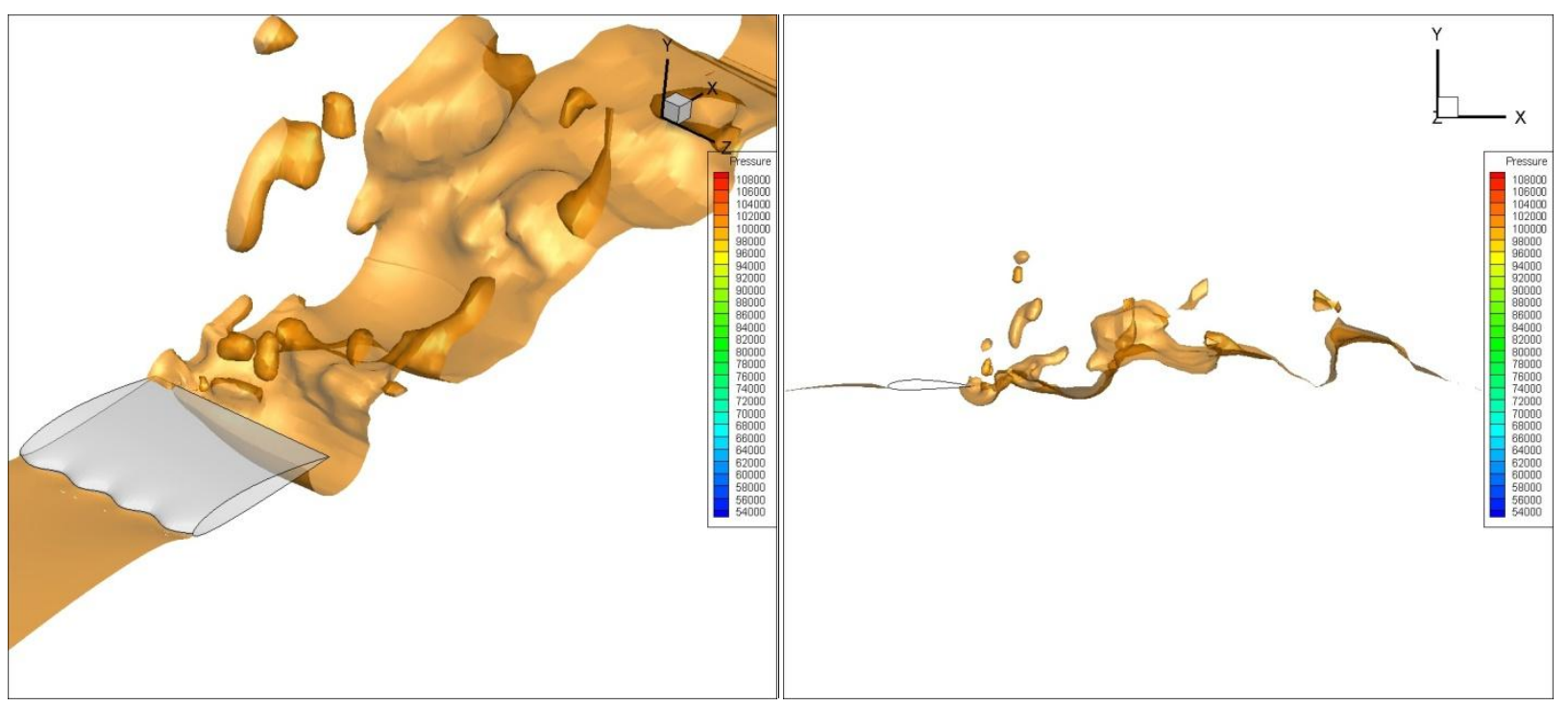

Figure 5.28 Instantaneous pressure iso-surface of 2B wing colored by pressure

\subsection{Discussion}

The performance of wings with leading-edge protuberances is different than the performance of wing with smooth leading edge. It was observed that all wings with leading-edge protuberances produced slightly lower lift and higher drag in the pre-stall regime. However, in the post-stall regime, wings with leading-edge protuberances proved to be more beneficial than those without protuberances. Apparently it is advantageous to retain the smooth leading edge on wings during the pre-stall regime and to have protuberances in the post-stall regime. This suggests that an active mechanism that introduces protuberances on the leading edge of wings in the post-stall regime of the baseline is required to exploit the protuberances. Having such a mechanism on wings or on any control surfaces can be beneficial by retaining the lift and drag produced by baseline in the pre-stall regime, while increasing the lift and slightly less drag or no drag penalty in the post-stall regime. It was also shown that during the post-stall regime $(\alpha \approx$ $20^{\circ}$ ), the drag coefficients on all wings were almost the same, because at higher angles, wings become bluff bodies such that the protuberances have little effect on wing drag. However, 
protuberances increase the amount of separation in the pre-stall regime, which generated higher drag coefficients at lower angles of attack.

The detailed simulation results show significant differences in the flow field over the wings with protuberances, unlike the baseline. The presence of leading-edge protuberances introduces the spanwise flow along the leading edge in the form of streamwise vortices. These vortices were responsible for added lift in past the stalling angle of the wing. Most likely the larger regions of separation on modified wings due to protuberances are responsible for the lower lift coefficients during the pre-stall regime. Previous experimental studies on hydrofoils with leading edge protuberances $[6,19]$ yield similar results. 


\section{CHAPTER 6}

\section{CONCLUSIONS}

The numerical simulations were conducted in Fluent on wings with an NACA 2412 cross section, in order to derive the effects of protuberances on the leading edge. Including the baseline, four other cases having protuberances along the leading edge of the wing with varying wavelength and amplitude were considered. All wings had a chord of $0.1 \mathrm{~m}$ and a span of $0.1 \mathrm{~m}$. The wavelengths and amplitudes used in this research were in the range of those found on the flippers of the humpback whale. Wavelengths ranged from $25 \%$ to $50 \%$ of chord length $(0.25 \mathrm{c}$ and $0.5 \mathrm{c})$, and amplitudes ranged from $2.5 \%$ to $5 \%$ of chord length $(0.025 \mathrm{c}$ and $0.05 \mathrm{c})$. The simulations were carried out with 0.24 Mach number for turbulent flow domain using DES based on SA and k- $\omega$ models. The following conclusions can be drawn from the numerical results.

The numerical results revealed the aerodynamic characteristics of wings with leadingedge protuberances. The difference between lift and drag coefficient characteristics between wing with a smooth leading edge and wings with leading-edge protuberances were clearly observed. All wings with protuberances generated less maximum $C_{L}$ and stalled, unlike the baseline. At low angles of attack (in pre-stall regime), all wings with protuberances generated less lift than that of the baseline, and at high AoA (in post-stall regime), wings with protuberances were efficient in producing higher lift. The drag produced by wings with protuberances was significantly higher in the pre-stall regime when compared with the baseline because of a larger separation region over the surface of the wings. Past the stalling angle, drag was lower and became identical with the baseline, as $\alpha$ is increased. At high angles of attack, since all wings appear blunt, the drag was almost independent of protuberances. 
Further detailed study revealed that protuberances along the leading edge produced streamwise vortices. These vortices carried the higher momentum flow in the boundary layer, which kept the flow attached to the surface of the wing and, in turn, delayed the separation.

As mentioned previously, two different wavelengths and amplitudes were considered for the simulations. From the observations, the amplitude of protuberances played a prominent role in creating differences in force characteristics between the baseline and the wings with protuberances, whereas the wavelength of protuberances played a minor role.

Hence, conclusions can be drawn - that the higher aerodynamic performance of modified wings is due to streamwise vortices generated by protuberances and that it is possible to produce up to $48 \%$ higher lift than the baseline, by using protuberances in the post-stall regime with no consequences of drag. The DES turbulence model was successful in determining the wing aerodynamics at a low Reynolds number. 
REFERENCES 


\section{REFERENCES}

[1] Fish, F. E., and Battle, J. M., "Hydrodynamic Design of the Humpback Whale Flipper," Journal of Morphology, Vol. 225, July 1995, pp. 51-60.

[2] Adam Summers, and Patricia J. Wynne, "The Shape of the Humpback's Flipper might hold the Secret to more Maneuverable Submarines," As the Whale Turns, Natural History Magazine, [online source], URL: http://www.naturalhistorymag.com/biomechanics/082067/as-the-whale-turns [cited June 2004].

[3] Ask Nature, "Strategy: Flippers Provide lift, reduce drag: Humpback Whale," The Biomimicry Institute, [online source], URL: http://www.asknature.org/strategy/3f2fb504a0cd000eae85d5dcc4915dd4\#changeTab [cited $2008-2011]$.

[4] Watts, P., and Fish, F. E., "The Influence of Passive, Leading Edge Tubercles on Wing Performance," Proceedings of the Twelfth International Symposium on Unmanned Untethered Submersible Technology (UUST), UUST05, Autonomous Undersea Systems Inst., Lee, NH, August 2001.

[5] Miklosovic, D. S, Murray, M. M., Howle, L. E., and Fish, F. E., "Leading Edge Tubercles Delay Stall on Humpback Whale (Megaptera novaeangliae) Flippers," Physics of Fluids, Vol. 16, No. 5, May 2004, pp. L39-42.

[6] H. Johari, C. Henoch, D. Custodio, and A. Levshin, "Effects of Leading Edge Protuberances on Airfoil Performance," AIAA Journal, Vol. 45, No. 11, November 2007.

[7] Stein, B., and Murray, M. M., "Stall Mechanism Analysis of Humpback Whale Flipper Models," Proceedings of Unmanned Untethered Submersible Technology (UUST), UUST05, Autonomous Undersea Systems Inst., Lee, NH, August 2005.

[8] Miklosovic, D. S, Murray, M. M., Howle, L. E., and Fish, F. E., "Effects of Leading Edge Tubercles on a Representative Whale Flipper Model at Various Sweep Angles," Proceedings of the Twelfth International Symposium on Unmanned Untethered Submersible Technology (UUST), UUST05, Autonomous Undersea Systems Inst., Lee, NH, August 2005.

[9] Hugo, T. C. Pedro, and Marcelo, H. Kobayashi, "Numerical Study of Stall Delay on Humpback Whale Flippers," AIAA Aerospace Science Meeting and Exhibit, 7-10, January 2008, Reno, Nevada.

[10] Muller, T. J. and DeLaurie, J. D., "Aerodynamics of Small Vehicles," Ann. Rev. Fluid Mech., Vol. 35, 2003, pp. 89-111. 


\section{REFERENCES (Continued)}

[11] Nathan Logsdon, "A Procedure for Numerically Analyzing Wings and Wing Sections," Master's Thesis, University of Missouri, December 2006.

[12] “Gambit User’s Manual,” Gambit Ver. 2.3.16, Gambit Inc.

[13] Abbot, I. H., and von Doenhoff, A. E., "Theory of Wing Sections”, Dover 1959.

[14] Klaus A. Hoffmann, and Steve T. Chiang, "Computational Fluid Dynamics," Volume III, EES-books 2000.

[15] “Fluent User’s Manual,” Fluent Ver. 6.3.26, Fluent Inc.

[16] Shur, M., Spalart, P. R., Strelets, M., and Travin, A., "Detached-Eddy Simulation of an Airfoil at High Angle of Attack," $4^{\text {th }}$ Int. Symposium on Eng. Turb. Modeling and Experiments, Corsica, France, May 1999.

[17] Menter, F. R., "Two-Equation Eddy Viscosity Turbulence Models for Engineering Applications," AIAA, Vol. 32, 1994, pp. 15-98.

[18] Spalart, P., "Young-Person's Guide to Detached-Eddy Simulation Grids," NASA/CR2001-211032, 2001.

[19] Custodio, D., "The Effect of Humpback Whale-like Leading Edge Protuberances on Hydrofoil Performance," Master's Thesis, Worcester Polytechnic Institute, Dec. 2007.

[20] Bushnell, D. M., and Moore, K. J., "Drag Reduction in Nature," Ann. Rev. Fluid Mech., Vol. 23, January 1991, pp. 65-79.

[21] Fish, F. E., and Lauder, G. V., "Passive and Active Flow Control by Swimming Fishes and Mammals", Ann. Rev. Fluid Mech., Vol. 38, 2006, pp. 193-224.

[22] Ernst A. van Nierop, Silas Alben, and Michael P. Brenner, "How Bumps on Whale Flippers Delay Stall: An Aerodynamic Model," Physics Review Letters Vol. 100, 054502, 8 Feb. 2008.

[23] Michael, J. Stanway, "Hydrodynamic Effects of Leading Edge Tubercles on Control Surfaces and in Flapping Wing Propulsion," Master's Thesis, Massachusetts Institute of Technology, Feb. 2008.

[24] Anderson, J. D., "Fundamentals of aerodynamics,” McGraw-Hill 1991.

[25] White, F. M., "Viscous Fluid Flow”, McGraw-Hill 1991. 